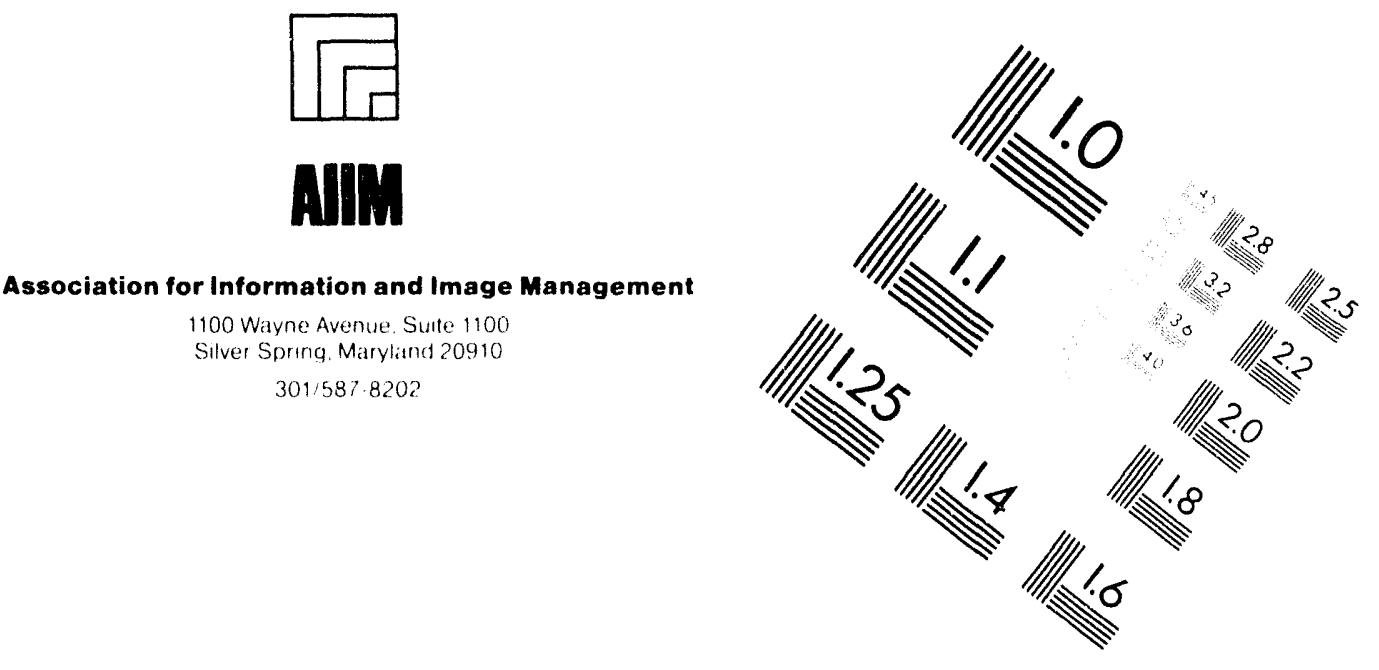

\title{
Centimeter
}

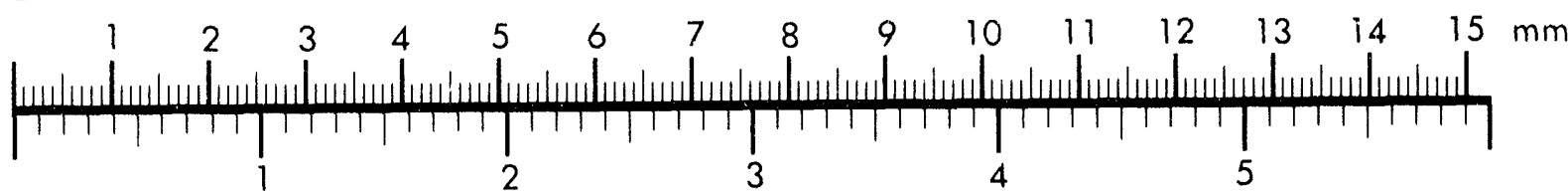
Inches
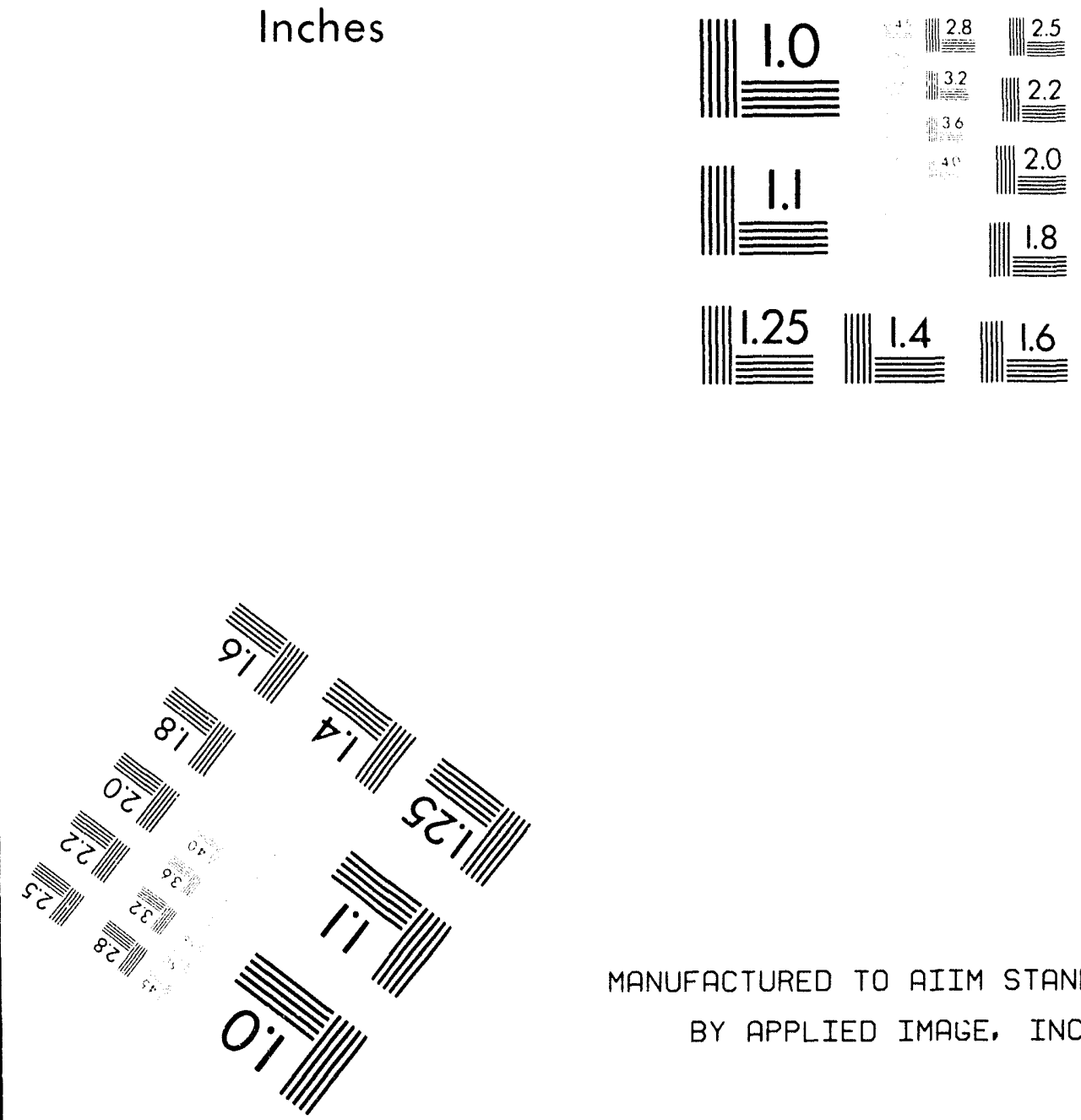

MANUFACTURED TO AIIM STANDARDS

BY APPLIED IMAGE, INC.

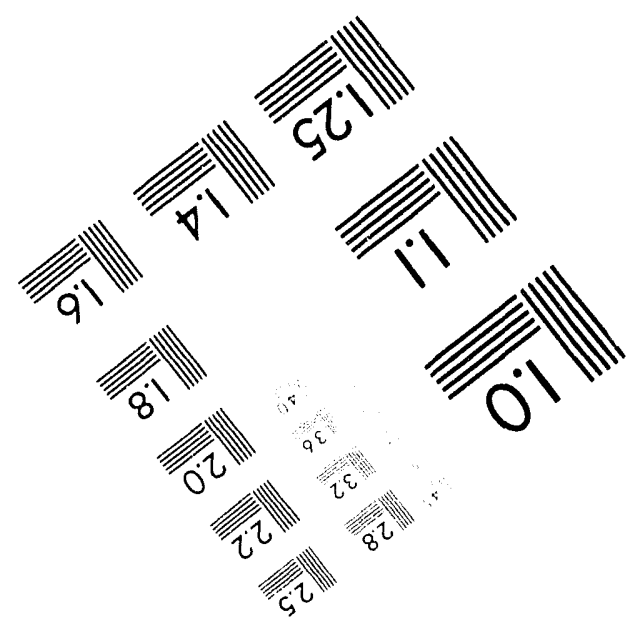




\section{ENVIRONMENTAL ASSESSMENT \\ FOR THE \\ PROPOSED B-FACTORY \\ (ASYMMETRIC ELECTRON POSITRON COLLIDER)}

November 1993

\section{U.S. Department of Energy}

\section{RECERE \\ JUL 221994 \\ OSTI}


(CSSR) in Bhecen Now Yout The BFectary would produce cortain aubalomic particles. toowr 18 aneos. that are importent to high -angy physica. Subsequent to the rolease of the En and Propaced FaNsl. the Secruary of Energy announced on Octaber 4. 1093. that SLAC had bann solested as DOE's proferrod site.

Based on tho analyess in tho EA. DOE has determined that the proposed action is not a major Foderel ection significantly affocting the quelity of the bumen environment within the meening of the National Environmental Policy ACt (NEPA) of 1969. 42 U.S.C. 4321 et eaq. Three documents were recoived fom the public which provided comments on the proposed FONSI. EA or project. The Town of Ithace. New York. indicated that it concurned with the FONSI. The Deparment of Planning of Tompkins County. New York. expressod concers about the poscibility. of spills of bezardous matarials mas Cascadillo Croal and requested copies of the Spill Proveation Cootsol and Countermeasures Plno and the Stormwater Pollution Preventios Plas. A citizen from Woodside, Californis. wrole a lelter expressiog cancerns with alternative energies and the econamics of afficiency impronements wibict would ganerate mors jabs No Foderel or Slate agencies respanded. DOE hes reviewed the comments recaived and hes concluded that no new informetion u'as provided that would change the dolermination tbat the proposed caina does not constitute a major Federal oction significantly aflocting the qualing. of the huroes enviranment withio the meaning of NEPA. 42 U.S.C. 4321 a $m$ Therefore, en environmental impect statement is not required. Further. it is

\section{DEPAFTMENT OF ENERGY}

Finding of No Signimeant Impact; Proposed B-Factory (Aoymmetric Electron Posliron Collider)

AGEnCY: U.S. Deparment of Enengy. ACnow: Finding of no significant impact

summary: Tho Deparment of Energy (DOE) issues this Finding of No Significant Impact (FONSI) on its proposal to construct and operate the B. Foctory. This foding is based on the DOE B.Factory Environmedtal Assessment (EA). DOEJEA-0882. Soplember 1993, whicb ovaluated the environmental elfects of construction and operation of a proposed B.Factory particle accelerator (Asymmotric Electron Positroo Collider) at either the Stanford Linens Accoleratar Conter (SLAC) near Menlo Perk. Californic, or at the Cormell Eloctron Storage Ring
DOE's conclusion that the comments provided Do Dew information that would cause DOE to change its mind with rogard to the solection of SLAC as the prolerrod site.

FOR FUATES WFORUATON CONTACT: Requests for furtber is formation os the proposed project or for copies of the EA and FONSI should be seni to: fames $K$ Ferley. U.S. Deperment of Energ. Office of EDergy Research (ER-8). 1000 Independerco Averue. SW..

Weshington. DC 20585. (308) 003-2314 The FONSI. EA and roleted documents are also avallable for publie roview at tho DOE public reading roo.ns listod below.

Colifornio: U.S. Depertment of Energs.

San Francisco Oparations Offica i $13 i 1$ Clay Slreet. Room 700N, Ontlend. Californir 94612. (510) 637-1762 Distriat of Columbia: U.S. Dopartred of Energy. Froedom of Information 
Roading Room, Fornestal Buildiog, Room IE-60, 1000 Indepeodence Avenue, SW., Weshisgron, DC 20585. (202) $586-6020$

New Yark: Nowmen Laborilor. Camoll University, Itbace, Now Yort 148535001. (607) 255-4951

For Information on the avellability of opecific documents and the bours of operetion of the DOE raeding rooms. please contact reading rooms of the ielepbone numbers provided.

For generd information or the DOE NePA reviow process, conlect Carol $M$ Borgstrom. U.S. Departmant of Energy. Office of NEPA Oversight (Et-25). 1000 Indeperdence Aveave. SW. Weshipgton, DC 20585. (202) $306-4600$ or (800) 472-2756.

\section{CUPPIEMENTARY WFOAMATKOW:}

Proposed Action

Tho proposed action is 10 build a B. Factory at one of two location SLAC or Cormell. by modibcation of coing collider or ecoleretor fecilities of oither site. At SLAC, the existing toility is boown as the Positron-Electron Colliding-Beam Stornge Ring Project (PEP); a Comell, the existing toility is called the Cornell Electron Sionge Ring (CESR). Ater the EA and the Proposed FONSI nere issued. DOE arosenced that SLAC was chosen as the proferred diersetive site for the B-Fectary.

\section{B.Foctory of SLAC}

Construction and operatio of $B$. Fectory at SLAC, roferrod to $\approx$ PEP-П and identibed by the Secretry as the preferrod site, would inpolve collaboration of SLAC. LunToco Borkeley Loboratory (LBL). ad Lawrence Livermoro Nationel Laboratory (LLNL), as well $s$ ocher institutions. in the design. and testing of components and equipment for the B-Facior. No conventional construction or modification to surface builtiogs would be required for PEP $-\square$. The eciring conventional facilities for FeP consist of beam bousings, research beis support buildings, roeds, oartbwort frocing. landscaping. electrical and enchenical utilities. and the sanitary-serer and torm-drain systems. These exiring systems and focilities beive edaquato

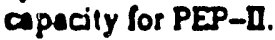

The upgrade of the exisen PEP collider to the PEP $\square$ B-Fartary would involve:

(1) The removal and disesombly of verious components rucb angnots. vecuum chambers, otc:

(2) The refurbishmedt of musable PEP componants:
(3) The fobrication of new componepts at SLAC. LBL LUNL of other collabornting institutions:

(4) Tbe ascembly of PIP $\square$ components into the existing tunnels and detection fecilities at SLAC.

(5) Minor modifcations to the linen eccolerator focusing and transport syctoms; and

(6) Disposel of some compononts that cannot be roused. possibly as low-lovel rediouctive waste.

Operation of PEP - I ts expected to begin in 1998, witb en estimated operational life for experimentation of 10-15 years. During oporations. positrons and electrons would be accolerated in a linear occolerntor and injected into storage rings where they would circulate in opposite disections. until they ar brougbi together and collide in an interection hall of a tunnel. thereby producing the $\mathbf{B}$ mesons for observation and study.

\section{CESR-B Atemate Site}

The upgrede of the existing CESR -ccelerator at Cornell to B. Factory. referted to as the CESR-B, would involve: (1) The removel and disassembly of existing components; (2) conventional construction to provide approximately 49,500 squire foet of additional space for electrical and mechanical equipment and $x$-roy beam lines: (3) conventional construrtion to add 2,900 squere feet to the tunnel flare: (4) construction to expand existing routes of electric transmission lines; (5) rouse of some CESR components in CESR-B; and (6) disposal of some components, with possibly ofow pioces disposed of as low-lovel redioactive waste. Component design, assembly. and construction at Comell would take $3-4$ years. Operetion is expected to begio in 1998, with an estimated life of about 15 years.

\section{Nieroatives}

Two eliernatives to the proposed ection were considered: (1) No ection: and (2) the construction and operation of a B-Factory at a DOE facility oiber then SLAC or Cornell. Under the no action alternative. the B.Factory would nol be built. end existing SLAC and Cornell facilities would continue to operate until the termination of their useful lifotime. AI SLAC, the existing PEP facility would remain idle until now uses aro dotermined or lt is decommissioned. Al Comell, the existing CESR would continue to operate for about five years. The aliemetive to construct and operate a B. Foctory of enother DOE facllity was nol ovaluated further in the EA due to lis leck of foesibility in moeting the obfectives of time, cost, and technical potontial.

\section{Enviranmestel inpacts}

Tho EA andyzed the impacts of constructing and operating B-Factory at both tho SLAC and Cornell sites for ffects from construction, normal operations, eccidents, decontamination and docommissioning, and cumulative and long torm impacts. The EA considered impacts to air and water quality, land use, biological resources. Doise, unffic, and bazardous materials usage. As described in the EA. there would be no significant impacts fom construction or upgrade of the existing facilities at SLAC or Cornell.

\section{PEP-Il Alternate Sile}

Operation of the PEP-Il would not significantly affect air and waler qualits. worker bealth and safely. public health and safety, and wasto manogement oystems. The impacts of ionizing rediation produced during operation are enticipated to be negligible. Nearly all of the radiation would be absorbed by the colf-sbielding copper vacuum chamber. the concrote tunnal walls. and the surrounding earth. Induced redionctivity could occur in a sman number of components or devices. The number of workers that nould be exposed to meesurable amounts of redistion from PEP- $1 \mathrm{~d}$ in the course of normal operations would not exceed 50. Basod on e dosoto-rish conversion factor of $4 \times 10^{-4}$ latent cancer falalities per person-rem for adult w'orkers, the risk of fatal cancer to the potentially exposed population of 50 worhers over the 15-year operating period is less then 0.03 . There are no persons residing within $0.3 \mathrm{~km}$ of the SLAC boundar: The population residing betwoen $0.3 \mathrm{~km}$ and $0.5 \mathrm{~km}$ from the SLAC boundary is about 1200 people. Based on e dose-10risk conversion factor of $5 \times 10-4$ latemt cancer faralities per person-rem for the whole population. the estimated latent cancer fatalities for this population over: the 15-year operation of PEP- $\|$ is less then 0.002 . (A conversion factor of $5 \times 10^{-4}$ is used for the general population to reflect the presence of children. who eppeser to be al prester risk of dying from cancor as a result of . exposure 10 radiation than edulis.)

Impects from rediological accidents would not significantly affect worker or public healtb and sefely ot PEP-II. The most serious accident involving worter and/or public exposure 10 radiation would be beam dumns from componem and sub-system foilures. The mexumum potential dose equivalent at the PEPD site boundary of the most serious rediation eccident would ba less then 
0.005 mrem in a yeas, fer bolow the cperating limit of $10 \mathrm{~mm} / \mathrm{mens}$. For a population of 1.200, en expocure of 0.005 mrear/your rewhls in a population dose of 0.09 person-rom over 15 years: less then $5 \times 10^{-S}$ latent ancer fatelities. Deconenmination and decommissloring (DED) ectivitios at FEP-II are estjcipoted to have segligiblo impacts 10 worker and public bealth and safety. Nos-radiological effocts would be similer to thow involved in facility construlstion: potential shorttarm effects to air and water quality, noiso. dust, vehicle emissions, slorm-water menagement. and weste bandling and disposal. Radiological impacts aro enticipaled to be minimal through cootrollad siorage of material with isidual rodicactivity and shipment to as approved low-level naste disposal scility.

No cumulative a messumble long. lerm edvironmedtal irrfacts are expected from the propaced PEP-II iscility. The contributions of waste products trom construcion, operetion. maintenanco, and DAD activities would 3fd to waste rocumulation and the exrifonmental impacts escociated with disposal facilities. Their contribution to such impacts nould be regligible. PEPI! operetions are not expacted to cause soll or groundwate acuiation. The :adiological irse equirzinot attribuloble is PEP-II operotions would bave $\therefore$ eg! igible contributions to the cirulative impact of SLAC operations. There are no currest or reasonably oresoesble nusias cacst-zition projects $: n$ ibe immediate viciditi of SLAC: thus. the PEP-D facisty woule dor bave any substantial efiects on loca' offsito cosstructicn.

\section{CESR-B Al:ermate Site}

Oporation of the CDSR-B would not s:gnificantly effect air ard weter quality. worter beolib aod safert public boalth and safety. and urese nieragement sislers. The iepacts of ianizing rediation producad durize operation ere sucipated to be oeglicitie. Nearly all of - je syochrotson rediatia would be i jsorted by the coppar incuum ihember. Based os in ascupation risk iactot of $4 \times 10^{-4}$ fital caxcers/porcon:erm. the alibber of poiestial falal caocers for ndiation watars is 0.024 . ad for Den-rediation niaters is 0.0006 . Tte dose to the gaveral piublic over the 15-jeer operational life a' the facility is stimated 10 bo less the $=0.1$ pareon. mon. or leas than 0.00005 fotal onnous (using 5x10-4 fitel cancerdpareon-rom rick (ector).

No cumulative or manumblo long corm environmental impects as expected fram the proposed CSSR-B fecility. The contributions of wasto products from conerenction. operation. maistanesces, and DAD cativities would be oegligible. CESR-B operations are pol expected to cause eall or groundwater ectivetion. The rediotogical dose equiriont ettributable to CESR-B operntions would make a segligible contribution to the cumulative impact of radiological operations at Caroell Tbe only other source of radiation exposurs on campus is the Ward research resclor which sheres Do facilities with CESR and would not be a source of cumulative exposures to workers or the public. Tho cumulative redionctive exposurs to the public are anticipated to be negligible.

\section{Determination}

Based on the analyses in the EA and the comments recoived on the proposed FONSI, the DOE bes determined that the proposed construction and operation of - B.Faclory al SLAC does dot constitule - major Federal action significantly affecting the quality of the buman onvironment withis the meaning of the NEPA. Therefore, an environmental impact statement is Dot required.

lesued in Weshington. DC this isth day of Decomber. 1993.

Tare OTowle.

Assistant Sectetary. Environment. Sofety and Heolth.

[FR Doc 93-31682 Filed 12-28-93; 8:45 am] culve cooc ureor- 
Environmentel Assessment for Proposed B-Factory (Asymmeiric Electron Positron Collider)

TABLE OF CONTENTS

Page

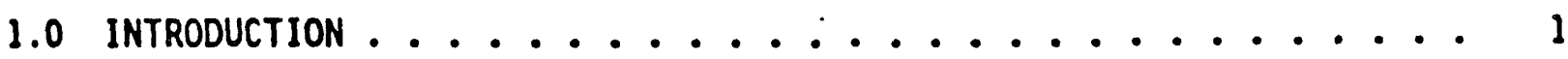

2.0 PURPOSE AND NEED FOR A B-FACTORY ................. 2

3.0 DESCRIPTION OF THE PROPOSED ACTION .............. 2

3.1 Project Description for PEP II . . . . . . . . . . . 2

3.1.1 Preoperational Project Phases ........... 9

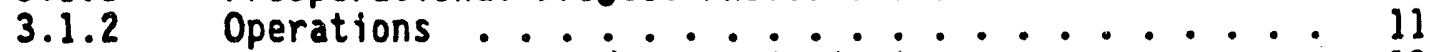

3.1.3 Decontamination and Decommissioning ....... 13

3.1.4 Waste Minimization and Pollution Prevention..... 14

3.2 Project Description for CESR-B ............ 14

4.0 DESCRIPTION OF ALTERNATIVES . . . . . . . . . . . . 20

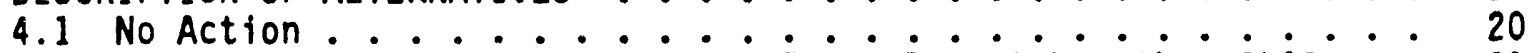

4.2 Construction and Operation at DOE Facility Other than SLAC . . 21

5.0 DESCRIPTION OF THE EXISTING ENVIRONMENTS ............. 21

5.1 Existing Environment for PEP-II . ............ 21

5.1.1 Air Quality - Non-Radiological ........ 23

5.1.2 Water Quality and Hydrology ........... 23

5.1.3 Hazardous Materials Usage and Waste Production ... 25

5.1.4 Archaeological and Historic Sites......... 26

5.1.5 Sensitive Species.............. 26

5.1.6 Floodplains/Wetlands ............ 27

5.1.7 Radiological Aspects ............. 28

5.2 Existing Environment for CESR-B .............. 31

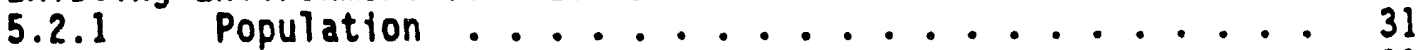

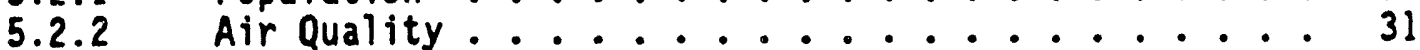

5.2.3 Water Quality and Supply ........... 32

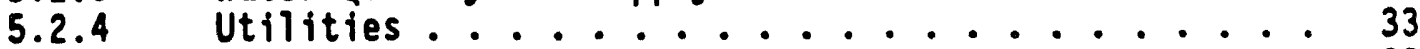

5.2.5 Archaeological and Historic Sttes......... 33

5.2.6 Protected Natural Features ............ 34

5.2.7 Threatened/Endangered Species .......... 34

5.2.8 Floodplains/Wetlands ............ 34

5.2.9 Hazardous Materials and Waste Management ..... 35

5.2.10 Radiation............. 36

6.0 POTENTIAL ENVIRONMENTAL EFFECTS OF THE PROPOSED ACTION . . . . . 40

6.1 Potential Environmental Effects of PEP-II . . . . . . . . 40

6.1.1 Effects From Construction ............ 40

6.1.2 Effects From Normal Operations ........... 44

6.1.3 Effects From Accidents ............. 50

6.1.4 Effects From Decontamination and Decommissioning . . 55

6.2 POTENTIAL ENVIRONMENTAL EFFECTS OF THE CESR-B ........ 56

6.2.1 Effects From Construction ........... 56 
Environmentel Assessment for Proposed B-Foctory (Asymmetric Electron Positron Collider)

6.2.2 Effects From Normal Operations ........... 62

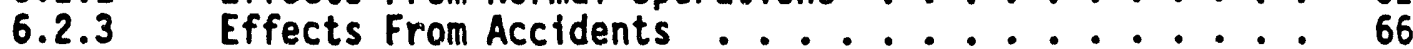

6.2.4 Effects From Decontamination and Decommissioning . . 69

6.3 Unavoidable Adverse Impacts . . . . . . . . . . . 69

6.4 Irreversible and Irretrievable Commitments of Resources . . . . 69

6.5 Cumulative and Long-term Impacts ........... 69

6.5.1 Cumulative and Long-Term Impacts for PEP-II ..... 69

6.5.2 Cumulative and Long-Term Impacts for CESR-B..... 70

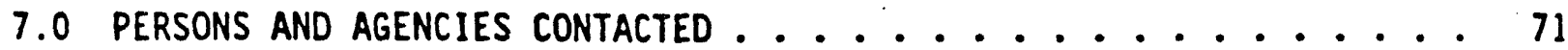

8.0 GLOSSARY AND ACRONYMS . . . . . . . . . . . . . 73

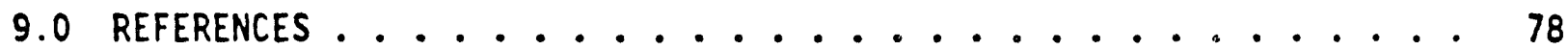

10.0 APPENDIX A - AGENCY CONSULTATION LETTERS . . . . . . . . . . A-1

List of Tables

Table 1. Natural and Man-Made Sources of Radiation Exposure to the

Public ....................... 28

Table 2. Comparison of Corneli ALARA Radiation Leveis With State and

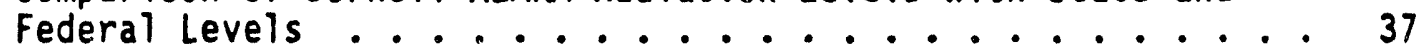

Table 3. Estimate of Neighbor Exposures ............ 38

Table 4. CESR-B Comparison With CESR (Wilson Lab) .......... 65

\section{List of Figures}

Figure 1. Locations of SLAC, LBL, and LLNL . . . . . . . . . . 3

Figure 2. SLAC Site Location ..................... 4

Figure 3. SLAC Site PIan Showing the General Configuration of the

Proposed B-Factory .................. 6

Figure 4. Cross-Sectional View of the Existing PEP Tunnel, Showing the Locations of Utilities and the Proposed High- and Low-Energy

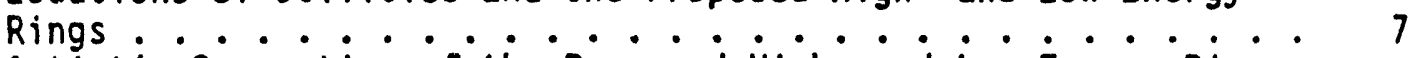

Figure 5. Artist's Conception of the Proposed High- and Low-Energy Rings in the PEP Tunnel ................. 8

Figure 6. The Injection Path of Positrons and Electrons for PEP-II . . . 12

Figure 7. Location of the Wilson Synchrotron Laboratory (Wilson Lab) on the Cornell University Campus . - . . . . . . 15

Figure 8. Cross Sectional View of the Accelerators in the Proposed CESR-B

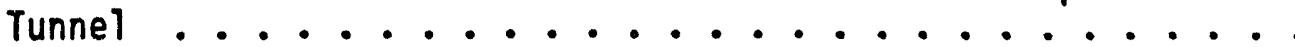

Figure 9. Modifications to Hilson Lab During Conversion to a B Meson Factory ............................... 18

Figure 10. Vacuum Chamber Residual Radioactivity for CESR Waste

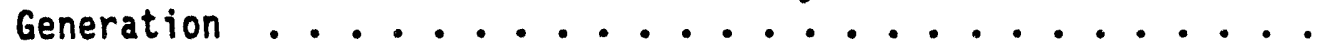




\section{SUMMARY OF IMPACTS}

This document presents the potential environmental consequences associated with the construction and operation of an Asymetric Electron Positron Collider, also known as a B-Factory. The U.S. Department of Energy (DOE) proposes to modify either the existing Positron-Electron Project (PEP) at the Stanford Linear Accelerator Center (SLAC) or the Cornell Electron Storage Ring (CESR) at Cornell University. As discussed in the main text, anong the four particle accelerators currentiy operating in the United States, PEP and CESR provide the most technically promising and practical options for a B-Factory. A B-Factory can be constructed by modifying the existing facilities and with minor or no conventional construction. In the case of the facility at SLAC, the B-Factory would be called PEP-II. At Cornell, the B-Factory would be called CESR-B.

The following chart summarizes and compares the potential environmental consequences of the two options for the proposed action, as well as the impacts associated with the no-action alternative.

COMPARISON OF ENVIRONMENTAL IMPACTS FOR THE ALTERNATIVES

\begin{tabular}{|l|l|l|l|}
\hline \multicolumn{1}{|c|}{ Comparison Factors } & No-Action & PEP-II & CESR-B \\
\hline BACKGROUND INFORMATION & N/A & Menlo Park, CA & Ithaca, NY \\
\hline - City, State & None & Stanford Univ. & Cornell Univ \\
\hline - Host Organization & None & DOE & DOE \\
\hline - Project Sponsor & Prot & \\
\hline
\end{tabular}

CONSTRUCTION IMPACTS

\begin{tabular}{|l|l|l|l|}
\hline - Soil Disturbance & & & \\
\hline $\begin{array}{l}\text { - Building } \\
\text { Construction }\end{array}$ & None & None & 4 acres \\
\hline - Roads & None & None & None \\
\hline - Parking & None & None & None \\
\hline - Land Use Conflicts & None & None & None \\
\hline - Air Quality & Negligible & Negligible & Negligible \\
\hline - Water Quality & Negligible & Negligible & Negligible \\
\hline - Ground & Negligible & Negligible & Negligible \\
\hline - Surface & Negligible & Negligible & Negligible \\
\hline
\end{tabular}


Environmentel Assessment for Proposed B-Factory (Asymmetric Electron Poshtron Collider)

\begin{tabular}{|c|c|c|c|}
\hline Comparison Factors & No-Action & PEP-II & CESR-B \\
\hline \multicolumn{4}{|l|}{ - Biologic Resources } \\
\hline - Flora, Fauna & Negligible & Negligible & Negligible \\
\hline $\begin{array}{l}\text { - Threatened and } \\
\text { Endangered } \\
\text { Species }\end{array}$ & Negligible & $\begin{array}{l}\text { Negligible } \\
\text { (Possible } \\
\text { presence of } \\
\text { San Francisco } \\
\text { Garter Snake, } \\
\text { no site survey) }\end{array}$ & $\begin{array}{l}\text { None (None } \\
\text { recorded near } \\
\text { site, no survey } \\
\text { avaitable for } \\
\text { site) }\end{array}$ \\
\hline - Wetlands & None & None & None \\
\hline - Traffic/Parking & Negligible & Negligible & $\begin{array}{l}\text { Negligible } \\
\text { (some rerouting }\end{array}$ \\
\hline - Cultural Resources & Negligible & Negligible & Negligible \\
\hline $\begin{array}{l}\text { - Hazardous } \\
\text { Materials/Waste }\end{array}$ & Negligible & Negligible & Negligible \\
\hline - Noise & Negligible & Negligible & $\begin{array}{l}\text { Negligible } \\
\text { (Conventional } \\
\text { construction } \\
\text { noise from } \\
\text { heavy machinery }\end{array}$ \\
\hline \multicolumn{4}{|l|}{ - Radiation Exposure } \\
\hline $\begin{array}{l}\text { - Involved Workers } \\
\text { - Non-involved } \\
\text { Workers } \\
\text { - General Public }\end{array}$ & $\begin{array}{l}\text { No } \\
\text { expected } \\
\text { harmful } \\
\text { health } \\
\text { effects }\end{array}$ & $\begin{array}{l}\text { No } \\
\text { expected } \\
\text { harmful health } \\
\text { effects }\end{array}$ & $\begin{array}{l}\text { No } \\
\text { expected } \\
\text { harmful health } \\
\text { effects }\end{array}$ \\
\hline
\end{tabular}




\begin{tabular}{|l|l|l|l|}
\hline Comparison Factors & No Action & PEP-II & CESR-B \\
\hline
\end{tabular}

OPERATIONAL IMPACTS

\begin{tabular}{|c|c|c|c|}
\hline - Air Quality & Negligible & Negligible & Negligible \\
\hline \multicolumn{4}{|l|}{ - Water Quality } \\
\hline - Ground & Negligible & Negligible & Negligible \\
\hline - Surface & Negligible & Negligible & Negligible \\
\hline \multicolumn{4}{|l|}{ - Biologic Resources } \\
\hline - Flora, Fauna & Negligible & Negligible & Negligible \\
\hline $\begin{array}{l}\text { - Threatened and } \\
\text { Endangered Species }\end{array}$ & Negligible & Negligible & Negligible \\
\hline - Wetl ands & None & None & None \\
\hline - Traffic/Parking & Negligible & Negligible & Negligible \\
\hline - Culturar Resources & Negligible & Negligible & Negligible \\
\hline $\begin{array}{l}\text { - Hazardous Materials/ } \\
\text { Waste }\end{array}$ & Negligible & Negligible & Negligible \\
\hline - Noise & Negligible & Negligible & Negligible \\
\hline \multicolumn{4}{|l|}{ - Radiation Exposure } \\
\hline $\begin{array}{l}\text { - Involved Workers } \\
\text { - Non-involved } \\
\text { workers } \\
\text { - General Public }\end{array}$ & $\begin{array}{l}\text { No } \\
\text { expected } \\
\text { harmful } \\
\text { health } \\
\text { effects }\end{array}$ & $\begin{array}{l}\text { No expected harmful } \\
\text { health effects }\end{array}$ & $\begin{array}{l}\text { No expected } \\
\text { harmful health } \\
\text { effects }\end{array}$ \\
\hline
\end{tabular}


Environmentel Assessment for Proposed B.Facton (Asvmmetric Electron Poshron Colliderl

\subsection{INTRODUCTION}

The Department of Energy (DOE) proposes to build an asymmetric $B$ meson factory for the purpose of conducting research in high-energy physics. A B meson factory is a type of particle accelerator that produces copious numbers of subatomic particles called B mesons. Observations of B meson decays provide an experimental arena for validation and modification of our understanding of laws and theories that are currently at the forefront of the frontier of science. In particular, they promise to shed light on one of nature's mysteries: a phenomenon known as Charge Conjugation and Parity (CP) violation.

There are four particle accelerators operating in the United States. The Positron-Electron Project (PEP) facllity at the Stanford Linear Accelerator Center (SLAC) and the Cornell Electron Storage Ring (CESR) at Cornell University both use colliding beams of electrons and positrons (the anti-particle of electrons) to produce particle interactions. This type of collision produces B mesons with a minimum of background (other particles that are not of primary interest in mesons). The other two particle accelerators, one at Brookhaven National Laboratory (New York) and the other at the Fermi National Accelerator Laboratory (IIIinois) both use protons as projectiles. While the use of protons has advantages in many areas of research, the proton facilities do not provide a good measurement environment for the broad-based study of CP violation using B mesons. A B meson factory can be constructed by modifying the existing facilities at SLAC or Cornell with minor or no conventional construction. The proposed action is to construct a $B$ meson factory by modifying PEP at Stanford or CESR at Corne11. The modified facility would be called PEP-II if Stanford were selected or CESR-B if Cornell were selected. This document describes environmental consequences of constructing a $B$ meson factory at Stanford, Cornell, or alternative sites. The no-action alternative, also addressed below, is to not construct a $B$ meson factory at any location.

The organization of this document is as follows. The purpose and need for DOE action .. that is, the construction and operation of a B-Factory .. is discussed in Section 2 . The details involved in the upgrading of an existing collider (i.e., the proposed action) are described in Section 3. The two alternatives to the proposed action are described in Section 4. Section 5 describes the existing environment at the SLAC and Cornell sites. Section 6 evaluates the impacts associated with constructing and operating the B-Factory at the SLAC and Cornell sites.

This document is prepared for compliance with the National Environmental Policy Act (NEPA) of 1969 (42 U.S.C. 4321-4347) and DOE's NEPA Implementing Procedures (10 CFR 1021). 
Environmentel Assessment for Aroposed B-Facton (Asymmetric Electron Positron Collider)

\subsection{PURPOSE AND NEED FOR A B-FACTORY}

High-energy physics seeks an understanding of the fundamental structure of matter and the laws that govern all physical phenomena. In order to add to this understanding, the DOE proposes to study a phenomenon called CP Violation. CP symmetry dictates that the collision of a particle with its antiparticle produces total annihilation of both. CP Violation is a sight distortion in this symmetry, and is the reason why our universe is composed of matter and not antimatter or an equal mixture of matter and antimatter or an equal mixture of matter and antimatter. CP Violation is the key to understanding why our matter-dominated Universe was formed. CP Violation has been discovered and observed experimentally, but there currently exists too limited a set of measurements to distinguish between competing models which propose a mechanism for the phenomenon. Studies of CP Violation in the decays of the $B$ meson system would provide the measurements needed to determine which theories and postulated mechanisms for CP Violation may be correct.

The importance of the physics goal is stressed by the DOE High Energy Physics Advisory Panel (HEPAP) subpanel report on the U.S. program of High Energy Physics Research (DOE 1992C). There, it speaks of "three important objectives (which) command special attention in the upcoming program of high energy research... He have to search for evidence of $C P$ Violation in all likely directions and test whether the currently favored picture is really correct." The report goes on to recommend the construction of an asymmetric electron-positron B-Factory as the best opportunity for achieving this objective. The asymmetric electron-positron B-Factory has the advantage of a background-free environment for the study of a wide variety of CP violating $B$ meson decays. The asymmetric nature of the machine provides an experimental configuration that is optimal for such studies.

\subsection{DESCRIPTION OF THE PROPOSED ACTION}

As discussed earlier, DOE proposes to build a B-Factory and to do so by modifying either the PEP facility at SLAC or the CESR facility at Cornell University. Because the existing machines are somewhat different, the project description for the proposed action has two parts, one for the B-Factory at SLAC, which will be referred to as PEP-II, and one for the B-Factory at Cornell, which will be designated CESR-B. Accordingly, two project descriptions are provided: one for PEP-II in Section 3.1 and one for CESR-B in Section 3.2 .

\subsection{Project Description for PEP II}

Construction and operation of PEP-II would be a collaborative effort involving three DOE Taboratories, SLAC, Lawrence Berkeley Laboratory (LBL), and Lawrence Livermore National Laboratory (LLNL). The locations of SLAC and the two collaborating laboratories in the San Francisco Bay Area are shown in Figure 1. Figure 2 shows the SLAC site location in the San Francisco 


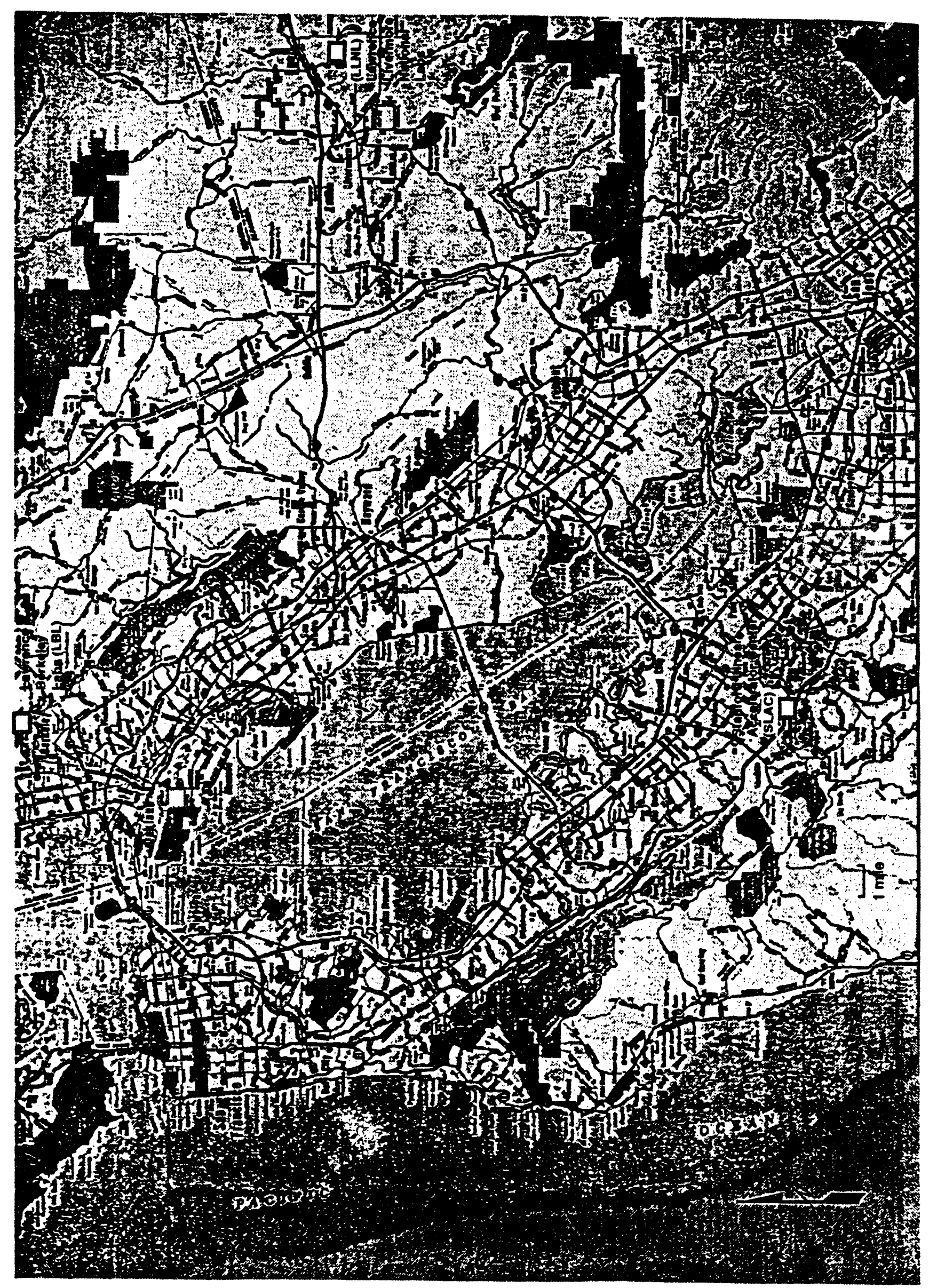

Figure 1. Locations of SLAC, LBL, and LLNL 


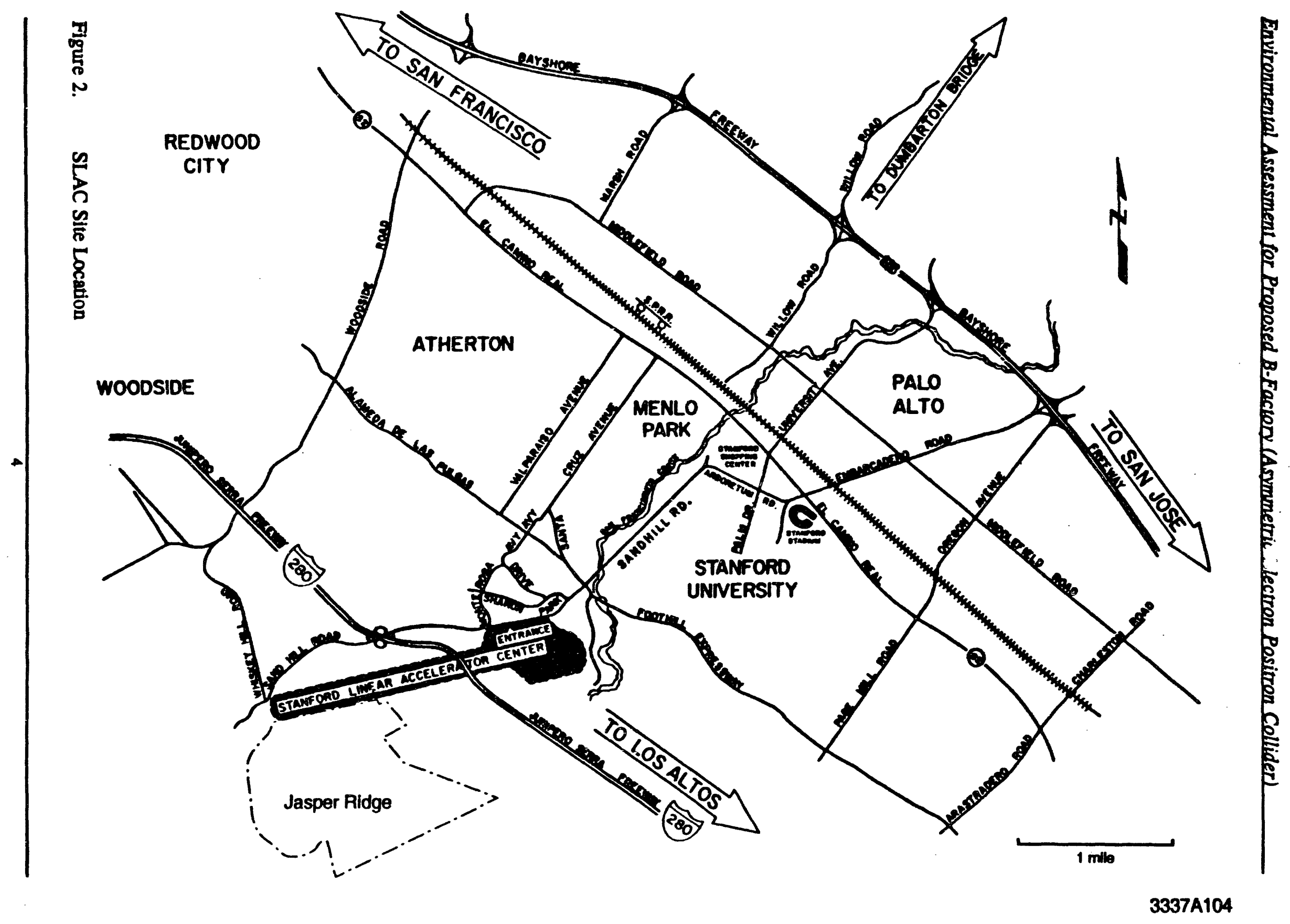


Peninsula. The general configuration of the proposed PEP-II is illustrated on a site plan in figure 3 . The cost of project construction is estimated to be $\$ 162.7$ million. There are additional costs for research and development in support of construction ( $\$ 3$ million) and for preoperational activities ( $\$ 4.7$ million), bringing the estimated total cost to $\$ 170.4$ million. SLAC also proposes to build a new detector, optimized for operation with asymmetric beams, at an estimated cost of $\$ 67.9$ million. The exact cost to the Federal government of the detector is certain to be less because of expected contributions from foreign collaborators. These estimates assume construction would begin in the fourth quarter of 1993 and operation would begin in 1998.

The asymmetric design of PEP-II would require a two-ring configuration. A high-energy electron beam would circulate in the existing PEF ring (after upgrading) while a low-energy positron beam would circulate in a new ring. Because the PEP tunnel was originally sized to house a second ring, ample room is available for the two rings.

Beam energies of $9 \mathrm{GeV}$ (billion electron volt) in the High-Energy Ring (HER) and $3.1 \mathrm{GeV}$ in the Low-Energy Ring (LER) would provide collisions at a center-of-mass energy of $10.6 \mathrm{GeV}$. By comparison, PEP currently consists of a single ring designed for a maximum center-of-mass collision energy of $36 \mathrm{GeV}$. Each beam would be housed in a vacuum system and would be guided by a lattice of magnets. Radiated power would be restored on each revolution by a radio-frequency (RF) system. Diagnostic and feedback hardware and software would measure and control the stability of the two beams. A cross-sectional view of the existing PEP tunnel, showing the relative locations of the proposed HER and LER, and an artist's conception of the HER and LER structures are shown in Figures 4 and 5 , respectively.

The HER and LER would be filled with electrons and positrons respectively from the existing SLAC linac, using partially new injection lines. The two rings would be brought together at one point in the tunnel at the existing interaction hall at Interaction Region 2 (IR-2), where the detector would be located to track and identify the particles produced (See Figure 3 ). The resulting electron-positron collisions, occurring at a collision energy of 10-11 GeV, would produce an abundant supply of $B$ mesons for observation and study.

The detector in PEP-II would be identical in scope to traditional electron-positron full solid-angle (4 pi) detectors, much like the detectors used in PEP. It would comprise a steel superstructure housing a large solenoid magnet and a series of detector elements, including a crystal cesium-iodide (CSI) calorimeter, gaseous charged-particle detectors, and a silicon vertex detector. The detector would consist primarily of newly fabricated components and would be located in an existing PEP experimental hall. 


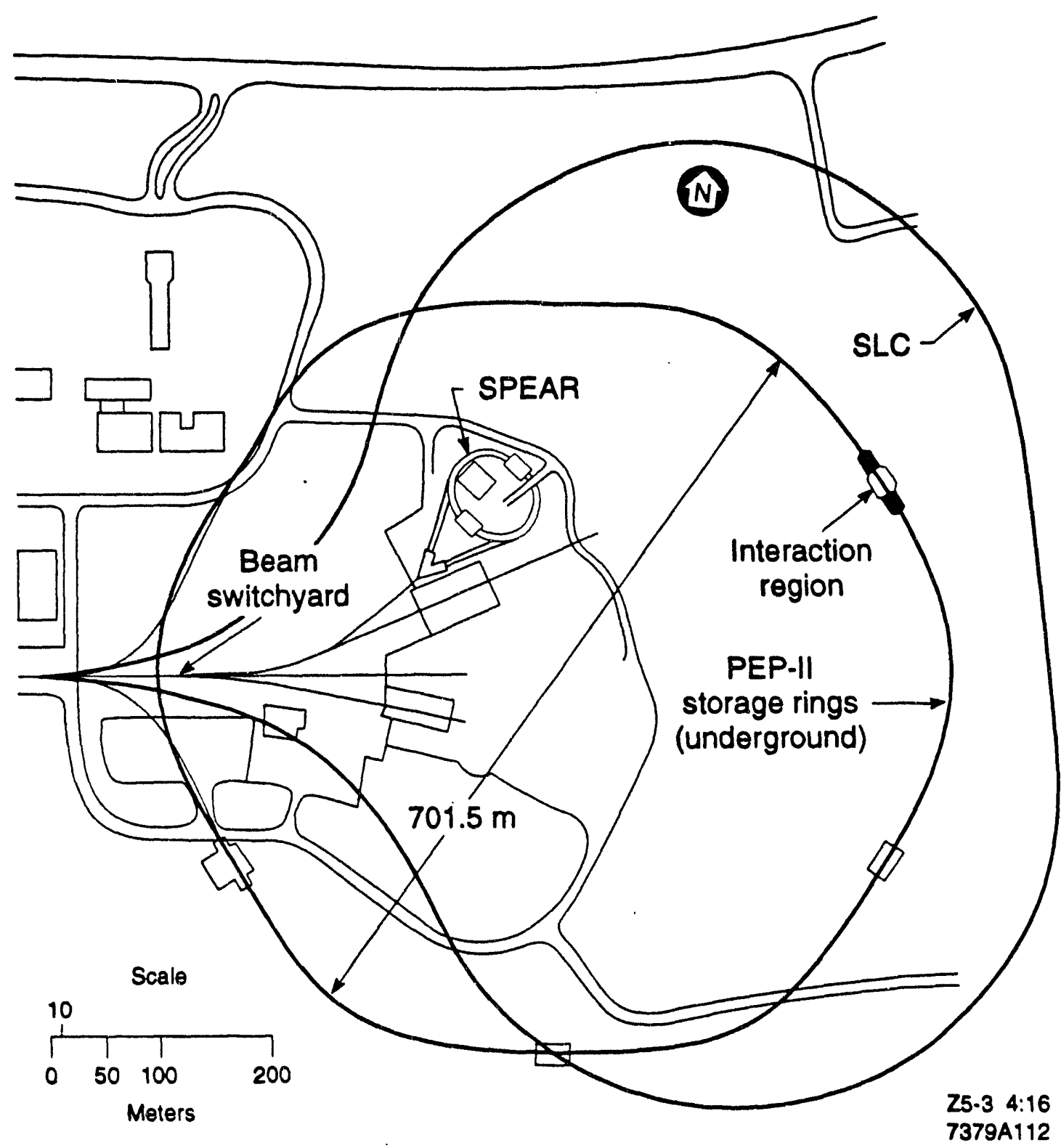

Figure 3. SLAC Site Plan Showing the General Configuration of the Proposed B-Factory 


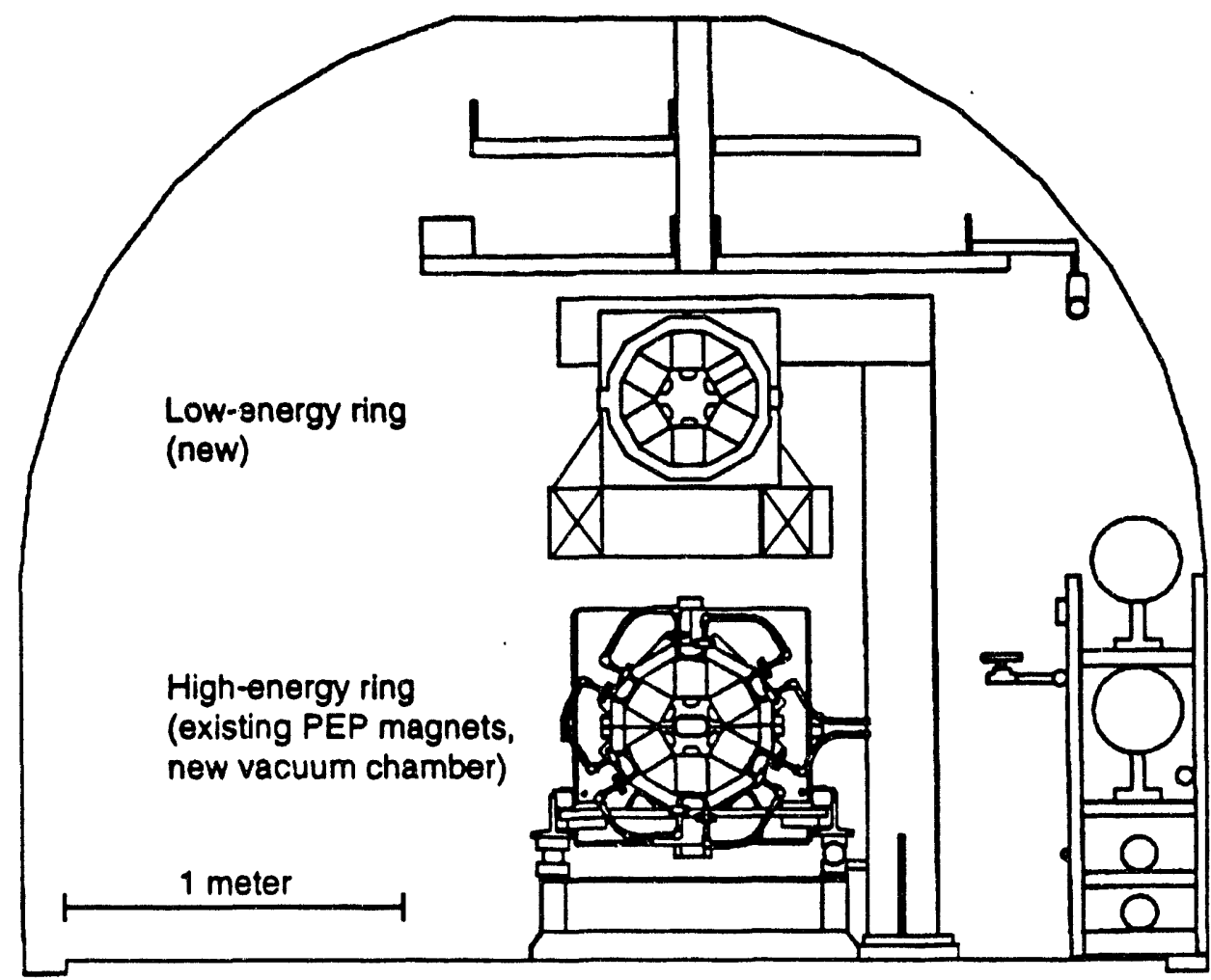

Z5-25 2:28

7379A120

Figure 4. Cross-Sectional View of the Existing PEP Tunnel, Showing the Locations of Utilities and the Proposed High- and Low-Energy Rings 


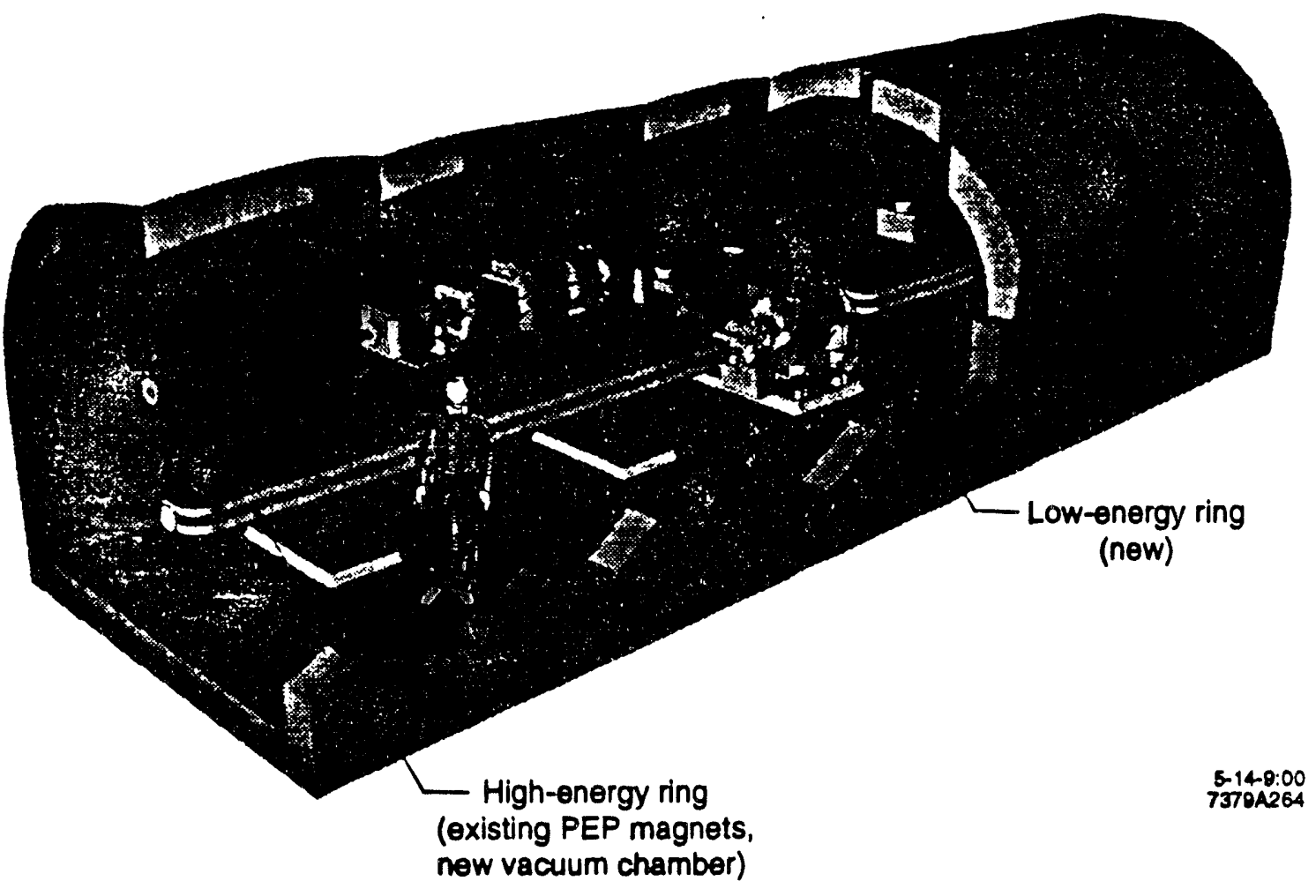

Figure 5. Artist's Conception of the Proposed High- and Low-Energy Rings in the PEP Tunnel 
No conventional construction and no augmentation to surface buildings would be required for PEP-II. The existing conventional facilities for PEP consist of all beam housings, research halls, support buildings, roads, earthwork, fencing, landscaping, electrical and mechanical utilities, and the sanitary-sewer and storm-drain systems. These existing systems and facilities have adequate capacity and would not require any modifications or expansion. Furthermore, no undisturbed grounds onsite would be affected by the project.

The current PEP ring components would be disassembled and, following inspection and refurbishment, $70 \%$ of them could be reinstalled in the tunnel on new supports as the HER. The HER will require new RF and vacuum systems. The second ring, the LER, would be newly constructed of components similar to those in the HER, and would be installed directly above the HER in the existing tunnel. Each ring would comprise the standard set of subsystems (e.g., vacuum chamber, RF system, diagnostic equipment) required for electron-positron storage rings.

The components and equipment for PEP-II would be fabricated at the collaborating institutions or at vendor facilities and tested in existing surface buildings at SLAC; LBL, or LLNL. Final assembly of all components would be performed at SLAC within existing buildings.

The construction and operation of PEP.II would not require any substantial change in staffing level, al though the distribution of employees would be changed. Staffing for PEP-II operations would be acquired from other SLAC programs as they wind down. Some staffing support for the PEP.Il project would be provided by LBL and LLNL.

The potential effects of the construction and operation of the proposed PEP-II project are discussed in Section 6.

\subsubsection{Preoperational Project Phases}

The upgrade of the existing PEP collider to the PEP-II B-Factory would involve: the removal and disassembly of various PEP components (e.g. magnets, vacuum chambers, etc.); the refurbishment of reusable PEP components; the fabrication of new components (e.g., magnets, vacuum system, etc.) at vendor facilities, SLAC, LBL, LLNL, or other collaborating institutions, and (4) the assembly of PEP-II components in existing facilities at SLAC. Minor modifications to the focusing and transport systems of the Iinac would be necessary. The potential impacts associated with these activities including hazardous-materials usage and waste production are discussed in Section 6.1 .

\section{PEP Ring Disassembly}

Space requirements for PEP component refurbishment and temporary storage were summarized in the Conceptual Design Report for the Asymmetric B-Factory (SLAC, 1991a). Space requirements for PEP disassembly of some 3,096 tons of magnets 
and support structures, HER assembly, and LER assembly, including storage requirements, are estimated to be $29,000 \mathrm{ft}^{2}, 11,000 \mathrm{ft}^{2}$, and $5,500 \mathrm{ft}^{2}$, respectively. SLAC's currently available crane-covered space of approximately $40,000 \mathrm{ft}^{2}$, together with space at collaborating laboratories (LBL and LLNL), would provide sufficient space for disassembly, storage, refurbishment, and installation of components.

Removal and disassembly of PEP components would include the magnets, concrete, supports, lead shielding, and vacuum chambers.

\section{PEP Component Refurbishment}

To refurbish the PEP magnets for PEP-II service, the magnets would be removed from PEP, disassembled, inspected, and cleaned. The coils would be stripped of their surface protection, repainted, sealed, and retested. Prior to painting, the magnet cores would be degreased and cleaned by hand (e.g., wire brushing). Degreasing operations will be conducted utilizing BAAQMD-permitted vapor degreasers at SLAC. Depending on the specific vapor-degreasing operation, the solvents used will be either 1,1,1-TCA or Freon TF. All stripping, cleaning, and painting operations would be performed onsite under conditions approved by SLAC's Environment, Safety, and Health (ES\&H) Division and monitored by ES\&H staff. The coils and cores would then be reassembled, tested, and readied for reinstaliation into PEP-II.

\section{PEP-II Component Fabrication}

All of the new magnets required for the HER and LER would be manufactured either at vendor facilities or at one of the three collaborating DOE laboratories. The magnets that would be newly fabricated for PEP-II would require the same degreasing procedure as the refurbished magnets, and would then be painted. Most of the parts for the HER copper vacuum system would be fabricated at vendor facilities. New klystron tubes for the RF system would be fabricated at a vendor facility or at SLAC; most of the remaining RF components would be fabricated at vendor facilities. Detector components would be fabricated at SLAC, other collaborating institutions, and at vendor facilities.

\section{Component Assembly}

Assembly of the components for PEP.II would be performed in existing facilities at SLAC, and would be conducted and monitored in accordance with established ES\&H procedures.

Brazing of vacuum-chamber subassemblies would be performed at SLAC in hydrogen furnaces with controlled atmospheres. Electron-beam or Tungsten-Inert Gas (TIG) welding would be used for some joints. Assembly of the vacuum chamber components would occur at SLAC prior to installation in the PEP tunnel. 
Environmentel Assessment for Proposed B-Focton (Asymmetric Electron Postron Colliderd)

HER dipole magnets would be mounted on new supports. The HER quadrupole and sextupole magnets would be mounted together on a raft and prealigned to facilitate installation in the tunnel as a single unit. Similariy, the dipole, quadrupole, and sextupole magnets for the LER would be mounted on rafts and prealigned. The rafts would then be transported to the tunnel and installed as complete units.

Final assembly of the detector components would be conducted at SLAC in the Interaction Region 2 (IR-2) complex. The IR-2 hall affords sufficient space for assembly operations, after which the detector would be moved directly onto the PEP-II beamline at this location.

\section{Linac Modifications}

Additional magnets would be added to the linac to permit electron and positron beams to be extracted for PEP-II. As illustrated in Figure 6, positrons would be extracted from the linac near the beginning of Sector 4, and electrons near the beginning of Sector 8 . They would be transported via new bypass 1 ines, to be assembled within the existing linac tunnel, to the east end of the linac at Sector 30. Here these lines would connect to the existing South Injection Transport (SIT) and North Injection Transport (NIT) lines. Additional magnets would be added at the SIT and NIT entrances and exits to accommodate optical matching of the transport lines with the injection line but the optics and geometry of the NIT and SIT lines would not be changed. These modifications would include the relocation of one injection line from SIT to the second ring (the LER) and, for the HER, conversion from horizontal injection to vertical injection. There would be no construction activities associated with these modifications to the linac.

\subsubsection{Operations}

During PEP-II experiments, positrons and electrons would be accelerated in the linac and injected into the storage rings where they would circulate in opposite directions. At one point in the tunnel (the interaction hall at IR-2), the two rings would be brought together to allow electron-positron collisions. The particle detector would be positioned at this location to detect the decays of $B$ mesons.

Commissioning and start-up of PEP-II would occur over a period of about one year. The currently anticipated period of experimentation is ten to fifteen years. During this time, the accelerator would run essentially continuousiy 24 hours per day, 7 days per week, interrupted by scheduled maintenance averaging two days per month. Occasional down-time would al so occur for non-routine maintenance (usually one to two shifts in duration). In addition, a routine, summer down-t ime of three months for major maintenance is also expected, similar to the historical operation of PEP. 

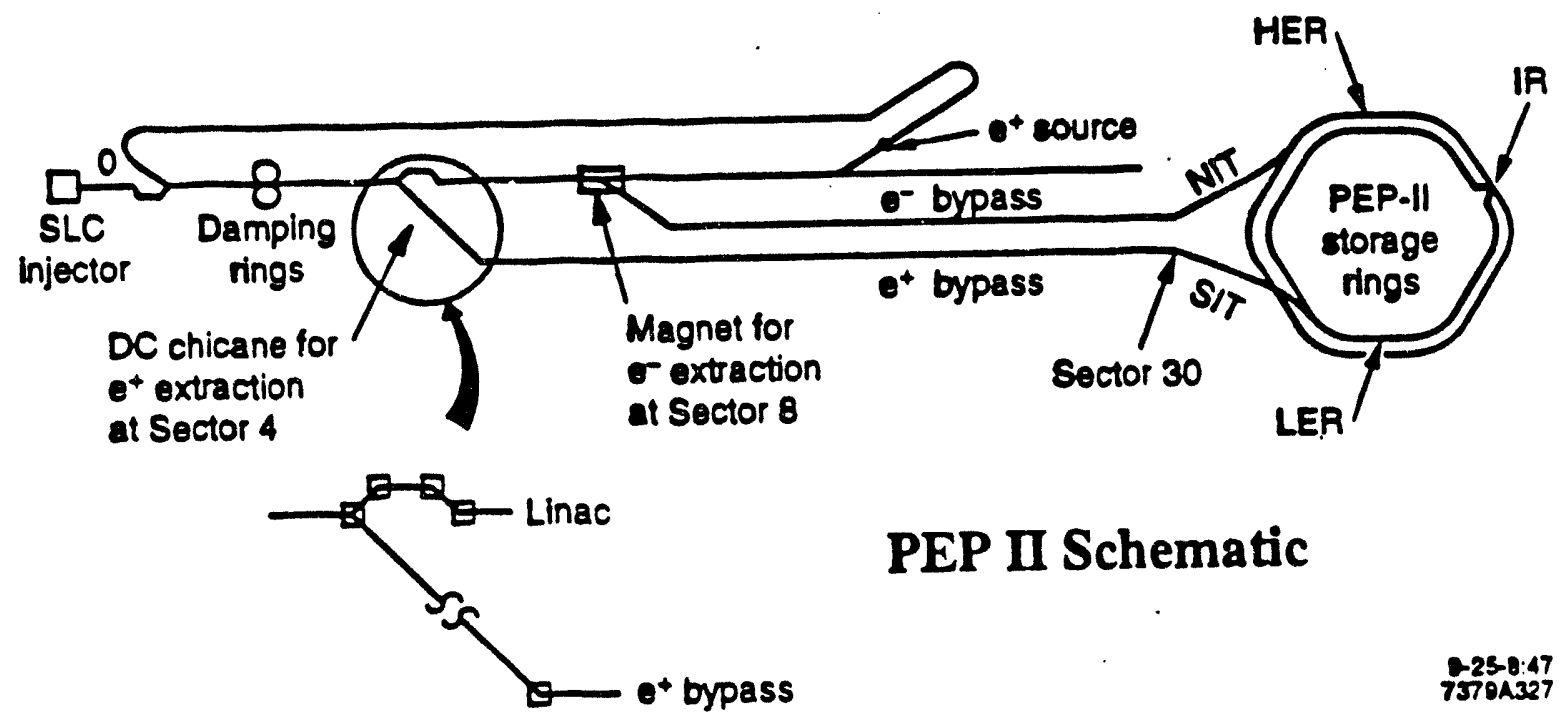

PEP II Schematic

Figure 6. The Injection Path of Positrons and Electrons for PEP-II 
Routine maintenance involves activities such as equipment and components repair and replacement, component cleaning, replacement of cartridges on the deionized water systems, and replacement of air fliters. Management of the groundwater seepage into the tunnel would also require the routine maintenance of drains, gutters and pumps (See Section 5.1.2). In addition to the routine maintenance, experience with other accelerators indicates that PEP-II would likely require minor modifications in order to achieve design-criteria operational parameters. These modifications would add, replace, change or remove equipment and components, but would not change PEP.II design parameters or increase the potential effects from operations as described in Section 6. There may be modifications to, or replacement of, the detector that would provide capabilities (such as data acquisition and analysis) beyond the original design; however, these improvements would not increase the impacts to human health or the environment as identified in Section 6 . Modifications would include, or be similar in nature to:

- the fabrication, replacement, modification and addition of pulsers, DC power supplies and $A C$ distribution systems from existing substations;

- the fabrication and installation of wire scanners, beam position monitors, and associated components; the replacement and upgrade of existing communications equipment, computers, and machine protection and feedback control systems; the installation of measuring and monitoring instrumentation; and

- the removal, replacement or modification of magnets, segments or components of the vacuum system, collimators, and modulators and RF driving and phasing equipment for klystrons.

The PEP tunnel was originally designed and shielded to accomnodate a $2006 \mathrm{6eV}$ proton beam and maximum electron-positron collision energy of $36 \mathrm{GeV}$. In contrast, PEP-II would normally run with a $9 \mathrm{GeV}$ electron beam and a $3.1 \mathrm{GeV}$ positron beam, producing a collision energy of $10.6 \mathrm{GeV}$. Over the service life of the PEP.II facility, the electron beam energy could be increased to about $12 \mathrm{GeV}$, or the positron beam to about $4 \mathrm{GeV}$, to explore other areas of interest. The beam energies in the two rings would not be increased simultaneousiy. Increases in the beam energy of the high-energy ring, for example, would only require a possible increase in the number of RF stations. Incidental increases in PEP-II operating conditions over the course of its projected service life would not exceed the design capacity for the electrical distribution systems.

\subsubsection{Decontamination and Decommissioning}

At the conclusion of PEP-II's useful IIfe, conservatively estimated to be 15 years, decontamination and decomissioning of the equipment would be performed in accordance with applicable laws and regulations, as reflected in established SLAC policies and procedures. For a project of this type, a 
Environmeniel Assessment for Proposed B-Factory (Asymmetric Electron Positron Collider)

radiological survey would be performed and if any components or materials are determined to have residual radioactivity, they would be stored onsite pending future reuse or ultimate disposal. Based on radiological surveys conducted for PEP, no residual activity would be expected for PEP-11. Potential impacts associated with decontamination and decommissioning activities are discussed in Section 6.1.4.

\subsubsection{Waste Minimization and Pollution Prevention}

The inherent design of PEP-II (1.e., the use of the existing PEP tunnel and the reuse of a majority of the existing PEP components) is consistent with DOE's policy on Waste Minimization and Pollution Prevention (WMIN/PP) (DOE, 1992a). By reusing as much as $70 \%$ of the PEP components, construction of PEP-II would avoid and reduce the generation of hazardous substances, pollutants, wastes, and contaminants at the source. PEP components (uncontaminated) not destined for reuse in PEP.II would be evaluated for their salvage potential.

In addition, it is anticipated that magnet refurbishment (i.e., degreasing) would make use of alternative solvents resulting from current nationwide research efforts aimed at developing solvent substitutes with decreased environmental effects. The WMIN/PP policy would be incorporated into PEP-II operations through SLAC's ongoing programs for identifying ozone-depleting compounds and developing alternative solvents for cleaning operations. SLAC is phasing out ozone-depleting halogenated solvents at an accelerated rate and will utilize non-ozone-depleting solvents as they are approved for use and made available for commercial use. SLAC anticipates a complete phaseout of ozone-depleting solvents prior to the federal 1995 deadiline.

\subsection{Project Description for CESR-B}

As discussed in Section 2, a B meson factory produces B mesons in quantities that allow the observation of decay processes that are of fundamental importance to our understanding of the laws of physics. One option for the proposed action would be to build a B meson factory at Cornell University by modifying the equipment and facilities at the existing Wilson Synchrotron Laboratory (Wilson Lab).

Figure 7 shows the location of the Hilson Lab on the Cornell University Campus. The lab houses the Cornell Electron Storage Ring (CESR) which is one of four high energy particle accelerators currently operating in the United States. In its unmodified condition, the CESR stores and accelerates beams of electrons and positrons contained in an evacuated tube having a circumference of $1 / 2$ mile. The electron beam and positron beams travel in opposite directions guided by a lattice of magnets which bend and focus the beams.

Radiated power is replenished by means of a radio frequency accelerating system. The beams are guided to a point on the ring called the interaction 


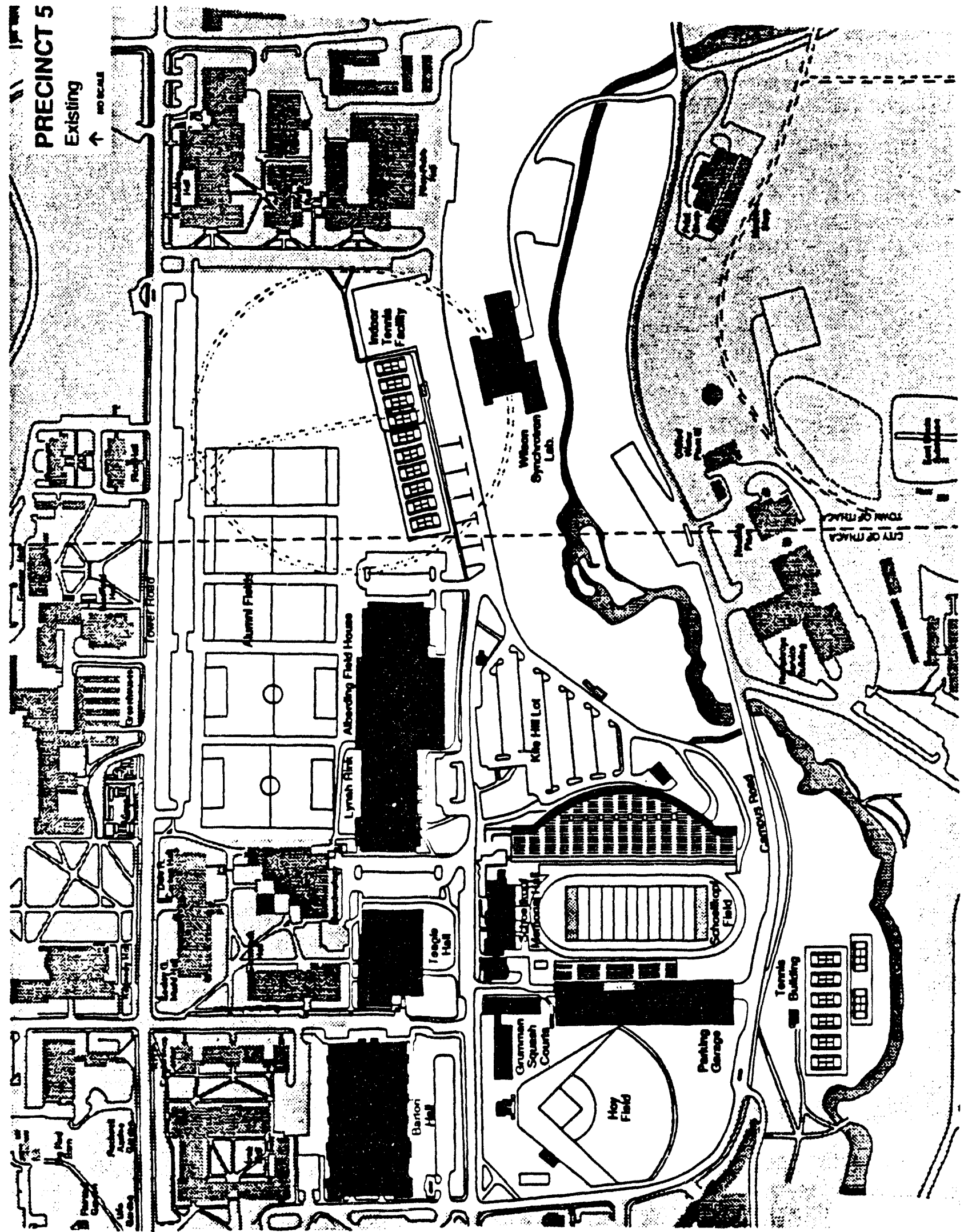

Figure 7. Location of the Wilson Symchrotron Laboratory (Wilson Lab) on the
Cornell University Campus 
point, where the beams collide to produce $B$ mesons and other particles. For the existing CESR, the electrons and positrons have the same energy. Because the quality of the data is greatly enhanced if the two beams have different energies, CESR would be modified to provide a low energy ring (LER) and a high energy ring (HER). The modified facility would be called CESR-B to emphasize the facility's role as a B meson factory. Figure 8 illustrates the position of the two rings in the tunnel together with another machine, the synchrotron injector ring. Currently the proposed action is to modify the CESR using the $H E R$, adding an LER, and retaining the synchrotron in a lower position, to accomodate the LER.

The HER operating at $8 \mathrm{GeV}$ energy and LER operating at $3.5 \mathrm{GeV}$ would be filled with electrons and positrons from the existing injector consisting of a linear accelerator (linac) followed by a synchrotron. The two beams would be brought to collision at an interaction point and the particles produced by the collisions would be detected, tracked and identified by use of a modified version of the detector now used at CESR, known as CLEO.

Radio frequency accelerating structure research in support of CESR-B would be conducted at Newman Laboratory which is located approximately 1/2 mile northest of Wilson Lab. The Laboratory of Nuclear Studies (LNS) is the University administrative unit for Wilson and Newman Laboratories.

Figure 9 shows the proposed changes to the existing Wilson Lab. Conventional construction would be required to provide additional space for electrical and mechanical equipment on the east side $(17,600 \mathrm{sq}$. ft.). CHESS $x$-ray beam lines $(7,000 \mathrm{sq}$. ft.) and additional room for scientists in a new fourth and fifth floor $(22,000$ sq. ft.). The CHESS $x$-ray beam 1 ines and $40 \%$ of the new fourth and fifth floors are a related action and will not be funded as part of this project. However, the impacts of these actions are discussed in chapter 6 . In addition, there will be 2,900 sq. $\mathrm{ft}$. added to the tunnel flare, and 5,800 of the tunnel flare will be renovated.

The existing cooling tower on the east side of Wilson Lab would be relocated approximately 200 feet to the east, and expanded. New electric feeders would be added, either to an existing underground duct bank running from the kite Hill switching station or directly from the Cornell $115 \mathrm{kV}$ substation using an existing overhead corridor. In either case, approximately 200 feet of new underground duct banks would be constructed. Additional chilled water will be needed from the campus central chilled water system for space cooling.

Existing chilled water transmission mains are adequate, and additional chilled water production will be provided by new capacity already planned to occur.

32,800 cubic yards of earth would be displaced from the east side of the laboratory and 17,300 cubic yards from the west side for tunnel expansion. Approximately 12,500 cubic yards and 15,200 cubic yards of earth would be used as backfill for the east and west sides, respectively. About 22,400 cubic yards of soil would be removed from the site. In addition, 750 cubic yards of 


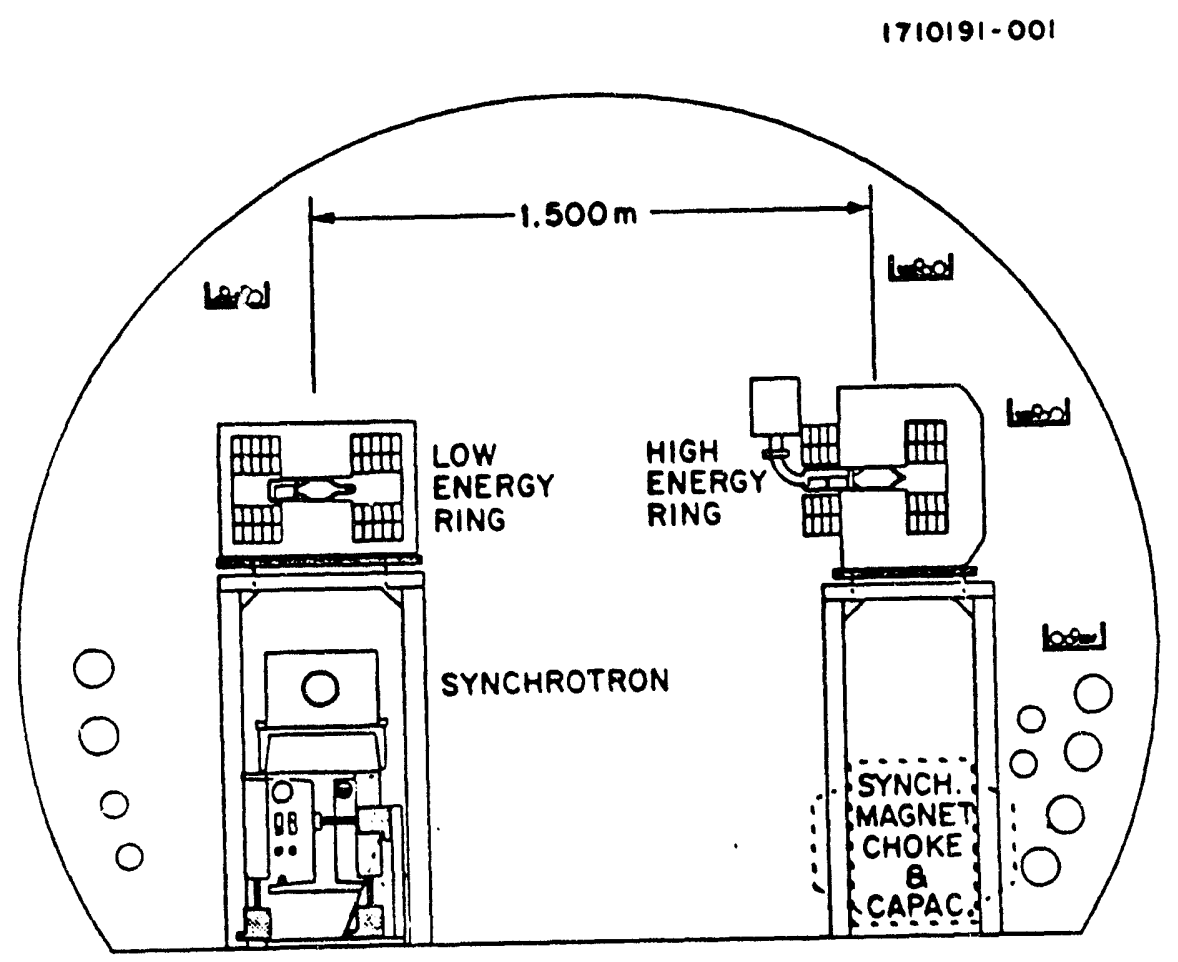

Figure 8. Cross Sectional View of the Accelerators in the Proposed CESR-B Tunnel 


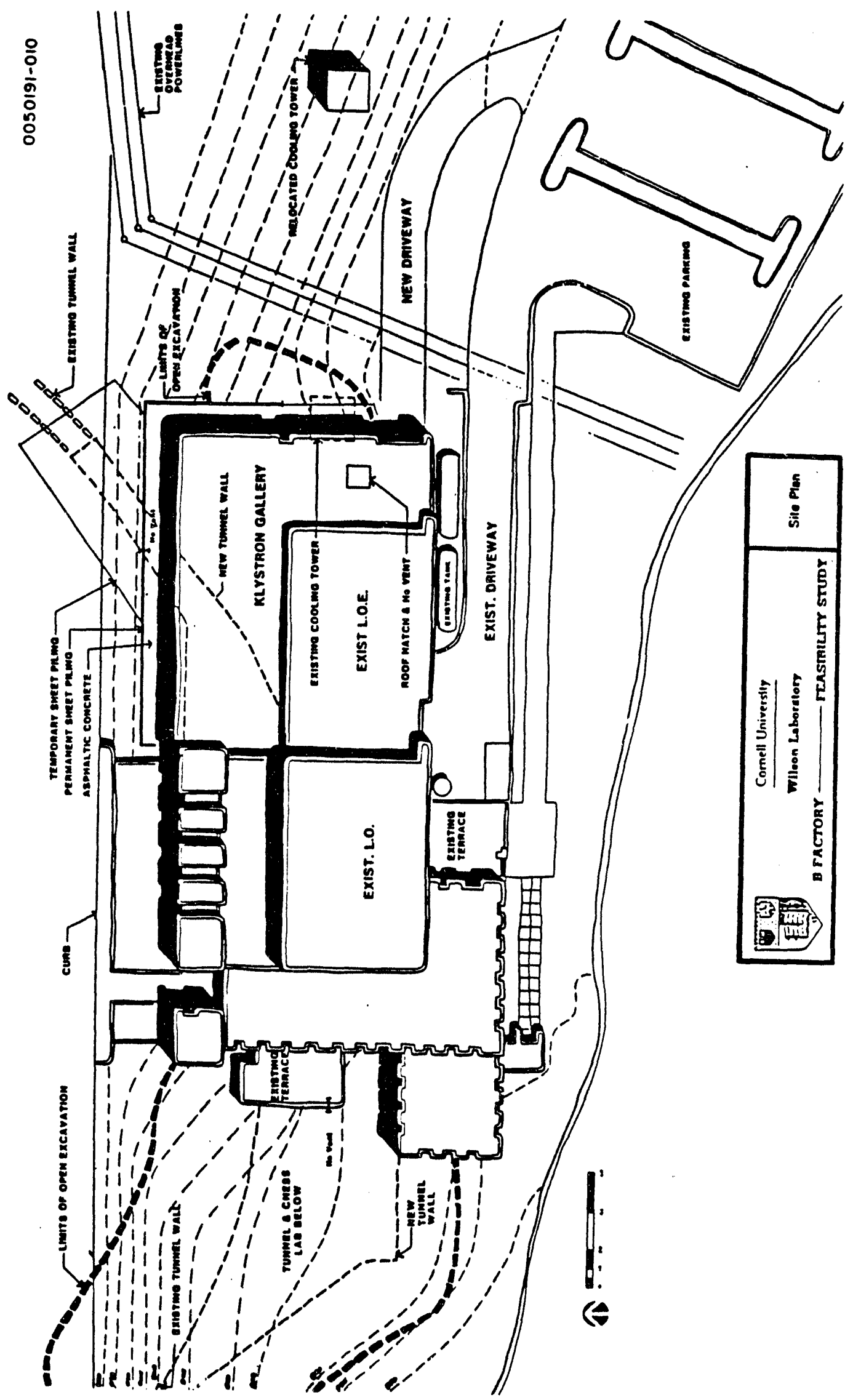

Figure 9. Modifications to Wilson Lab During Conversion to a B Meson Factory 
construction and demolition debris would be removed. Construction is estimated to disturb approximately 2.5 acres immediately adjacent to the laboratory, and an additional 1.5 acres nearby for laydown areas for construction equipment and storage for excavated soli. Construction on the CESR-B would begin at the end of 1993 and colliding beam and detector operations would begin in October, 1997. The cost of project construction is estimated to be $\$ 99.5 \mathrm{million}$. There are additional costs for research and development in suuport of construction (\$2.4 million) and for preoperational activities ( $\$ 2.7$ million). An additional amount of $\$ 7$ million is estima ad for meeting DOE requirements and regulations governing construction of facilities, bringing the estimated total cost to $\$ 111.6$ militon. Cornell also proposes to modify the existing CLEO detector, which is optimized for operation with symmetric beams, at an estimated cost of $\$ 18.2$ million. The exact cost to the Federal government of the detector is certain to be less because of expected contributions from foreign collaborators.

The current CESR components would be disassembled and, following inspection and refurbishment, the bending magnets that comprise most of the buik and weight of the storage ring will be reinstalled as the HER. The quadropole magnets will be reinstalled as the focusing magnets of the LER. Prior to this reinstallation, the synchrotron would be disassembled and remounted, as shown in Figure 9. The linac will remain in place with minor modifications, as described in "CESR-B Conceptual Design for a B-Factory Based on CESR", Cornell University, June 1993. When finished, each ring would be comprised of the standard set of subsystems required for electron storage rings, 1.e. bending and focusing magnets, vacuum, radio frequency systems, diagnostics, and controls. In the new configuration, the LER bending magnets and the HER focusing magnets will be new, as will the vacuum and radio frequency systems for both rings. The components will be bullt on-site, at facllities of collaborating institutions, or at vendor facilities. The material will be received and tested at existing laboratory facilities at Cornell. Radio frequency system work will be done at the Newman Lab, located approximately one-half mile northwest of the Wilson Lab. The Laboratory of Nuclear Studies (LNS) is the University administrative unit responsible for Wilson and Newman Labs.

At the conclusion of CESR-B's useful life, estimated to be 15 years, decontamination and decommissioning of the equipment would be performed in accordance with applicable laws and regulations. A radiological survey would be performed and if any components or materials are determined to have residual radioactivity, they would be stored onsite pending future reuse or ultimate disposal.

Additional description of the Hilson Lab and the CESR are included in Section 5.2. Additional description of the proposed CESR-B is presented in Section 6.2 . 


\subsection{DESCRIPTION OF ALTERNATIVES}

\subsection{No Action}

Under the No-Action Alternative, the B-Factory would not be built and existing SLAC and Cornell facilities would continue to operate under current management practices. The idle PEP facility would not be upgraded; it would remain in a stand-down mode until future uses are determined or decomissioning is initiated.

While in the stand-down mode, continuing control and management of groundwater seepage into the PEP tunnel would be necessary. Groundwater seepage would continue to be channeled into the drainage gutters, and regular maintenance would be performed to keep all drains and gutters clear and pumps operational. It would eventually be necessary, per Regional Water Quality Control Board (RWQCB) requirements to reroute the gutters so that discharge of groundwater seepage would be directed to the sanitary sewer rather than the storm drain, as is the current configuration.

The PEP facility would remain in a semi-secured state to prevent unauthorized access. General surveillance of the facility would remain in effect. The few PEP components, used in the PEP-II design efforts (i.e., mock-up), would be collected, inventoried, and appropriately stored until future use is identified.

There would be no change from current environmental or health effects associated with the implementation of this alternative.

If the No-Action Alternative were selected, the B-physics and accelerator physics programs at Cornell would continue for about 5 years. At the end of that period, CESR operations would probably be terminated at Cornell.

Particle physics experiments of the type conducted at Cornell would need to be accomplished by using other laboratories. Accelerator physics and training in accelerator physics would be sharply attenuated or terminated entirely.

In the event that the B-Factory would not be built at all, the U.S. would lose its current leadership in heavy quark physics. Of equal or greater importance, U.S. physics would have a much diminished opportunity to be first in unraveling the mystery of $C P$ Violation.

1 As stated in Section A(6) of the Califomia General industrial Stomwater Permit, the Storm Water Pollution Prevention Program must contain certfication that all non-stormwater discharges have been eliminated from the stormdrain system. 


\subsection{Construction and Operation at DOE Facility Other than SLAC}

The possibility exists to study CP Violation using $B$ mesons produced at DOE facilities with proton colliders, such as the Tevatron at Fermi National Accelerator Laboratory or the Superconducting Super Collider. Another DOE site, Brookhaven National Laboratory (BNL), with its lower energy proton beam, operates in fixed target mode and provides a copious source of $K$ mesons (the much lighter "cousin" of the $B$ meson) for a very productive $K$ meson program. However, B meson studies are not feasible at BNL. Proton machines offer a considerably more limited program of $C P$ measurements and do not have the breadth inherent in the asymmetric electron-positron approach. Without a broad-based program, it will not be possible to test competing theories for $C P$ Violation.

The relative strength of the asymmetric B-Factory approach has been stressed several times by the High Energy Physics Advisory Panel. Following its meeting of June 4-5, 1991, HEPAP wrote to the DOE Director of the Office of Energy Research that it "is convinced that understanding the origin of CP Violation is one of the central goals of particle physics. Moreover, it is our opinion that this important question can be addressed in much more depth by the (asymmetric) electron-positron machines than by hadron [proton] colliders.... While proton colliders produce B mesons copiousiy, there are very substantial problems in detecting even the pristine modes. This is discussed in the 1992 HEPAP subpanel report on the U.S. Program of High Energy Physics Research (DOE 1992C) which states, "At hadron [proton] colliders, many questions about backgrounds, rates, triggering and other detector issues will have to be addressed before a broad program of CP Violation measurements can be carried out there. "The report goes on to stress the advantages of the asymmetric electron-positron approach and to recommend construction of such a facility for the U.S. program.

The use of a proton collider will not meet the technical requirements of the study of CP Violation; an electron-positron collider is necessary. To build such an accelerator at another site would entail a substantial amount of construction and would raise the project cost and increase construction time considerably. The potential construction-related impacts would be relatively greater for this alternative than for either PEP-II or CESR-B. The potential impacts of operation at another site would be expected to be similar. Due to the greater cost and time involved, this alternative was not considered further.

\subsection{DESCRIPTION OF THE EXISTING ENVIRONMENTS}

\subsection{Existing Environment for PEP-II}

SLAC is a national facility operated by Stanford University under contract with the U.S. Department of Energy. SLAC is located on the San Francisco Peninsula between San Francisco and San Jose, California, as shown in 
Figure 2. The site is located on a belt of low rolling foothills between the San Francisco Bay to the east and the Santa Cruz Mountains to the west. The SLAC site occupies 426 acres of land owned by Stanford University and is located west of the University and the city of Palo Alto. SLAC's facilities are located on a parcel roughly 1,000 feet wide and three miles long, oriented in an east-west direction. The width of the parcel expands to about 3,000 feet at the target (east end) to allow space for buildings and experimental facilities. The 1.4-mile-circumference tunnel of PEP and its associated surface bulldings are located at the eastern end of the site. The PEP tunnel is located 25 to 50 feet below ground, depending on topographic variances. The linac extends 2 miles to the west from the PEP facility. It was the source of electrons and positrons for PEP and is still the source of these particles for the high-energy physics experiments at SLAC.

The SLAC facility is situated in a moderately hilly area covered largely by grassland and oak woodland. The Jasper Ridge Biological Preserve of Stanford University is located south of the accelerator and southwest of the PEP tunnel. San Francisquito Creek flows through the preserve near its northern boundary, roughly parallel to the linac, and ultimately flows into San Francisco Bay. Because this preserve has long been recognized as a unique ecological resource representing extraordinary biological diversity, SLAC construction activities have been conducted so as to prevent or minimize adverse impacts to this area.

The SLAC site is underlain by bedrock comprised of sandstone and claystone. In general, the bedrock on which the western half of the accelerator rests is of Eocene age (over 50,000,000 years old) and that under the eastern half is of Miocene age (over 10,000,000 years old). On top of this bedrock at various places along the accelerator alignment are found alluvial deposits of sand and gravel generally of Pleistocene age $(1,000,000$ years $01 d)$. At the surface is a soil overburden of unconsolidated earth materials averaging from three to five feet in depth. The San Andreas Fault, which extends nearly the entire length of the state, is present about a mile west of the site boundary. The probability of a strong earthquake (magnitude of 6.5 to 8.5 on the Richter scale) originating in the proximate section of the San Andreas Fault is in the range of 0.05 to 0.1 per annum (i.e., once every ten to twenty years) and may be increasing with time. However, when only the more severe earthquakes are considered (i.e., magnitude of 7 to $8+$ ) the probability of occurrence drops to 0.01 to 0.001 per annum (1.e., once every 100 to 1,000 years). Peak accelerations would be expected to be in the range of $0.5 \mathrm{~g}$ to $0.8 \mathrm{~g}$ (SLAC, 1982). Facilities constructed on the SLAC site employ appropriate building techniques such that seismic risks are reduced to acceptable levels (SLAC, 1992j).

SLAC is located in San Mateo County and is mainly surrounded by five communities: Atherton; West Melo Park; Portola Valley; Hoodside; and Stanford. The populated area around SLAC is a mix of office, schoot, university, housing and pasture. Population data from the recent 1990 census 
for the five communities total about 38,000. There are currently approximately 1,700 staff and contract personnel employed at SLAC.

\subsubsection{Air Quality - Non-Radiological}

The air quality in the San Francisco Bay Area Air Basin is generally fair and is improving. However, health-based ambient air quality standards are occasionally violated for ozone $\left(\mathrm{O}_{3}\right)$ in inland valleys during summer and for carbon monoxide $(\mathrm{CO})$ in urban areas on cold winter nights. As a result, the Basin is currently classified by the EPA as a nonattainment area for these contaminants, ${ }^{2}$ and is classified as "serious" for CO by the California Air Resources Board. The Basin also exceeds state standards for PM $_{10}$ (particulate matter with mean diameter less than 10 microns).

Non-radiological air emissions from stationary sources at SLAC are regulated by the Bay Area Air Quality Management District (BAAQMD). Primary sources of non-radiological air emissions include: volatile organic compounds (VOC3) from solvent cleaning and coating operations; nitrogen oxides $\left(\mathrm{NO}_{x}\right)$ from industrial boilers; and particulates from metal-and wood-working activities in various shops. Currently, SLAC has 26 air-pollution sources listed with the BAAQMD, and two additional pending sources. Of the 26 current sources, 22 are permitted and 4 are exempt from permitting requirements. Nevertheless, these four units are 1isted with the BAAQMD because they are associated with a pollution-abatement device in their operation.

The SLAC facility is currently in compliance with Federal, state, and local regulations and all requirements included in its active permits regarding both Criteria Pollutants and Toxic Air Contaminants.

Radiological aspects, both background conditions and contributions from SLAC operations, are discussed in Section 5.1.7.

\subsubsection{Water Quality and Hydrology}

There are no drinking-water wells at or near SLAC, mainly because the groundwater is naturally high in total dissolved solids (TDS) and has very low flow rates. A report prepared for SLAC (King, 1989) to identify and evaluate potential underground water supplies concluded, based on the information available, that the Tertiary bedrock beneath the facility did not constitute a viable water source for SLAC.

2 As of the time this document was prepared, the Basin had not exceeded Federal standards for ozone for the past three years or for carbon monoxide throughout 1992. Accordingly, EPA may consider reclassifying the Basin as an attainment area for these pollutents (Taylor, 18921. 
An onsite groundwater monitoring network comprises 21 wells located in areas of the facility that have either historically or presently store, handle, or use chemicals or radionuclides posing potential threats to groundwater quality. Samples collected from the monitoring wells are analyzed for a wide range of constituents. Analytical results indicate that groundwater samples collected from several of the wells contained various metals llead, copper, chromium, and 2 inc) and/or chlorinated solvents (TCE, TCA, Methylene chloride, and freon) at or above the State of California Maximum Contaminant Levels (MCLS) for drinking water. There is, however, no known groundwater. contamination in the vicinity of the PEP tunnel. The detection of the metals in groundwater samples could be due to their natural occurrence in the rocks beneath the SLAC site. The presence of chlorinated solvents is most likely due to past practices related to paint shop operations, degreasing and general cleaning and maintenance activities (Earth Sciences Associates, 1993). SLAC has institutionalized training of hazardous materials operators. As a result of increased awareness, training, and improvements in procedures over time, the overall potential for groundwater contamination due to disassembly and refurbishment activities has been minimized.

SLAC maintains a National Pollutant Discharge Elimination System (NPDES) permit administered by the RWQCB. Originally, this permit was obtained to regulate cooling-tower blowdown water, which has since been diverted to the sanitary sewer. As a result, the permit and the associated sampling and analysis of this discharge are no longer required. When the current permit expires, it will not be renewed.

Due to a normally high water table and the low hydraulic conductivity associated with the consolidated sandstones underlying SLAC, groundwater continually seeps into the PEP tunnels and other underground areas at the facility, primarily the excavated sections. This seepage is corrosive and attacks iron, aluminum, and some plastics. It also supports the growth of algae. In addition, the high mineral content of this water produces deposits that can clog drain pipes, drainage channels and gutters (SLAC, 1991a). The volume of groundwater seeping into the PEP ring varies from 50 to 200 galions per day. In general, the seepage volume is correlated with seasonal variations in rainfall and groundwater recharge, rather than any specific operations at SLAC.

Previous efforts to prevent groundwater from entering the tunnel have been unsuccessful. As a result, the seepage is now channeled into a sump which contains a level-activated pump that discharges to the storm-drain system. This discharge to the storm drain is allowed, per a documented verbal agreement with the RWQCB (Dubrow, 1992), as iong as the groundwater seepage is not contaminated. SLAC is currently in consultation with the RWQCB to determine a plan and timeframe for replumbing the sumps so that groundwater seepage would be discharged to the sanitary sewer rather than the storm drain. It is anticipated that this would nost likely occur in a few years. 


\subsubsection{Hazardous Materials Usage and Waste Production}

Approximately 350 tons of hazardous wastes are generated at SLAC on an annual basis. As defined by the Resource, Conservation, and Recovery Act (RCRA), SLAC is a "generator" of hazardous waste and is allowed to accumulate waste onsite for a maximum of 90 days before it must be transported offsite to a permitted Treatment, Storage and Disposal Facility (TSDF) for recycling, treatment, or disposal. Examples of waste types or waste streams generated at SLAC include heavy-metal-bearing wastes from plating shop operations; solvents from degreasing operations; olls and coolants from equipment, heavy machinery, and automobiles; contaminated soils from remedial activities; PCB wastes from transformers; and transformer carcasses.

PEP operations infrequently generated "California Only" (non-RCRA) regulated wastes due to leakage or seepage from oll-filled equipment. The equipment was repaired or replaced, and the hazardous waste was disposed of or recycled according to California's Hazardous Waste Control Laws (HWCLS).

No radioactive wastes were routinely generated by the operation of PEP. SLAC generates a small amount of low-level radioactive waste from accelerator operations. Low levels of radioactivity were induced in some accelerator components, including some from PEP. Most of the induced material has not been declared waste but, rather, is held on site for potential reuse at SLAC. Nonreusable components are surveyed, according to established policies and procedures, and if found to be activated, are stored onsite. These wastes are stored in the fenced and bermed radioactive material storage yard while awaiting disposal at the Westinghouse Hanford Corporation disposal facility.

The potential hazards to workers from hazardous materials are addressed by the SLAC Industrial Hygiene Program, which is detailed in the ES\&H Manual. This program identifies all occupational health hazards, quantifies and documents the extent of employee exposure, and implements administrative, engineering, work practice, and personal protective equipment control methods to el iminate or minimize health hazards in the work place. There are no current or anticipated activities at SLAC that would expose workers to concentrations of air contaminants at or above the OSHA permissible exposure limit or the American Conference of Governmental Industrial Hygienists threshold limit values (ACGIH, 1990). Facility-wide procedures for storing, transporting, handling, inspecting, and disposing of hazardous materials and wastes are contained in the SLAC Hazardous Materials Management Handbook (SLAC, 1992e). The SLAC waste minimization policy is detailed in the SLAC Waste Minimization Program Plan to Comply with California's Hazardous Waste Source Reduction and Management Review Act of 1989 (SLAC, 1992b) and the SLAC Waste Minimization Program Plan to Comply with Department of Energy Order 5400.1 (SLAC, 1992C). In addition, all personnel who handle hazardous materials or hazardous wastes are required to complete Hazards Communication (HAZCOM) training and Hazardous Materials and Waste Management training. 


\subsubsection{Archaeological and Historic Sites}

The Stanford University Archaeologist's office complles and maintains maps and detailed descriptions of all archaeological sites known on Stanford property, many of which lie along San Francisquito Creek. Examination of these materials revealed approximately 20 sites south of the SLAC facility on both sides of the creek, but none in the vicinity of the existing PEP tunnel.

There are also no known historic sites in the vicinity of the PEP tunnel. Furthermore, the State Historic Preservation Officer (See Appendix A) has notified DOE that he does not object to the determination that this undertaking will not affect historic properties and that no further DOE action is required to comply with Section 106 of the National Historic Preservation Act.

\subsubsection{Sensitive Spectes}

Six threatened or endangered species have been recorded from the general area around SLAC (SAIC, 1991a). The Natural Diversity Database (NDDB), compiled and maintained by the California Department of Fish and Game, incorporates information on both federal- and state-1isted threatened and endangered species. The NDDB indicates the potential presence of five of these sensitive species in the area delineated by the 7.5-minute topographic quadrangle for Palo Alto, which encompasses the SLAC facility. This information indicates that the primary distribution of three of these species do not overlap with the SLAC site boundaries (SAIC, 1991a).

The fourth species recorded from the area, the San Francisco Garter Snake (Thamnophis sirtalis), has been known to occur on and around the SLAC facility (Barry, 1976). However, the subspecies designated as endangered by the

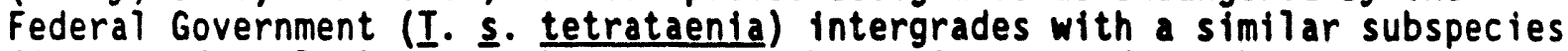
(I. s. infernalis) in southeastern San Mateo County and northwestern Santa CTara County (Seib and Papenfuss, 1982). In other words, the SLAC facility lies near the northeastern edge of the endangered subspecies' distribution, rather than near its center. Given its specific habitat requirements, this subspecies' presence in this area is considered highly unlikely, according to biologists currently working at, and familiar with, Jasper Ridge.

Four other species of plants and animals potentially occurring in the area around SLAC are: the San Francisco forktail damselfly (Ischnura gemina); the Bay checkerspot (Eurphydryas editha bayensis), the Califorria tiger salamander (Ambiystoma tiarinum californiense), and serpentine bunchgrass. According to staff biologists and researchers at the Jasper Ridge Preserve, both the butterfiy and the bunchgrass are strongly assoclated with outcrops of serpentine solls, no examples of which occur on the SLAC property. In addition, the salamander can be found downstream at lake Lagunita on the Stanford University campus, but prefers marshy ponds to running waters (1ike storm drain systems). Of the four species, therefore, the occurrence of three 
of them is considered to be unlikely (SAIC, 1991a). The damselfly is known to occur outside the Jasper Ridge area, although its distribution is not well known and would require field surveys for a conclusive determination. Given the above considerations, however, such surveys are not warranted, especially in light of the limited areal extent of the potential wetlands at SLAC and the extended drought conditions in the area.

According to an earlier California Department of Fish and Game document (CDF\&G, 1976), the Californta Condor (Gymnogyps callfornianus) was then the only animal species listed by the state as rare or endangered and known to have existed in San Mateo and Santa Clara Counties. The primary condor habitat remaining, however, is now restricted to several small areas in Ventura and Los Angeles Counties, in southern California. No condors currently exist in the wild, but reintroduction of young condors born in captivity to their remaining natural habitat in southern California is pending. Because SLAC is hundreds of miles from the area currently designated as condor habitat, it is not considered an area for the reintroduction of that species. The U.S. Fish and Wildilfe Service has concluded that this project will likely have negligible impacts on fish and wildlife resources. However, formal consultation has not occurred with the California Department of Fish and Game. This consultation would be made prior to initiation of the proposed action should this site be chosen.

\subsubsection{Floodplains/Wetlands}

Examination of Federal Emergency Management Agency (FEMA) floodplain maps for the area indicates that a 100-year flood is confined to the San Francisquito Creek channel and would not reach the PEP factilties - or even the SLAC site (SAIC, 199la).

No wetlands have been identified in the vicinity of the PEP tunnel. Approximately 1,000 feet southeast of the eastern end of the linac, marshy areas of very limited extent do exist, although it has not been determined whether the area meets the criteria for designation as wetland due to persistent drought conditions. The area where the three conditions (hydric soils, aquatic vegetation, and soil saturation) necessary for wetlands status occur is approximately 750 feet long and averages 1 foot in width. This amounts to less than one-tenth of an acre where the potential for wetlands remains a question. As a point of comparison, the Army Corps of Engineers (the agency responsible for much of the nation's wetlands) has used ten acres as a functional cutoff for "significant" wetlands.

The 1992/1993 rainy season brought the first year of normal amounts of rainfall since 1986/1987. Although the drought is officially over, the environmental conditions brought on by the drought still exist. Until these environmental condkions are normalized, any further investigations would most likely result in indefinitive conclusions. 


\subsubsection{Radiological Aspects}

Given the range of potential hazards associated with PEP-II construction and operation, those associated with radiation are relatively low. However, because they are not standard safety hazards, this section has been included to provide context and define relevant terms.

\section{Natural Sources of Radiation and Background Levels}

Radiation from natural sources permeates the universe and thus is an inherent aspect of life on earth. All living things are continuously exposed to this natural radiation, both externally from cosmic radiation and natural radioactive material in the earth, and internally from natural radioactive materials taken into the body via air, water, and food. The public also receives, and generally accepts the risks associated with, radiation exposure from medical $x$-rays, nuclear medicine procedures, and some consumer products (e.g., tobacco, building materials, some water supplies).

The standard unit for expressing the amount of radiation received or absorbed is the millirem (mrem). As shown in Table 1, an average member of the public in the United States receives 300 millirems per year (mrem/year) from natural sources of radiation and $60 \mathrm{mrem} /$ year from man-made sources (NCRP, 1987a; NCRP, 1987b), for a total of approximately $360 \mathrm{mrem} / \mathrm{year}$, or $1 \mathrm{mrem} /$ day.

Table 1. Natural and Man-Made Sources of Radiation Exposure to the Public

\begin{tabular}{|c|c|c|}
\hline $\begin{array}{c}\text { Source of } \\
\text { Radiation }\end{array}$ & $\begin{array}{c}\text { Annual Dose } \\
\text { Average } \\
\text { Equivalent Rate } \\
\text { (mrem/y) }\end{array}$ & Type of Radiation Source \\
\hline \hline \multirow{4}{*}{ Natural } & $60^{\circ}$ & $\begin{array}{c}\text { Cosmic, Primordial, and } \\
\text { Cosmogenic }\end{array}$ \\
\cline { 2 - 3 } & 40 & $\begin{array}{c}\text { Internally-deposited (not } \\
\text { including radon or radon } \\
\text { daughters) }\end{array}$ \\
\cline { 2 - 3 } & 200 & $\begin{array}{c}\text { Internally deposited radon } \\
\text { and radon daughters }\end{array}$ \\
\hline $\begin{array}{c}\text { Medical } \\
\text { Procedures }\end{array}$ & 50 & Man-made \\
\hline $\begin{array}{c}\text { Consumer } \\
\text { Products }\end{array}$ & 10 & Man-made \\
\hline
\end{tabular}

$60 \mathrm{mrem} / \mathrm{y}$ is the average dose rate for an individual residing in the San Francisco Bay Area (LLNL, 1990). 
The figures shown in this table are approximations and are subject to some variation. For example, the dose-equivalent rate from cosmic radiation at sea level in the U.S. averages $32 \mathrm{mrem} /$ year with a range of 25 to $50 \mathrm{mrem} /$ year, dependent on geographic location. By comparison, the dose-equivalent rate from cosmic radiation at an altitude of approximately 1 mile, such as on the Colorado Plateau, averages $63 \mathrm{mrem} /$ year, with a range of 50 to $100 \mathrm{mrem} / \mathrm{year}$, dependent on altitude (NCRP, 1987a; NCRP, 1987b).

Exposure to some types of radiation, both man-made and natural, is voluntary or can be controlled. Average dose equivalents to individual members of the public from medical $x$-ray examinations can range from 1 mrem for an extremity examination to over 400 mirem for a barium enema (NCRP, 1987a). A 5-hour jet flight across the U.S. can result in a dose equivalent of 2.5 mrem, due primarily to cosmic radiation (Lamarsh, 1983).

\section{Contributions to Background Radiation Levels from SLAC Operations}

High-energy particles are absorbed by design at five separate locations at SLAC: the Beam Switch Yard (BSY), the Positron Source (PS), the electron and positron beam dumps in the Final Focus System (FFS), the Final Focus Test Beam (FFTB) dump, and Beam Dump East, which is associated with End Station A.

Because these systems are designed to absorb high-energy particles, they are potential sources of detectable gaseous radioactive emissions. Occasionally, these systems are vented at the end of an experiment cycle, after allowing at least one hour for decay of short-lived gaseous radionuclides. Venting is the process through which radionuclides could be introduced into the surrounding air. The linac, PEP, SPEAR, and the experimental areas at SLAC are designed to transport (i.e., convey), rather than absorb, high-energy electrons and positrons. As a result, radioactive gases are not produced by these systems in measurable quantities.

Airborne emissions from the exhausters of the five SLAC areas just discussed are continuousiy monitored while these facllities are in operation. During 1991 , no measurable releases of radioactive gases were detected at any of these locations (SLAC, 1992a). In compliance with the National Emissions Standards for Hazardous Air Pollutants (NESHAPS), a report prepared by SLAC calculated the maximum release levels of airborne radionuclides from these five areas, using the EPA-approved software code CAP-88. These calculations yielded a maximum effective dose equivalent of $0.09 \mathrm{mrem} / \mathrm{year}$, which represents less than one percent of the NESHAPs standard of $10 \mathrm{mrem} /$ year (SLAC, 1992a).

The SLAC boundary is monitored by six peripheral air monitoring stations, which measure and record doses and dose equivalents due to gamma rays and neutrons. Signals from these monitoring stations are fed into a central control station. The monitors measure both background radiation from natural sources and any radiological emissions associated with SLAC operations. The maximum dose equivalent above background for an individual at the location of 
the nearest residence 24 hours per day is estimated to be less than 2 mrem in a year as discussed in the SLAC Annual Environmental Monitoring Report (SLAC, 1992a). This level of exposure from radioactive gases is substantially less than one percent (1\%) of the total background radiation received from natural sources.

The possibility of radioactivity in surface water and ground water, along with potential activation in solls and sediments, has been addressed at SLAC. Tritium is the primary radionuclide of interest in groundwater or surface water, while gamma-emitting species are the potentlai concern in soil. It should be noted that SLAC has only electron accelerators which are much less likely, by a factor of about 10,000 , to produce activation in ground areas near shields than are proton accelerators. Surface water and groundwater are routinely monitored and the data indicate that there have been no offsite releases of radioactive substances.

Quarterly groundwater sampling for tritfum was initiated in July of 1992. These data show that one well ( $\$ 24$, also known as EXW-4) has shown levels of tritium ranging from $8,357 \mathrm{pCi} / 1$ to $12,237 \mathrm{pCi} / 1$. The EPA drinking water standard for tritium is $20,000 \mathrm{pCl} / 1$. Well 24 was sampled on a periodic basis for tritium beginning in 1968 until 1992 when quarterly sampling was initiated. This well is the closest well to a high-power beam dump used with the Fixed-Target Program. (High-power beam dumps are not used in the operation of storage rings such as PEP or PEP-II).

Unlike water, soils and sediments are not routinely sampled at SLAC. However, recent sampling and gamma spectral analysis indicates no onsite or offsite radioactivity associated with SLAC accelerator operations. Oniy naturally occurring radionuclides have been detected in environmental samples (SLAC, 1992d).

The SLAC Radiation Safety Program is designed to ensure that radiation doses above background received by workers and the public shall be as low as reasonably achievable (ALARA), as well as to prevent any person from receiving more radiation exposure than is permitted under federal government

regulations. The main provisions of the program ensure that access to high-radiation areas is prevented, and that the accelerator facilities and the associated detectors are provided with adequately shielded enclosures for times when the possibility exists for a radiation field to be present. Several technical, operations, and administrative systems exist to implement the program, as described in the SLAC Radiological Control Manual (SLAC, 1993i), the SLAC Radioactive Material Management Manual (SLAC, 1992f), and the Guidelines for Operations (SLAC, 1992g).

4 The ground water beneath the SLAC slte is not considered a potential drinking-water supply. ine drinking water standard for tritium is used only as a raference point. 


\subsection{Existing Environment for CESR-B}

\subsubsection{Population}

The Uilson Lab occupies approximately 9 acres (not incluading the underground ring) in the south-central portion of Cornell University's 745 acre campus. The laboratory lies within the boundaries of the Town of Ithaca, Tompkins County, New York. According to the 1990 census, the population of Tompkins County was slightly in excess of 94,000 . The population of the Town of Ithaca was nearly 18,000. Over the past ten years, the population of the town has increased by 11 percent; nearly doubling in population since 1960.

The student population varies from about 18,400 during fall and spring semesters to approximately 1,500 during the summer (based on 1990-1991 enrollment). The Cornell University student body comprised $29 \%$ of the county population in 1990. Total faculty and staff number approximately 10,000. Campus dormitories have a capacity of 6,500 students located with in one mile of the Wilson Synchrotron Laboratory. Wilson Lab currently has a staff of 160 people. In addition, there are 174 participating scientists with up to 60 collaborators on-site at one time. The lab is approximately 1,500 feet north of the Maplewood Apartments, and other residences on Maple Avenue, and is roughly 2,000 feet from the Oak Avenue and the Judd Falls neighborhoods.

The number of businesses located in the county has steadily increased from about 1100 in 1970 to nearly 2100 in 1988. A majority of firms in the county in 1988 were engaged in service and retail industries. The number of construction firms located in Tompkins County increased from 80 in 1970 to 174 in 1988. According to New York State 1990 County Profiles, the total labor force for Tompkins County was nearly 57,000 with a county unemployment rate of 2.1\%. Since 1980, the county unemployment rate has been 2 to 3 percentage points below the New York State unemployment rate.

\subsubsection{Air Quality}

Tompkins County is a largely rural area with no concentration of heavy industry. The New York State Department of Environmental Conservation (NYSDEC) does not monitor air quality within Tompkins County. Tompkins County is not listed by the NYSDEC as a non-attainment area for any of the Federal and New York State Ambient Air Quality Standards for the six (1.e., carbon monoxide, sulfur dioxide, ozone, nitrogen dioxide, lead, suspended particulate matter) primary air pollutants.

Cornell has one major source of air emissions. The Cornell Central Heating Plant (CHP) on Route 366 has NYC DEC permits for the operation of 2 existing coal fired boilers, and one existing oil fired boiler. The NYS DEC has issued a permit to construct for two new oil/gas fired boilers. One natural gas fired boiler is exempt from permit requirements. Recent air dispersion modeling has shown that emissions from all existing and new sources at the CHP 
will result in ambient air concentrations that are well within the Federal and State ambient standards.

There are approximately 12 fume hoods on the campus that are permitted for radioisotope emissions. These are used for iodination. There are no permitted or unpermitted radioisotope air emissions from the Laboratory of Nuclear Studies (LNS).

The LNS has no air emissions that are regulated by New York State or the Federal Government. Several chemicals are used in Newman Laboratory: these include methanol, acetone, isopropanol, nitric acid, phosphoric acid, hydrofluoric acid, and sulfuric acid. These chemicals are used in fume hoods with the potential for air emissions in the exhaust. Because these chemicals are not carcinogens, and are emitted from fume hoods, they may be emitted without a NYS DEC permit (cite 6 NYCRR $201.6(j)(1))$. They are not considered hazards to health or to the environment.

\subsubsection{Water Ouality and Supply}

The drinking water source for the University is the Cornell Filtration Plant, which uses Fall Creek, approximately 3000 feet northwest of Wilson Lab, as a raw water source. The source of drinking water for the City of Ithaca is a City water filtration plant on Six Mile Creek, approximately 5,000 feet southwest of Wilson Lab. Much of the surrounding area is served by a regional water filtration plant that uses Cayuga Lake as a source.

Process and space cooling water is supplied by the campus central chilled water system. This system currently supplies 500 tons of cooling water to Wilson Lab. Half of the load is used for space coolir $;$ and the other half for process cooling in a $65^{\circ} \mathrm{F}$ loop. There are also two $85^{\circ} \mathrm{F}$ cooling loops. One is supplied by evaporative coolers in the original building. The other loop is supplied by a recently installed cooling tower with a plate heat exchanger on the east side of the lab. That cooling tower is sized to reject approximately $5 \mathrm{MW}$ electric heat load. Cooling tower blowdown is routed to the sanitary sewer. The newer cooling tower uses approximately 40,000 gallons of water per day.

The Wilson Lab is located approximately 50 feet north of Cascadilla Creek, which is a tributary of Cayuga Lake, located about 4 miles northwest from the proposed CESR-B. In the vicinity of the WiIson Lab, Cascadilia Creek flows from east to west. This creek is classified by the New York State Department of Environmental Conservation as class " $C$ " water in the vicinity of the laboratory. Class " $C$ " water is suitable for primary and secondary contact such as swimming and fishing. The State of New York Code of Rules and Regulations requires that class " $C$ " waters maintain a $\mathrm{pH}$ between 6.5 and 8.5 with dissolved oxygen in excess of 5 milligrams per liter. For class " $C$ " waters, the monthly geometric mean value of fecal coliform must not exceed 200 for 100 milliliters of samplè over five examinations. 
The lab is located in the southern half of the Hestern Oswego River Basin. Principal aquifers in this basin can provide wells with yieids in excess of 1,000 gallons per minute. Such aquifers occur in gravel and sand deposits found in major valleys of the basin. Where streams are in hydraulic contact with aquifers, yields of several million gallons per day are possible. The Cascadilla Creek Valley is not classified as a primary, principal, or sole-source aquifer. According to several studies included in the "Draft Generic Environmental Impact Statement Prepared for Development Program for Possible Future Expansion Southeast of Cornell University's Main Campus" (DGEIS for campus expansion), the area surrounding the lab is characterized by glacial deposits that do not sustain high yielding wells and that do not provide a major source of recharge for groundwater.

\subsubsection{Utilities}

Cornell's main campus receives electric service from a University-owned 110 megavolt-amperes (MVA) transmission voltage substation that steps the voltage from 115 kilovolt (KV) to $13.2 \mathrm{kV}$ for distribution to the campus. Three $1200 \mathrm{~A}, 13.2 \mathrm{kV}$ overhead circuits bring the electricity from the main substation to three switching stations located on the campus perimeter. Electric power is distributed from the switching stations to campus loads via cables in underground duct banks. The campus peak demand is presently 37 MVA.

The existing electric service to Wilson Lab consists of a pair of 350 Amperes (A), 13.2kV underground feeders, providing a fully redundant 8 MVA service to the Lab. The redundant service allows components to be deenergized for maintenance without interrupting lab operations.

Wilson Lab receives steam for space heating purposes from the Cornell University Central Heating Plant. The CHP produces and distributes steam to the majority of the Cornell Campus. Steam is served to Wilson Lab through a $4^{\prime \prime}$ line fed off a $12^{n}$ main steam line.

\subsubsection{Archaeological and Historic Sites}

A study entitled "Special Areas at Cornell: Designated Buildings and Lands of Special and Natural Interest on the Corneli Campus" (April 1991), completed by the Campus Planning Office and included in the Appendices of the DGEIS for Campus Expansion, indicates that there is only one National Historic Landmark, Morrill Hall, on the Cornell campus. This building is approximately 3400 feet northwest of Wilson Lab. The nearest designated historic building is Wing Hall, which is Iisted on the National Register of Historic Places. Wing Hall is approximately 600 feet northeast of Wilson Lab.

The "Stage IA Cultural Resources Survey", included in the Appendices to the DGEIS for Campus Expansion, contains an evaluation of potential archaeological resources or sites for the area adjacent to and southeast of Wilson Lab. No such sites or resources were found on or adjacent to this area. The area 
Environmentel Assessment for Proposed B-Encton (Asvinmetric Electron Positron Colliderl

surrounding Wilson Lab has already been developed, with no previous indications of archaeological resources present.

\subsubsection{Protected Natural Features}

The Cornell Campus Planning Office maintains a plan for campus development. This plan includes consideration of facilities in relation to open spaces, natural areas, campus growth, circulation and parking, recreational areas, and other physical features. The proposed CESR-B expansion complies with this campus plan. Also, "A Strategic Framework for Campus Precinct Development", adopted by the Cornell Administration in January of 1992, indicates that the area around Wilson Lab has been designated as an area where building can be conducted without constraint.

Portions of the Cascadilla Creek, to the southeast and southwest of Wilson Lab, are used for recreational purposes. The Town of Ithaca maintains a recreation trail along parts of the Creek's corridor. The Town has an irrevocable agreement with the university to lease this corridor. However, in the area near Wilson Lab, no recreational trails exist.

\subsubsection{Threatened/Endangered Species}

No rare, threatened, or endangered plant or animal species were identified in the DGEIS for Campus Expansion study area. Given that the Wilson Lab site is adjacent to the DGEIS study area and has less natural habitat due to development, it is highly unlikely that there are any rare, threatened, or endangered species on the Wilson Lab site.

\subsubsection{Floodplains/Wetlands}

The Wilson Synchrotron Laboratory building, at the closest point, is located approximately 50 feet from Cascadilla Creek. Cascadilla Creek has a deep channel as it passes to the south of Wilson Laboratory. The banks are at least 15 feet above the normal water level. According to the Flood Boundary and Floodway Map published by the Federal Emergency Management Agency for the Town of Ithaca, New York, Wiison Laboratory and the proposed CESR-B are not within the 100-year floodplain associated with Cascadilla Creek. In fact, a recent 100-year flood event in 1981 did not impact Hilson Lab.

There are no wetlands in the area that would be disturbed by the proposed construction. All disturbed areas are on well drained hillsides and embankments. There are no New York State designated wetlands adjacent to Wilson Lab (New York State, 1984). Should this site be selected for a BFactory, a wetlands delineation will be completed prior to any construction in order to confirm the absence of wetlands. 


\subsubsection{Hazardous Materials and Waste Management}

As discussed in section 3.2, magnetic fields are used to guide electrons and positrons in the synchrotron and storage ring. In support of CESR, Cornel.1 University conducts superconducting cavity research in the nearby Newman Laboratory. This research requires acid etching and cleaning with methanol, acetone, isopropanol, nitric acid, phosphoric acid, hydrofluoric acid, and sulfuric acid. Technicians who perform these cleaning and etching operations have completed Cornell University sponsored training programs designed to insure compliance with the Occupational Safety and Health Administration Hazard Communication Standard (29 CFR 1910.1200) and Laboratory Safety Standard (29 CFR 1910.145).

Hazardous materials or waste generated are handled through the University's Environmental Health and Safety (EHS) comprehensive hazardous material management program. EHS has a storage facility capable of storing 8,800 gallons of waste with secondary containment for 12,000 gallons. Solvents are transported by Tonawanda Tank Transport to Buffalo where, after testing for PCB's, heavy metals, sulfur and halogens, they are burned locally as fuels. Acids are disposed of by approved means by local companies. Oils may be burned on campus after testing for contaminants. Cornell's waste management facilities are in full compliance with applicable Federal and State requirements.

Transportation is conducted in accordance with Department of Transportation and Nuclear Regulatory Commission requirements. On campus, hazardous materials are transported in safety containers and external packaging prior to use. Waste material is collected on-site by EHS staff. Waste materials are screened for content, container type, segregated to hazards class, packaged prior to transport to Cornell's waste staging facility. External waste contractors are hired to package and transport hazardous wastes to offsite disposal facilities. All loading and unloading operations are executed in controlled conditions - secondary containers are employed and full response capability for accidental spills is readily available.

Hazardous materials used in support of laboratory operations include: methanol, acetone, isopropanol, nitric acid, phosphoric acid, hydrofiuoric acid, sulfuric acid, and some oils. An inventory control program has been in place since last year which has reduced the quantity of chemicals stored on site and provides a mechanism for monitoring both inventory and use. Average use has been 36 gallons of acids and 56 gallons of solvents per month. Recent inventory averages are 80 gallons of acids and 101 gallons of solvents. Contact from acids is minimized through safe handiing practices, use of personal protective equipment, process-specific ventilation controls and specialty storage systems. Employee exposures to acids have been evaluated following the standard National Institute of Occupational Safety and Health analysis No. 7903 typically used for measurements for occupational exposure. 
Measurements representative of employee exposure are shown below in comparison with OSHA permissible exposure limits. These OSHA limits are the $B$ hour time-weighted average (TWA) and short term exposure limit (STEL):

\begin{tabular}{|c|c|c|c|}
\hline $\begin{array}{l}\text { Material } \\
\text { (ppm) }\end{array}$ & $\begin{array}{l}\text { OSHA Limit } \\
\text { TWA (ppm) }\end{array}$ & $\begin{array}{l}\text { OSHA Limit } \\
\text { STEL (15 minutes) } \\
\text { (ppm) }\end{array}$ & Exposure Data \\
\hline $\begin{array}{l}\text { Methanol } \\
\text { Acetone } \\
\text { Isopropanol } \\
\text { Nitric Acid } \\
\text { Phosphoric Acid } \\
\text { Hydrofluoric Acid }\end{array}$ & $\begin{array}{r}200 \\
250 \\
400 \\
2 \\
0.25 \\
3\end{array}$ & $\begin{array}{r}250 \\
1000 \\
500 \\
4 \\
0.75 \\
\text { None }\end{array}$ & $\begin{array}{l}\star \\
0.01 \\
\text { none detected } \\
0.03\end{array}$ \\
\hline
\end{tabular}

* exposure not tested due to process specific exhaust ventilation and low frequency and duration of employee exposure.

Analysis of exposure data indicate that engineering controls, personal protective equipment and use procedures are working to keep employee concentrations well below the established guidelines.

Handling procedures have been developed to limit accident potential and material release. EHS provides and coordinates emergency response services should they be necessary. Campus emergency response time to on-campus emergencies is 2.7 minutes on average.

\subsubsection{Radiation}

Operation of the CESR is conducted under the jurisdiction of the New York state Department of Health (10 NYCRR, Part 16). Radiological monitoring is conducted by employees of the LNS. Results of the monitoring program are reviewed by the Cornell University Department of Environmental Health and Safety. Cornell conducts an As Low As Reasonabiy Available (ALARA) Program designed to limit occupational radiation exposures to no more than one-tenth of the allowable exposures under Federal and State regulations. Table 2 compares Cornell's ALARA radiation levels with State and Federal levels.

There are two sources of radiation from CESR. One consists of electrons or positrons lost during injection or storage. The other is comprised of synchrotron $x$-rays. The radiation from CESR is a mixture of gamma rays, 
Environmentel Assessment for Proposed B.Facton (Asymmetric Ekectron Positron Collider)

Table 2. Comparison of Cornell ALARA Radiation Levels With State and Federal Levels

\begin{tabular}{|l|c|cc|}
\hline & $\begin{array}{c}\text { Cornel1 } \\
\text { ALARA }\end{array}$ & & \\
\hline & 500 & 5,000 & mrem/year \\
\hline Whole body dose & 2,000 & 30,000 & mrem/year \\
Skin of whole body & 2,000 & 75,000 & mrem/year \\
Hands, forearms, feet & 100 & - & mrem total \\
Embryo/fetus & 50 & - & mrem/month \\
& 100 & 500 & mrem/year \\
General public, whole body & 50 & & mrem/month \\
& &
\end{tabular}

neutrons, and $x$-rays. Most of the CESR is approximately 50 feet below ground. Hence, soil surrounding CESR provides a natural radiation shield.

The experimental hall is constructed on the grade side of the ring and provides the only break in the earth shielding. Thick shielding walls were built into the hall to handle the much more stringent requirements of the extracted beams from the original Wilson synchrotron. Concrete shielding block walls define the radiation area within the experimental hall. Inside the radiation area, additional shielding reduces the radiation levels from the injector and other high loss rate points near their source.

ALARA goals are achieved with a number of different techniques: controlled access to radiation areas, electronic area monitors, area survey badges, surveys by a radiation safety personnel, and personal radiation film badges and dosimeters. A system of gates and iight beams isolate the radiation areas from the rest of the facility. Entry can only be made by a system of access keys which, in hardware, either disable 11 or parts of the accelerator or enable local area monitor trip circuits (depending on the location of the particular area). Keys can only be released by the CESR Operator. Electronic radiation monitors are placed near the shielding around the perimeter of CESR. Neutron and gamma levels are continually recorded by a computer. Hardware interlocks in each monitor trip the accelerator or injector if either level exceeds $2 \mathrm{mrem} / \mathrm{hr}$. Several monitors are placed at a distance from the wall and are set to trip at $1 \mathrm{mrem} / \mathrm{hr}$. Inspection of graphs of the history of these monitors show averages typically less than a tenth of the trip levels. Film badges are also placed around the building to monitor integrated doses near the accelerator. Radiation safety personnel survey areas near the machine whenever changes are made or where low levels have been seen; all areas are surveyed every six months. When personnel are involved in activities likely to result in an exposure, they wear pocket dosimeters so they can monitor their exposure while working. Survey instruments are also made available in the control room and near the entry points of areas where an 
Environmental Assessment for Proposed B-Facton (Asymmetric Electron fositron Colliderl)

Table 3. Estimate of Neighbor Exposures

\begin{tabular}{|l|r|r|r|r|r|}
\hline & $\begin{array}{c}\text { distance } \\
\text { (feet) }\end{array}$ & $\begin{array}{c}\text { number } \\
\text { of } \\
\text { people }\end{array}$ & $\begin{array}{c}\text { ratio } \\
\text { occupied }\end{array}$ & occupancy & $\begin{array}{c}\text { exposure } \\
\text { (person-rem) }\end{array}$ \\
\hline Front sidewalk & - & 2 & 0.5 & 1 & 0.015 \\
\hline Riley Robb Hall & 500 & 500 & 0.25 & 125 & 0.007 \\
\hline $\begin{array}{l}\text { Chilled Water } \\
\text { Plant }\end{array}$ & 600 & 40 & 0.25 & 10 & $<0.001$ \\
\hline $\begin{array}{l}\text { University } \\
\text { Print } \\
\text { Shop }\end{array}$ & 700 & 40 & 0.25 & 10 & $<0.001$ \\
\hline $\begin{array}{l}\text { Humphreys } \\
\text { Service }\end{array}$ & 900 & 200 & 0.25 & 50 & $<0.001$ \\
\hline $\begin{array}{l}\text { Schoellkopf } \\
\text { Stadium }\end{array}$ & 1300 & 30,000 & 0.007 & 210 & $<0.001$ \\
\hline $\begin{array}{l}\text { Schoellkopf } \\
\text { Stadium }\end{array}$ & 1300 & 100 & 0.33 & 33 & $<0.001$ \\
\hline $\begin{array}{l}\text { Maple Avenue } \\
\text { Residences }\end{array}$ & 2000 & 1000 & 1.0 & 1000 & 0.001 \\
\hline
\end{tabular}

TOTAL

0.029

Assumptions:

1. All buildings to the north, including the Tennis Facility, are shielded by at least fifty feet of earth. No earth shielding was assumed for all the others, including Riley Robb and Schoellkopf.

2. The source is taken to be the center of the experimental hall; the level as $0.001 \mathrm{rem} /$ year at the building wall, decreasing as the inverse square of the distance.

3. The project life is fifteen (15) years.

exposure might occur. Radiation safety personnel work with workers and experimenters to devise ways of minimizing exposures when they can be anticipated.

The personal film badge exposures serve as feedback on the effectiveness of these measures. More than 99\% of the badge exposures are "M", which is less than 10 mrem for a 2-week period (recently changed 20 a monthiy program). Median and average accumulated exposures for the 1992 year were less than 10 mrem for all employees and experimenters. From the 1992 badge records LNS estimates the average whole body exposure of radiation workers to be less than ten (10) mrem/year. All film badge reports, radiation monitor levels, and survey results are maintained in LNS files. 
Radiation exposure off site due to CESR is below detectability with conventional instruments. The site is on the edge of the campus. On the campus side (north) the nearest neighbor is the tennis court across a parking lot from CESR. It and all of the other bulldings on the north side are shieided by the earth of the side of the valley. On all other sides the neighbors are hundreds of feet away (see Table 3 ). Doses to the general pubiic are calculated to be less than $1 \mathrm{mrem} / \mathrm{year}$ without any duty cycle considerations, well less than the Cornell ALARA level of 100 mrem/year.

Some radioa:tivation of accelerator components occurs in the present operation. Surveys of CESR components after operation typically show less than $1 \mathrm{mrem} / \mathrm{hr}$ on contact and rarely $10 \mathrm{mrem} / \mathrm{hr}$. The injection synchrotron components frequently show readings of a few mrem $/ \mathrm{hr}$. The linac and the injection and transfer lines have readings ranging from tens of mrem/hr up to $200 \mathrm{mrem} / \mathrm{hr}$ at the positron target. After a 2 week cooling off period most of these have fallen by a factor of 2 . The longest lived isotope in steel and copper is cobait 60 with a 5 year half-life; the longest life isotope in aluminum is sodium 22 with a 2.5 year half-ilfe. These components are all part of the machine. A locked 2 -room storage vault is available for use for decay during CESR decommissioning at LNS and additional storage is available at the University.

Some activation of cooling water and air also occurs. Highest levels orcur at the positron target in the linac. The most frequentiy produced nuclides, "C, ${ }^{13} \mathrm{~N}$ and ${ }^{15} \mathrm{O}$, are all short-lived (the longest being 20.4 minutes). The positron target cave is weakly ventilated and most of the activated air decays in place. The same isotopes in the cooling water decay in the recirculation system. Tritium is al so weakly produced in the cooling water. A sample counted by the Cornell Department of Environmental Heaith and Safety showed activity less than or equal to 6.8 picocuries/mi., the limit of their equipment sensitivity. Any beryllium that is created is captured in the resin of the demineralizer; a sample of water from the bed showed no detectable activity at the same sensitivity. Activation of air and water in all other areas is at a much lower level.

Radioactive sources are used for calibration of radiation monitors and experimental equipment development and calibration under a ifcense issued to Cornell University by the State of New York. Only sealed sources are used by the LNS. Under a program to reduce hazardous materials at the lab the number of sources in inventory was reduced to about 60 . More than 300 other sources were disposed of through Cornell's Department of Environmental Health and Safety.

The Ward Nuclear Reactor is located in the Engineering Quad on campus, one half mile from the Wilson Lab. It is 0.5 megawatt research and teaching facility. Their activities, staff and student body are independent and unrelated to the LNS. They maintain direct radiation at the boundaries of their building to less than $10 \mathrm{mrem} /$ year. 


\subsection{POTENTIAL ENYIRONMENTAL EFFECTS OF THE PROPOSED ACTION}

\subsection{Potential Environmental Effects of PEP-II}

The proposed action involves no major conventional construction or any new ground-disturbing activities, and would therefore have no construction-related impacts on threatened and endangered species and their habitats, wetlands, and floodplains. Approximately $70 \%$ of the existing components in the PEP facility would be reused in PEP-II, and most of the work would be performed within existing bulldings with essentially the current labor force. Accordingly, construction-related effects from the proposed action on noise, transportation, visual aesthetics, cultural resources, and land use would be negligible. Activities associated with the construction or operation of PEP-II would not expose workers to concentrations of air contaminants at or above the OSHA permissible exposure limit or the American Conference of Governmental Industrial Hygienists threshold limit values (ACGIH, 1990).

From a safety standpoint, PEP-II would not present any new hazards. All of the potential hazards associated with the proposed project have been encountered before during previous construction or experimental activities at SLAC. A variety of programs are in place to address these hazards in order to protect the environment along with the health and safety of workers and the general public. Further, installation of the B-Factory in the existing PEP tunnel at SLAC would take advantage of a number of currently-used, proven safety features and systems. Their presence and operational readiness would provide an extra measure of safety during the dismantling of PEP and the construction and commissioning of PEP-II. The construction and operation of PEP.II would not require any substantial change in SLAC staffing level, a) though the distribution of employees would be changed. Staffing for PEP-II operations would be acquired from other SLAC programs as they wind down. Some staffing support for the PEP-II project would be provided by LBL and LLNL.

\subsubsection{Effects From Construction}

No new buildings would have to be constructed for PEP-II. Disassembly of the PEP ring and refurbishment of the PEP magnets would be performed within existing structures at SLAC. Existing buildings and structures at SLAC, LBL, LLNL, or other collaborating institutions would be utilized for the fabrication of new components for the HER and LER and fabrication of detector components. These refurbishment and fabrication activities are rout ine operations at the respective facilities and therefore pose no additional health or environmental impacts.

Air Quality

VOC emissions generated from solvent cleaning and painting/coating operations would comply with the BAAQMD air-permit conditions specified for each 


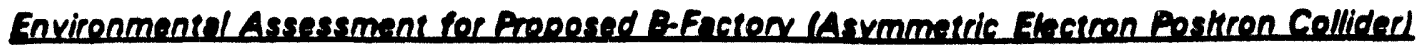

facility. SLAC's paint booth is equipped with pollution-abatement devices to control emissions of particulates and organic compounds.

Construction activities associated with PEP-II would not cause any impacts on air quality beyond the existing conditions discussed in section 5.1.1.

Water Ouality

Because there would be no conventional construction associated with PEP-II, surface-water runoff associated with excavated soll would not occur.

Components intended for removal from the tunnel and stored outdoors, pending either refurbishment or disposal, would first be surveyed or sampled to ensure that no contamination of any kind exists that could affect surface runoff.

As described in Section 5.1.2, under normal meteorologic and hydrologic conditions (i.e., non-drought conditions), groundwater seepage into tunnels and other underground structures occurs on the SLAC site. This same groundwater infiltration would be encountered during PEP.II construction activities but is not expected to interfere, as the groundwater seepage has been successfully managed and controlled in the past (see Section 5.1.2).

Although PEP.II construction and pre-operation activities are not expected to introduce contaminants to the groundwater seepage, water accumulated in the PEP tunnel sumps would be sampled to check for contaminants before discharge to a storm drain. If the sump contents were found to be contaminated, they would be discharged to the sanitary sewer or otherwise disposed of as appropriate.

\section{Industrial Hazards}

Generic hazards to SLAC workers from construction activities cover a wide range that includes conventional industrial accidents, dust and organic vapor exposure, and noise. Contact with, or inhalation of, organic vapors would be minimized or eliminated by performing solvent degreasing at existing permitted degreaser stations whenever possible, thereby minimizing solvent-reiated cleaning activities performed within the PEP tunnel. Given the active research efforts nationwide to develop solvent substitutes, degreasing may in fact be performed using newly developed and approved alternative solvents having decreased environmental impacts relative to existing solvents.

Worker noise exposure would be mitigated by providing ear protection and implementing a hearing conservation program if decibel levels from disassembly, refurbishment, or assembly activities exceed OSHA standards.

Health effects to members of the public from PEP-II construction could involve slightly increased traffic on access roads due to transportation of newly fabricated components to the site and transport of waste and recyclable 
materials offsite. However, the total volume of truck traffic to and from SLAC is not expected to be noticeably greater than the current situation.

\section{Radiation}

No radionuclide emissions would be generated or released by the disassembly of PEP, the refurbishment of its components, or the assembly of PEP-1I. Standard dosimeters would be provided to onsite workers refurbishing or installing components for PEP-II.

Based on preliminary surveys and experience from PEP, few PEP components are expected to have residual radioactivity. The maximum measured surface dose rate from a PEP beamline component is 1.2 mrem/hour. The average surface dose rate for components with measurable activity above background is 0.1 mrem/hour. These activated components are in the injection portion of the tunnel. Components that are located in the other portions of the tunnel have no activity. detectable above background. From these measurements the estimated average dose rate in the tunnel is less than $0.01 \mathrm{mrem} / \mathrm{hour}$. The estimated average exposure to workers from PEP components with residual activity would thus be less than $20 \mathrm{mrem} /$ year (the detection 1 imit of the SLAC dosimetry system). Assuming that the maximally exposed worker could receive 100 mrem during the 1 year of PEP disassembly, the incremental iffetime cancer risk would be $4 \times 10(-5)$. The disassembly is expected to involve less than 50 person years, resuiting in a collective dose of 1 person-rem. This results in an estimate of 0.0004 latent cancer fatalities (LCF).

Any material determined to have residual radioactivity would be handled and transported in accordance with established SLAC policies and procedures. AII nonreusable components would be surveyed by SLAC's Department of Operational Health Physics (OHP); any materials with residual radioactivity would be stored onsite in the Radioactive Material Storage Yard (RAMSY) pending future reuse or ultimate disposal in accordance with SLAC's Low Level Radioactive Waste Management Program (1992f). The detection of residual radioactivity on reusable components would not affect the plans for their reuse.

There would be no radiological exposure to the public resulting from the PEP-II construction activities.

\section{Hazardous-Materials Usage and Maste Production}

Hazardous, non-hazardous, and radioactive wastes could be generated during the construction of PEP-II. As noted above, $70 \%$ of the existing PEP components, including the current PEP ring magnets, would be refurbished and reused in PEP-II. The various materials removed from the PEP tunnel would be surveyed for residual radioactivity or other contamination and, if none is detected, would be salvaged as scrap or disposed of as non-hazardous waste at off-site 
landfills. These materials include:

- concrete girders (925 tons)

- support materials ( 32 tons)

- aluminum vacuum-chamber pipe (10 tons).

If nonreusable PEP materials are found to have residual radioactivity, they would be handled and stored onsite, or disposed of at an approved radioactive waste disposal facility, in accordance with the procedures of the Radioactive Material Management Manual (SLAC, 1992f). (To date, testing of the aluminum vacuum chamber and concrete girders has indicated no trace of radiation, as discussed in Section 3.2.1.). If any nonreusable PEP materials were found to contain hazardous materials, they would be decontaminated and salvaged or disposed of as hazardous waste, in accordance with the procedures of the Hazardous Materials Management Handbook (SLAC, 1992e) and in accordance with RCRA requirements.

The aluminum vacuum-chamber pipe would be replaced with copper vacuum-chamber pipe. Fabrication of the 4.5-km copper vacuum system would result in approximately 500 meters of copper scrap, or approximately $11 \%$ of the original material. This material would be salvaged, probably by being sold to a local scrap-metal dealer.

Prior to use by PEP-II, the LCW system lines would be descaled with corrosive cleaning materials. The total volume of hazardous waste generated from this one-time process would be approximately 10,000 gallons, which would be handled in two phases. Initial flushing operations produce the highest concentrations of hazardous substances in wastewater, and this relatively small volume would be disposed of offsite at an approved TSDF. Currently, this type of waste is shipped to Norris Environmental Services in southern California. The rest of the wastewater generated by descaling would be treated in SLAC's onsite wastewater treatment plant.

Magnet refurbishment is expected to generate less than one 55-galion drum of solid waste, which could be determined to be hazardous waste under California statutes (Jensen, 1993). No beryllium-containing parts or components would be fabricated at SLAC for PEP-II, although, like the detectors used for PEP, the new detector would contain a fully encapsulated beryllium beam-pipe. This beryllium-containing component would be purchased from a vendor. Some PEP components would be treated with a permitted vapor degreaser at SLAC as part of their refurbishment for use in PEP-II. Painting of components for PEP-II would also be done onsite at permitted SLAC facilities (see Section 6.1.1, Air Quality).

No components currently located in the PEP tunnel contain either PCBs or asbestos (Jensen, 1993). The two kicker pulser units in the western arc of the tunnel originally contained PCB fluid, but have since been drained. These units will be removed for offsite disposal as part of SLAC's ongoing program 
to dispose of all oil-filled equipment contaminated with PCBs. Any residual oil stains on the concrete floor and in the drainage gutters would also be removed.

\subsubsection{Effects From Normal Operations}

Impacts from the operation of PEP-II and its detector are discussed below and would be similar to those experienced with PEP, and are well understood and documented. Possible incidental increase in the beam energy of one ring at a tine as discussed in Section 3.2 .7 would roughly be compensated by decreases in the operating parameters of the other ring, and would not exceed the facility design specifications or present additional impacts or hazards.

Routine maintenance and the minor modifications that would most likely be needed to achieve the design-criteria operational parameters of PEP-II (see Section 3.3) could produce some waste products due to the exchanging of parts and components. The Hazardous-Materials Usage and Waste Production discussion of this section, identifies the effects of rout ine maintenance operations. Each modification action would be individually reviewed to ensure that it would not result in impacts beyond those identified in this EA for normal operations. Any modifications that would change design parameters or increase impacts to personnel, the public or environment would be subject to a specific NEPA evaluation.

\section{Air Quality - Non-radiological}

The primary source of non-radiological air emissions during the operation of the proposed PEP-II facility would be water vapor from the cooling-tower water (CTW) system, much like the current SLAC operations. CTW emissions may contain trace concentrations of chemicals used to treat the water and maintain the pipes. However, no effects are known to be associated with these releases. Occasional maintenance and component replacement activities could involve machining or cleaning parts, possibly creating dust or VOC emissions. However, air emission levels would not exceed Federal or State standards.

Ozone would be produced by ionization of the air in the tunnel in the course of PEP-II operations. As was true for PEP, however, ozone levels in gas vented from PEP.II would be within regulatory thresholds. In addition, SLAC has initiated programs to identify ozone-depleting compounds and develop acceptable alternative solvents for cleaning operations.

The gas mixtures to be used in the detector would consist of conventional gases; the exact composition would be definitively determined during commissioning. In the main drift chamber, which represents by far the largest volume in the detector complex, the gas mixture would likely comprise argon $(83 \%)$, carbon dioxide (10\%), and 1soutane (7\%). ES\&H testing has determined that this mixture is not fiamable or explosive in air. Therefore, it would not be a concern in the vacuum environment in which detector operations would 
Environmentel Assessment for Proposed B-Fucton (Asvmmetric Electron Posihron Colliderl

occur. In the event that a superconducting (cryogenic) magnet were used in the detector, liquid nitrogen and liquid helium would be used. With the ongoing cryogenic operations and the routine use, handling, and storage of cryogenic substances (e.g., boil-off of liquid nitrogen, a standard procedure at SLAC), SLAC has estabilished policies and procedures to address these operations.

Radiological air emissions from PEP-II operations are described in the Radiation discussion of Section 6.1.2.

\section{Nater Quality and Hydrology}

Groundwater seepage into the PEP-II tunnel during operations would be managed in the same manner as was done for PEP: the seepage would be channeled into the drainage gutters, and regular maintenance would be performed to keep all drains and gutters clear and pumps operational (SLAC, 1991a). It would eventually be necessary, per RWQCB requirements to reroute the gutters to the sanitary sewer.

Operation of PEP-II is not expected to produce any additional impacts on efther surface water or groundwater. As required by the RWQCB variance, measures would be instituted to ensure that process water (including any LCW that could leak from the cooling systems in the tunnel) is prevented from contacting the groundwater seepage at any point and sampling would be conducted. Preservation of groundwater quality would be facilitated through implementation of the groundwater monitoring program, which SLAC is developing in compliance with DOE Order 5400.1. The Groundwater Protection Management Plan for SLAC will be completed in September 1993, and the groundwater monitoring program is expected to be fully implemented by FY1996.

\section{Industrial Hazards}

Typical industrial hazards associated with operation of PEP.II would be similar to those invoived with PEP, and as such are addressed by the SLAC ESEH program (SLAC, 1991C). These include the danger from high-voltage systems and components, confined spaces, compressed gas cyl inders, liquid nitrogen and liquid helium (should cryogenic operations become involved), and the handing of hazardous materiais.

Electrical safety procedures are contained in the Guidelines for Operations (SLAC, 1992g). A Lock and Tag Program for Control of Hazardous Energy (SLAC, 1992h) is also being implemented. Hazards associated with confined spaces and hazardous atmospheres are addressed in the Guidelines for Operations and are controlled by the SLAC Industrial Hygiene Program. Management of these hazards invoives severai separate monitoring/alarm systems: Hazardous Atmosphere Detector Systems for explosive gases (although not currentiy anticipated to be necessary); Toxic Material Systems for toxic gases (including ozone); and Oxygen Deficiency Systems to monitor oxygen in ambient 
air. Detection of any industrial hazard activates both visible and audible alarms to notify personnel in the area.

Hazardous levels of ozone could accumulate in enclosed spaces during PEP-II operation. However, this hazard would be effectively eliminated by the use of a copper vacuum-chamber system, which is self-shielding. In addition, venting procedures minimize or eliminate exposure hazards to workers by controlling releases from the tunnel.

\section{Radiation}

Non-ionizing radio frequency and microwave radiation, as well as static electric and magnetic fields, would be generated by the various electrical components associated with PEP-II operations. Although these hazards are expected to exist to approximately the same degree as with PEP, worker exposures to non-ionizing radiation would be maintained below the limits recommended by the American Conference of Governmental Industrial Hygienists (ACGIH, 1990). Ionizing radiation would be generated in the tunnels during PEP-II operations when the electrons and positrons radiate energy or interact with materials such as the beam pipe, the collimating devices, or other beamline components. Nearly all of this radiation would be absorbed by the self-shielding copper vacuum chamber, the concrete tunnel walls, and the surrounding earth. The induced radioactivity in materials may persist after the beam is turned off. Aside from the BSY and PS areas, the level of this induced radioactivity is very low and non-hazardous. Elevated levels of induced radioactivity could develop in collimators, stoppers, and other devices specifically designed to intercept and absorb or "scrape", rather than transmit, part or most of the beams. In general, activation of most components from PEP-II operations would be expected to be less than $25 \mathrm{pCi} / \mathrm{g}$. Radiation dosage expected to be received by personnel transporting such activated components from PEP-II operations would be expected to be well below $100 \mathrm{mrem} / \mathrm{year}$, and most probably non-measurable due to the low level of induced activity expected from PEP-II operations.

As discussed in Section 5.1.7, recent soll sampling indicates no radioactivity associated with the accelerator operations at SLAC. It is not anticipated that any detectable soil activation would result from PEP-II operations.

Radioactivity could also be induced in air or water. In air, the various radioactive isotopes that would be produced $\left({ }^{18} \mathrm{O},{ }^{13 \mathrm{~N}},{ }^{11} \mathrm{C},{ }^{3} \mathrm{Cl},{ }^{20} \mathrm{C}\right)$, and ${ }^{4} \mathrm{Ar}$ ) are all short-lived, with half-lives less than two hours. Potential release points to the outside environment from PEP-II include access openings and forced-air ventilation ducts. When the beam is on, all access openings would be covered and administratively secured. The forced-air ventilation system would also be shut off. As discussed below, releases under normal operations could occur only after the beam is shut down, access ports are opened, and the forced-air ventilation systems are turned on. Some of this radioactivity, but not measurable doses, could diffuse out of the tunnels into 
occupied areas in the IR Halls. Any accumulated dose equivalents to workers from this source would be measured as part of their external radiation exposure.

The only long-lived activity that is likely to be produced in water is tritium. Since there will not be any use of high power beam dumps in storage rings such as PEP-II, no activation of groundwater is expected from PEP-II operation. Existing conditions relating to groundwater are discussed in Sections 5.1.2. There could be some activation of water in the closed-10op LCW system that is used for cooling beam-line components. However, records on hand indicate no detectable tritium in LCW samples from PEP operations, using assays with a $500 \mathrm{pCI} / \mathrm{I}$ detection limit. PEP.II operations would have similar effects.

Radiation from PEP-II that could affect the public originates from two sources: direct radiation (ganma rays and neutrons) and short-lived airborne activation products. Radiation exposure to the public from DOE facilities is controlled and minimized in accordance with DOE Order 5400.5 (DOE, 1990a). This order stipulates an effective dose-equivalent limit to a member of the public of $100 \mathrm{mrem} /$ year from all routine DOE activities, and $10 \mathrm{mrem} / \mathrm{year}$ for airborne emissions of radioactive materials. The latter 1 imit is also specified by EPA regulations in 40 CFR 61.

Direct radiation that cou, a reach members of the public could be produced by any of the following operations: normal beam losses during commissioning of PEP-II; start-up operations; injection for beam diagnostic purposes should a problem occur; complete loss of one or both beams; normal injection losses during "topping-off" (the replenishment of the beam current to $100 \%$ after it has, over a period of about an hour, lost about $20 \%$ of its intensity) and "scratch" start-up (the refilling of an empty ring to $100 \%$ beam current, after the beam has been completely lost or dumped); and normal parasitic losses. During normal operations, radiation exposure at the SLAC site boundary would result from radiation penetrating the roofs of the $I R$ buildings and being diffused in the air while coming down to ground level. Assuming that beam losses are equally distributed around the ring over time, the maximum annual dose-equivalent at any point on the site boundary would not exceed the EPA limit of 10 mrem in a year. This exposure level is calculated for 900 8-hour accelerator operation shifts, the largest number recorded per calendar year in the last five years. All forms of radiation would be monitored and corrective actions (e.g., rescheduling of beam operations, installation of additional shielding) would be taken as necessary to maintain the site-boundary dose-equivalent below 10 mrem in any given year (Kase et al., 1993). Members

- The assumption of an equal distribution of beam losses is reasonable for estimating the maximum mdiation doses outside the chialded areas. If all the losses were to occur in one, or a few, bertions in the IR buildings, those bcations would be bcally ehielded. If the losses always occur in the tunnels, there would be no rediation exposure to individuals outside because the tunnels are well shielded. 
Environmentel Assessment for Proposed B.Fucton. (Asymmetric Electron Positron Collider)

of the public residing in the area around SLAC would have even lower exposures from PEP-II activities than the site-boundary estimates, since the intensity of the dose decreases with increasing distance.

The maximum dose-equivalent to the public from the release of airborne radioactive materials is documented annually in the SLAC Annual Environmental Monitoring Report (SLAC, 1992a) and is due to the short-lived activation products discussed earlier in this section. Based on the saturation activity in the various enclosed spaces of PEP-II, the maximum quantities of radioisotopes that could be released and the resultant maximum potential dose-equivalent to the public were calculated using the EPA-approved software code CAP-88. The dose-equivalent associated with airborne radioactive emissions from PEP-II operations to a maximally exposed individual was calculated to be 0.001 mrem in one year (Tran, 1993). Indeed, even this low dose would not occur during routine operations because the spaces involved would remain sealed for periods of an hour or more after shutdown, during which time the majority of the short-lived airborne activation products would decay to stable isotopes.

Based on a conversion factor of $5 \times 10^{-4}$ latent cancer fatalities per person-rem for the whole population (NCRP Report No. 116, 1993) the maximally exposed member of the general public $(0.01 \mathrm{rem} /$ year) would have an est imated annual probability of fatal cancer induced by radiation of $5 \times 10^{-6}$. The risk of fatal cancer to the maximally exposed individual over the projected exposure period is approximately $8 \times 10^{-5}$. Assuming that the population of maximally exposed individuals outside the SLAC boundary will not exceed 10, the risk of fatal cancers to this potentially exposed population over the operating period of 15 years is approximately 0.0008 . There are no persons residing within $0.3 \mathrm{~km}$ of the SLAC boundary. The population residing between $0.3 \mathrm{~km}$ and $0.5 \mathrm{~km}$ from the SLAC boundary is about 1,200 people. The estimated maximum annual dose at $0.3 \mathrm{~km}$ from the PEP-II operation is $2 \times 10^{-4}$ rem (Kase, et al, 1993). Based on a risk-to-dose conversion factor of $5 \times 10^{-4}$ latent cancer fatalities per person-rem for the whole population (NCRP Report No. 116, 1993), the estimated latent cancer fatalities for this population over the 15 year operation of PEP-II is less than 0.002 .

Activities that could expose workers to radiation would include the same processes that produce potential exposure to the public. The DOE Radiological Control Manual, DOE N 5480.6, (DOE, 1992b) specifies an annual effective dose-equivalent limit to workers from both internal and external radiation sources of 5 rem (1.e., 5,000 mrem) and an Administrative Control Level of 2 rem (i.e., 2,000 mrem). Potential dose equivalents have been calculated based on simultaneous losses of both beams. Beam-loss events were hypothesized to be equally distributed around the ring throughout the year. Because the IR buildings would be occupied during operation, and because these buildings have the least amount of shielding, the potential for radiation exposure would be expected to be highest in these areas. Although workers would be present in the IR buildings (outside the shielding walls) during operation of PEP-II, 
access control systems (e.g., the PPS) would ensure that no personnel remain inside the shielded enciosures in the IR buildings or in the beam tunnel during operation. Based on the fraction of the total beamline circumference that is exposed in the IR halls, maximum dose-equivalent rates of less than 1 rem per year were calculated for a work year of 900 8-hour shifts. This dose equivalent is based on 1-meter concrete shield and a 5.4-meter distance between the beamline and the nearest occupled areas. It was calculated at 1.8 $m$ above the floor of the interaction hall, which approximates the height of an average human.

Occasionally, when a conscious and intentional decision is made to vent the BSY, the PS, or the associated beam dumps in less than an hour after beam shutdown, radionuclide emissions to the air could result in a slight increase in radiation exposure. Monitoring data from PEP and SPEAR operations and projected emissions from PEP-II indicate that the maximum release level of radionuclides would result in a dose equivalent at the site boundary of less than $0.1 \mathrm{mrem} /$ year. In general, worker exposure, as a result of early entry, would produce a dose-equivalent of less than $100 \mathrm{mrem}$.

Activation of beamline components and support structures would be confined to the PEP-II tunnel or interaction region, and no release of activated material would occur from these areas. Occupied areas would be routinely monitored to ensure that the dose-equivalent to persons working near PEP-II would be maintained as low as reasonably achievable (ALARA), in accordance with established SLAC policy. Radiation detectors would be placed in all potentially occupied areas in the IR buildings, connected to the Persor." I Protection System (PPS) controlling tunnel access, and set to shut down the beam if excessive dose rates were detected. All areas accessible to workers would be routinely monitored and appropriate signs posted. Horker exposure would also be routinely monitored using personal dosimeters.

Based on relevant experience at SLAC with other projects, it is expected that doses from the proposed PEP-II project would be maintained well below $1 \mathrm{rem} /$ year for workers and well below $10 \mathrm{mrem} /$ year for individuals off site.

The number of workers that would be exposed to measurable amounts of radiation from PEP-II in the course of normal operations would not exceed 50. The 1992 dosimetry records indicate that the average dose to exposed SLAC workers was 0.09 rem for the year. The maximum exposure to a worker predicted for the PEP.II operations is not likely to exceed 0.5 rem in one year. Based on conversion factor of $4 \times 10^{-4}$ latent cancer fatalities per person-rem for adult workers (NCRP Report No. 116, 1993) the maximally exposed worker would have an estimated annual probability of fatal cancer induced by radiation of 2 $x 10^{-4}$. The average exposed worker would have an estimated annual risk of approximately $4 \times 10^{-6}$.

The expected operational life for PEP-II is 15 years. The risk of fatal cancer to the average exposed individual over the projected exposure period is approximately $5 \times 10^{-4}$. It is assumed that the maximaliy exposed individual 
for any single year will not be exposed at the maximum rate for the entire 15 years of operation.

The risk of fatal cancers to the potentially exposed population of 50 individuals over the operating period of 15 years is approximately 0.03 .

Under these circumstances, workers engaged in this proposed project would not be expected to incur any harmful health effects from the radiation exposures they receive during normal operations.

\section{Hazardous-Materials Usage and Waste Production}

Section 5.1.3 describes the hazardous-materials usage and the types and quantities of waste produced during operation of PEP. Operation of PEP-II is expected to yield similar results. Limited quantities of hazardous waste would be generated, in virtually the same amounts as was with PEP. None of the equipment that would require routine maintenance contains hazardous materials. However, some waste ofls that are considered hazardous in the State of California could be generated due to leakage from, or mechanical failure of, oil-filled equipment. The equipment would be repaired or replaced, and any hazardous waste would be disposed of or recycled according to California's Hazardous Waste Control Laws (HWCLS). In addition, some organic solvents would be used for routine cleaning of components. The operation of PEP-II is not expected to generate hazardous wastewater nor would any PCB- or asbestos-containing materiais or articles be used.

As with PEP, no, radioactive waste would routinely be generated by the operation of PEP-II. Over the course of its service life, however, low levels of radioactivity would be induced in some PEP-II components. Any components repaired or replaced would be surveyed according to established policies and procedures and, if necessary, would be stored onsite or disposed of in an appropriate manner.

Repair of cooling-system equipment could involve the draining of LCW from all, or part, of the system. The LCW would be analyzed for tritium activity and, unless analytical results indicated otherwise, discharged to the sanitary sewer. Results from past analyses of LCW indicate no detectable tritium (detection limit of $500 \mathrm{pCi} / \mathrm{l}$ ).

Limited amounts of non-hazardous wastes would routinely be generated, primarily small quantities of "Office-type" paper wastes and materiais. As is the current practice, the office paper would be recycled as part of the Stanford University recycling program and used computer paper would be sold.

\subsubsection{Effects From Accidents}

In a facility such as PEP-II, accidents related to earthquake, high voltage, fire, and/or radiation could occur but the probability is very low. The most 
"reasonably foreseeable" incident with any consequences would be a cable fire caused by an electrical overload condition. Such an incident is described in the fire discussion below.

The potential for accidents at SLAC is addressed and minimized by the SLAC ES\&H Program as documented in the SLAC Environment, Safety, and Health Manual (SLAC, 1991C). The responsibility for safety and implementation of the Safety Program is a line function. Worker health and safety are addressed by specific radiation safety, industrial hygiene, electrical safety, fire protection, and industrial programs. Specific response and reporting procedures for incidents, emergencies, and alarms are contained in Guidelines for Operation (SLAC, 1992g), which implement the requirements of DOE Order 5000.3A, Occurrence Reporting and Processing of Operations Information (DOE, 1993a).

The safety performance of SLAC during the period of 1986 through 1991 was recently summarized in a draft Safety Performance Profile (EG\&G Idaho, 1992). This report indicated that the average total reportable case-injury accident rate was comparable to that of the DOE average for the same period: 3.0 per 200,000 work hours versus 2.5 per 200,000 work hours, respectively. There were no fatal accidents at SLAC during this period. A single fire was reported at SLAC during the same period, causing $\$ 15,000$ in damage.

\section{Earthquake}

The emergency situation most likely to occur at SLAC is an earthquake. Facilities constructed on the SLAC site employ appropriate building techniques such that seismic risks are reduced to acceptable levels (SLAC, 1992j). The PEP tunnel, above-ground structures, and utility structures were designed to withstand an earthquake of magnitude 8.0 on the Richter scale and an acceleration force of $0.75 \mathrm{~g}$ in any direction. The Loma Prieta earthquake of October 1989, with a magnitude of 7.2 and its epicenter 30 miles south of SLAC, affected numerous areas of SLAC, including PEP. Minor realignment of the magnetic components was the only corrective action required to restore the PEP complex to operational readiness. Potential damage to PEP-II due to a major earthquake would be expected to be similar to that experienced with PEP.

PEP-II would make use of the safety design features of PEP to ensure that, in the event an earthquake causes the stored beam to dump, the penetrating radiation levels at the site boundary would be negligible. In addition, all mechanical components of PEP-II would be secured to protect persons working in the area. All ring components for PEP-II would be designed to withstand an earthquake of magnitude $\mathbf{8 . 0}$ on the Richter scale and an acceleration force of $1 \mathrm{~g}$ in any direction. For complicated structures (such as the detector), static calculations would be checked with computer simulated dynamic anaiysis up to levels of $0.8 \mathrm{~g}$. Alignment procedures that would be employed for PEP.II have been much improved, relative to PEP, and would allow for rapid realignment should it be needed following an earthquake. 
Any damage to PEP-II resulting from an earthquake would not release any radionuclides, and the production of penetrating radiation would cease instantly with the loss of the stored beam. Tunnel gases with induced radioactivity could be released, but would not produce any deleterious effects, as discussed in Section 6.2.4. Returning the accelerator to operation following an automatic shutdown, such as that which would occur in the event of an earthquake, would not expose the public or the work force to any significant additional radiation than would be expected from normal operations.

The design and installation of all experimental equipment for PEP-II would be reviewed by the SLAC Earthquake Committee, as mandated by the SLAC Safety Program. Operation of PEP-II would be covered by the SLAC Earthquake Emergency Plan (SLAC, 1991b), which outlines the procedures to be followed in the event of an earthquake severe enough to cause possible structural damage or personal injury.

\section{High Voltage}

Potential hazards associated with high-voltage lines and equipment exist throughout SLAC, but established policies and procedures, together with an excellent safety record, show that these hazards can be effectively managed.

The PEP tunnels, interaction regions, and detector are potential sources of electrical hazards, as are the other accelerator areas at SLAC. Electrical safety at SLAC is addressed by the SLAC ES\&H Program (SLAC, 1991C) and the Guidelines for Operations (SLAC, 1992g). These include a Lock and Tag Program for Control of Hazardous Energy (SLAC, 1992h). Some energy sources in the PEP tunnels are deactivated when the Personnel Protection System (PPS) is in the "access allowed" mode (1.e., permitted access or restricted access).

The probability of a high-voltage accident in PEP-II would be reduced relative to the original PEP operation, due to the development of the programs noted above and implementation of lock-and-tag requirements. In a hypothetical accident scenario, a worker could be killed by electrocution in any of numerous areas at SLAC, including the PEP-II complex. However, no fatalities of any kind have ever occurred during operations at SLAC, as was documented in a comprehensive review of accidents at the facility (EG\&G, 1992). No offsite effects on the public or the environment would be possible from such events, except for potential temporary power losses (brownouts or blackouts) stemming from the incident.

Fire

Fire safety is addressed by the SLAC ES\&H Program (SLAC, 1991C). The Palo Alto Fire Department (PAFD) operates an onsite fire station (Station 7) to provide immediate fire-fighting and emergency response support to SLAC. PAFD 
personnel conduct fire safety inspections and citation prograns and provide training in the use of fire extinguishers to SLAC personnei.

The probability of fire in PEP-II would be expected to be similar to that for PEP. The SLAC ES\&H Program would minimize the hazards from fire to workers and the public from events at PEP-II, as it does for all areas and activities at SLAC. Like PEP, PEP-II would be constructed of essentially nonflamable components, and no large quantities of flammable materials are used in construction or operations. The PEP interaction halls and tunnels are equipped with sprinklers that meet or exceed applicable codes to minimize the spread and effects of any fires.

The most "reasonably foreseeable" incident with any substantial consequences would be a fire of the insulating material for electrical cables initiated by an overload condition. The typical insulating material on electrical cables is polyvinylchloride (PVC) because of its resistance to the deteriorating effects of ionizing radiation. PVC cable fires develop and spread slowly. Fires with major losses had occurred in other sites when PVC cables were not accessible to fire-fighting efforts and were not protected by fixed fire-suppression systems. However, the cables at PEP-II are exposed and the PEP ring has a fully automatic fixed sprinkler system.

A cable fire in PEP-II would be expected to develop slowly, providing sufficient time for egress by employees. There is no location in the PEP-II enclosure further than 800 feet from an exit and there is no location where two directions of egress are not available. On the SLAC site, there are two rescue electric carts equipped with medical emergency equipment and rescue self-contained breathing apparatus. The carts are maintained by the PAFD and would be brought over to the PEP-II ring should the need arise. PEP-II is provided with mechanical ventilation that is controlled at the Main Control Center (MCC). The automatic sprinkler system is expected to extinguish any fire which may occur within several minutes. The sprinkler riser and smoke detectors within PEP-II enunciate at the onsite fire station, MCC, and the City of Palo Alto dispatch center, providing early warning of a developing fire and initiating the onsite response. Typical response time is three minutes and consists of the onsite engine, an additional engine offsite, and one paramedic unit.

Should a fire occur in any part of the PEP-II complex, it is expected that there would be no personnel injuries and minimal property damage. No impacts to the public or environment, beyond those resulting from any other large structure fire, are expected. The physics research program is likely to be impacted due to the necessary factility repair.

\section{Radiation}

Possible accidents involving radiation at PEP-II that could affect the public or onsite workers include beam-loss events and release of induced 
radioactivity into the air from normally sealed spaces. The most serious radiation accident that could occur during PEP-II operations and affect the public would be the injection and subsequent complete loss of both stored beams at the maximum possible current and energy. The maximum possible combined-beam power is 13.4 kllowatts $(\mathrm{kW})$. If both beams are lost at a point in the ring adjacent to an interaction region--that is, outside the tunnei, where the shielding is least extensive--the dose-equivalent rate at the nearest site boundary point (a distance of 60 meters) would be about 20 mrem/hour (Kase et al., 1993), but this rate would last for only a fraction of a second, thereby producing a negligible radiation dose. Assuming such an event occurs once in a year, the resultant maximum potential dose equivalent at the site boundary would be less than 0.005 mrem in a year, far below the design/operating specification of $10 \mathrm{mrem} /$ year (Kase et. a1., 1993). For a population of 1,200, an exposure of $0.005 \mathrm{mrem} /$ year results in a population dose of 0.09 person-rem over 15 years. This leads to an estimate of less than $5 \times 10^{-5}$ latent cancer fatalities.

Should such a serious accident occur, the maximum dose-equivalent rate outside the shielding would not exceed 25 rem/hour. The corresponding maximum integrated dose-equivalent outside the shielded areas would not exceed $10 \mathrm{mrem}$ $(0.010 \mathrm{rem})$. By Comparison, the DOE Radiological Control Manual, DOE N 5480.6, (DOE, 1992b) specifies an annual effective dose-equivalent limit for workers from both internal and external radiation sources of 5 rem. For a population of 50 workers, an exposure of $0.01 \mathrm{rem} /$ year results in a population dose of 7.5 person-rem over 15 years. This leads to an estimate of less than 0.003 latent cancer fatalities.

Regarding induced radioactivity, the maximum possible dose to the public at the site boundary from the release of short-lived radionuclides into the air from normally sealed spaces was calculated by Tran (1993) to be $0.001 \mathrm{mrem}$, as described in the Radiation discussion in Section 6.1.2. This highly conservative estimate assumes that the equilibrium activity in all sealed spaces in the PEP.II complex is released immediately after shutdown--that is, no time elapses to allow for decay prior to venting.

The potential for accidents involving worker and/or public exposure to radiation is minimized by the SLAC Radiation Safety Program and the various Radiation Safety Systems. Shielding exists between beam-housing areas and areas that are occupied during operation, in order to maintain radiation exposures as low as reasonably achievable (ALARA). A Personnel Protection System (PPS) controls entry into and exit from beam-housing areas; doors to these areas are interlocked to prevent access whenever the potential exists for radiation generation. A Beam Containment System prevents the accelerated beam from diverging from the desired channel or producing excessive radiation in occupied areas. Finally, Beam Shut-Off Ion Chamber System utilizes radiation monitors outside the shielding barriers to verify that external radiation levels do not exceed design levels (SLAC, 1992g). In addition, 
these monitors shut off the beam if radiation levels exceed $100 \mathrm{mrem} / \mathrm{h}$ outside the shielded areas.

In the several decades of cumulative accelerator/collider operations at the various SLAC facilities (PEP, SPEAR, and SLC), it is noteworthy that no fatality has ever occurred. Nevertheless, in a serious accident the potential exists for a hypothetical worker to recelve a lethal dose of radiation by remaining in a tunnel for an extended perlod during operation. However. exhaustive precautions have been developed and implemented to minimize the probability of such an event, beginning with a thorough search of the entire area prior to operation. Before the accelerator is turned on, the lights in the housings are automatically flashed on and off for two minutes and then dimmed, and a recorded message is played stating that the beam is coming on. There are also emergency shut-down buttons and cables within the housing areas, which can be activated to stop the start-up process. When the accelerator is on, each of the enclosures within the shielding barriers becomes a Very High Radiation Area, as defined in the DOE Radiological Control Manual, DOE N 5480.6 (DOE, 1992b).

\subsubsection{Effects From Decontamination and Decommissioning}

At the conclusion of the PEP-II program, decontamination and decomissioning (D\&D) of the facility would be required. In general, the major facilities at SLAC (SPEAR, PEP, SLC/SLD) have remained in use once constructed, and D\&D operations are performed mainly on individual components. This pattern of continued use may apply to PEP-II, as well. D\&D activities are expected to comprise two separate stages: mothballing, followed by removal of any radioactive components (should they exist) and dismantling.

Mothballing constitutes placing the facility in a state of protective custody, and comprises the following operations: initial decontamination, drainage of liquid-filled systems, disconnecting of some or all operating systems, physical and administrative controls to ensure 11 mited access, characterization surveys to determine whether any residual radioactivity exists, and subsequent surveillance and maintenance, as necessary. This period is estimated to last for one year.

Should any radioactive components exist, their removal and dismantling would involve final decontamination or removal of equipment, materials, and buildings, as appropriate. Any items removed would be stored onsite for future use, or packaged according to DOT specifications and shipped to a DOE-approved radioactive waste disposal site. When the D\&D decision is before DOE, the NEPA process will be utilized, as appropriate, to assist decision making. 
Non-Radiological Impacts

Non-radiological impacts assoclated with D\&D work would be similar to those involved in facility construction, such as noise, dust, exhaust emissions, storm-water management, and related aspects. Associated environmental impacts would be temporary and would have only minor short-term or long-term effects on the SLAC facllity or the surrounding area. Hazardous liquid or solid waste generated by D\&D activities would be handled approprlately and disposed of offsite. Non-radiological material and wastes would be stored onsite or shipped to an approved disposal facility, as appropriate.

\section{Radiological Impacts}

Radiological impacts associated with DED at PEP-II would be minimal. As described for other activities involving potentially radioactive equipment, materials, or components, any of these items containing residual radioactivity would be stored onsite in a dedicated area or shipped to an approved radioactive waste disposal site.

\subsection{POTENTIAL ENVIRONMENTAL EFFECTS OF THE CESR-B}

\subsubsection{Effects From Construction}

\section{Socioeconomic Impacts}

Construction employment is expected to average 35-40 workers during the 59 week conventional construction period with an anticipated peak labor requirement of 50 workers. In addition, approximately 54 temporary laboratory employees would be hired for the perlod of CESR-B conventional construction and installation. These employees would include 38 technicians, 7 administrative and service employees, 4 drafters, and 5 engineers/physicists.

Cornell University hires approximately 75 percent of Its new permanent employees from within Tompkins County and the lamediately surrounding counties. Because construction has been a stable or growing sector of the local economy, it is anticipated that all of the required construction labor would be available within the local area. Similarly, it is anticipated that the temporary laboratory workers would be avallable locally. At most, 14 temporary workers, or $25 \%$, might be expected to relocate for the duration of construction and operation.

The total construction labor force represents less than two-tenths of one percent of the total labor force in Tompkins County. Therefore, no discernible impacts on the local economy or community services are expected from the labor force requirements associated with the proposed CESR-B. 
Air Ouality

Standard construction techniques would be used to expand the facility during conversion to a B meson factory. Construction activities would have only a temporary and negligible effect on air quality. Spray wetting would be used to mitigate the temporary generation of dust by heavy construction machinery and vehicular traffic, if necessary.

Water Ouality and Supply

Areas that would be disturbed by construction activities are immediately adjacent to and within 200 feet of the Wilson Lab. Approximately 2.5 acres would be disturbed by construction activities, including the cooling tower relocation and expansion. Another 1.5 acres would be disturbed to obtain access to the west side of the laboratory and for construction/spoils staging. Permanent building on the east side of the laboratory would disturb about 0.6 acres of land. The construction contractor would be required by Cornell University to adopt a Stormwater Pollution Prevention Pian with provisions to minimize the contamination of stormwater and the Cascadelia Creek. In the event that the disturbed area exceeds 5 acres, the federal stormwater permitting process would be adopted in accordance with 57FR41175, 9 September 1992.

There are no additional impacts of construction on water supply.

\section{Noise}

Noise impacts are not anticipated. Expected noise associated with CESR-B construction will involve the following equipment.

- Mobile earthmoving equipment such as dozers, backhoes, loaders, trur.ks, tractors, graders and pavers. These generate noise primarlly via their exhaust and structure in the 73 to 90 decibels in the $A$ weighted scale $d B(A)$ at 50 feet.

- Partially mobile material handling equipment (e.g., cement mixers, concrete pumps, and cranes) are expected to generate noise in the 75 to $85 \mathrm{~dB}(A)$ range at 50 feet.

- Stationary equipment such as pumps, compressors and generators are expected to generate noise in the 70 to $75 \mathrm{~dB}(A)$ range at 50 feet.

- Impact equipment such as pile drivers, Jackhammers, rock drills and pneumatic tools are expected to generate loud but intermittent levels of noise between 80 and $110 \mathrm{~dB}(A)$ at 50 feet.

- Other equipment such as saws and vibrators generate noise at levels ranging from 70 to $76 \mathrm{~dB}(A)$ at 50 feet. 
Noise output from these construction equipment sources would not have a negative impact on the community for the following reasons:

- Location of the construction site is such that sound attenuation is provided by topographical features and noted sizable distance from neighbors.

- Equipment use scheduling will take place as necessary to reduce noise impact.

- Noise reduction will take place as the distance from the source(s) is increased. Whan looking at the topography and distances involved with this project, nolse attributable to on-site construction activities will not present a noise problem for nearby residents or CESR facility occupants.

- Estimated additive effects from anticipated construction activities, local traffic, and other point sources are considered insignificant.

It is important to note that the Department of Environmental Health and Safety has measured construction noise for larger projects located in more noise sensitive areas of campus (e.g., close to dormitories, classrooms, and office areas). Results have indicated that noise from construction was not a problem and was not in violation of community noise standards. Furthermore, occupancies surrounding the proposed CESR-B construction area have not changed much since the Wilson Lab was built.--at that time construction noise impact was not a problem for the surrounding community.

\section{Utilities}

There would be no increase in steam use during construction, and electric use would decrease because CESR would be idle during construction of CESR-B. However, construction of additional electric transmission lines would be required to support operation of CESR-B. The disruption during construction would be minimal because existing routes of electric transmission lines would simply be expanded to provide the additional service.

The two alternate routes are described in Section 6.2.2, Effects From Normal Operations. The preferred method of supply would be to use existing buried concrete-encased duct banks that run from the Kite Hill switching station to near Wilson Lab. These have spare capacity and construction would not be necessary. It would be necessary to construct new buried ducts from Wilson Lab to the existing ducts north of Wilson Lab, a distance of less than 200 feet. This would be a routine utility project on the campus.

The alternate method of supply is to use an existing overhead service corridor that runs from the $115 \mathrm{kV}$ substation past Wilson Lab about 200 feet to the east. A second circuit would be added below the existing circult. It is 
Environmentel Assessment for Aroposed B. Focton (Asymmetric Electron Positron Collider)

likely that some poles would be replaced. In addition, a new underground duct bank would be run about 200 feet.

\section{Waste Generation}

Soll that is excavated as part of the construction of the proposed CESR-B would be clean fill and as such is exempt from solid waste regulations. Cornell University has an agreement with an owner of an inactive quarry within 2 1/2 miles that permits Cornell to use the quarry for disposal of soil and other exempt fill. Soll may also be used for landscaping or other construction projects on campus. Approximately 22,400 cubic yards of excavated soil would be available for such projects (or require disposal) after backfilling of the CESR-B construction site is completed.

Construction and demolition debris (as defined by 6NYCRR Part 360) would be disposed of offsite at disposal areas that have a permit from the New York State Department of Environmental Conservation (NYS DEC). There is sufficient available capacity in permitted disposal facilities for the estimated 750 cubic yards of debris that would be generated by the construction of the CESR-B.

\section{Sensitive Environmental Resources}

The areas that would be disturbed during construction of the CESR-B have been previously engineered and developed during the original construction of Wilson Lab. The construction would disturb only the area immediately around the lab, which consists of parking areas, mowed lawn, unmowed embankment, and a small wooded area totaling less than one acre. Ail trees that would be removed were either planted spruce or pine or native trees that have grown in the last 20 years. The proposed CESR-B is compatible with existing land uses.

Since there are no cultural, archaeological or historical resources; rare, threatened, or endangered species; or activities planned in floodplains or wetlands near the Hilson Lab, there would be no construction impacts on sensitive environmental resources.

\section{Transportation}

Construction for CESR-B would infringe on parking areas north of Wilson Lab that are associated with the tennis facility and student commuter parking. Traffic on affected campus roads would be rerouted through parking space during construction of the CESR-B. Any loss of parking would be off set by additional parking that is scheduled to be constructed in the space currently occupied by a tennis bubble. The removal of the tennis bubble and parking expansion is being undertaken independently of the proposed CESR-B project and is scheduled to be completed before construction would begin on CESR-B. In addition, temporary parking is available south of Wilson Lab to accomodate construction equipment and vehicles associated with the construction work 
force. Construction traffic to the Lab site is expected to have only minor impacts on local roads or intersections.

\section{Hazardous Materials}

Construction associated with expansion of the Wilson Lab would be similar to conventional construction routinely conducted on the campus. Materials used during construction would be disposed of in accordance with federal and state disposal regulations. An estimate of hazardous materials that would be used in construction is not available at this time. Due to the rout ine nature of construction activities for CESR-B, no deviation from standard hazardous materials use and disposal is anticipated.

As discussed in section 5.2.9, chemical processing at Newman Laboratory in support of CESR would not noticeably change during support for CESR-B. The chemical processing of superconducting cavities would require the use of acids and solvents similar in quantity to that used routinely in research. Most research activities would be suspended during cavity fabrication and there would be no substantial change in chemical usage. Occasional use of solvents and other chemicals in routine activities would continue as at present.

During construction, CESR would be decommissioned in preparation for expansion required for CESR-B operations. Since particle accelerator operations would cease, no additional radiation would be generated during the construction phases of CESR-B. Residual radiation would result in human radiation exposure. An upper limit for this exposure is estimated from the current tunnel background level of 0.02 millirem per hour or 0.04 rem per work-year. Decommissioning and handing of reused tunnel components would require less than 100 person-years. Using an occupational risk factor of $4 \times 10^{2}$ (from NRC, Preamble to Standards for Protection Against Radiation, 56FR23363, May 21, 1991), decomissioning is expected to result in less than 0.002 cancer deaths.

Some accelerator components such as the aluminum vacuum chambers would not be reused in the CESR-B. Many of the chambers have measurable radioactivity. Figure 10 is a histogram of the measured contact radiation of the CESR vacuum chambers. Only five of the chambers are over $0.25 \mathrm{mrem} /$ hour on contact. Most of these chambers could be disposed of as normal waste after a suitable waiting period (the longest half-life is the 2.5 years of sodium 22). The balance would be disposed of immediately by the Cornell Department of Environmental Health and Safety (DEHS) as low-level radioactive waste. The most massive group of components in CESR are the magnets; they would be reused. The entire synchrotron and the linac would aiso be reused.

Because of the relatively low potential of an electron storage ring for inducing radioactivity in materials, significant activation of the tunnel components and soil is unlikely. Tunnel surfaces in the regions of the planned demolition have been surveyed. An upper limit of 0.02 arem/hr (due to proximity of the synchrotron to the measurement area) was established. 
Environmental Assessment for Proposed B-Factory (Asymmetric Electron Positron Collider)

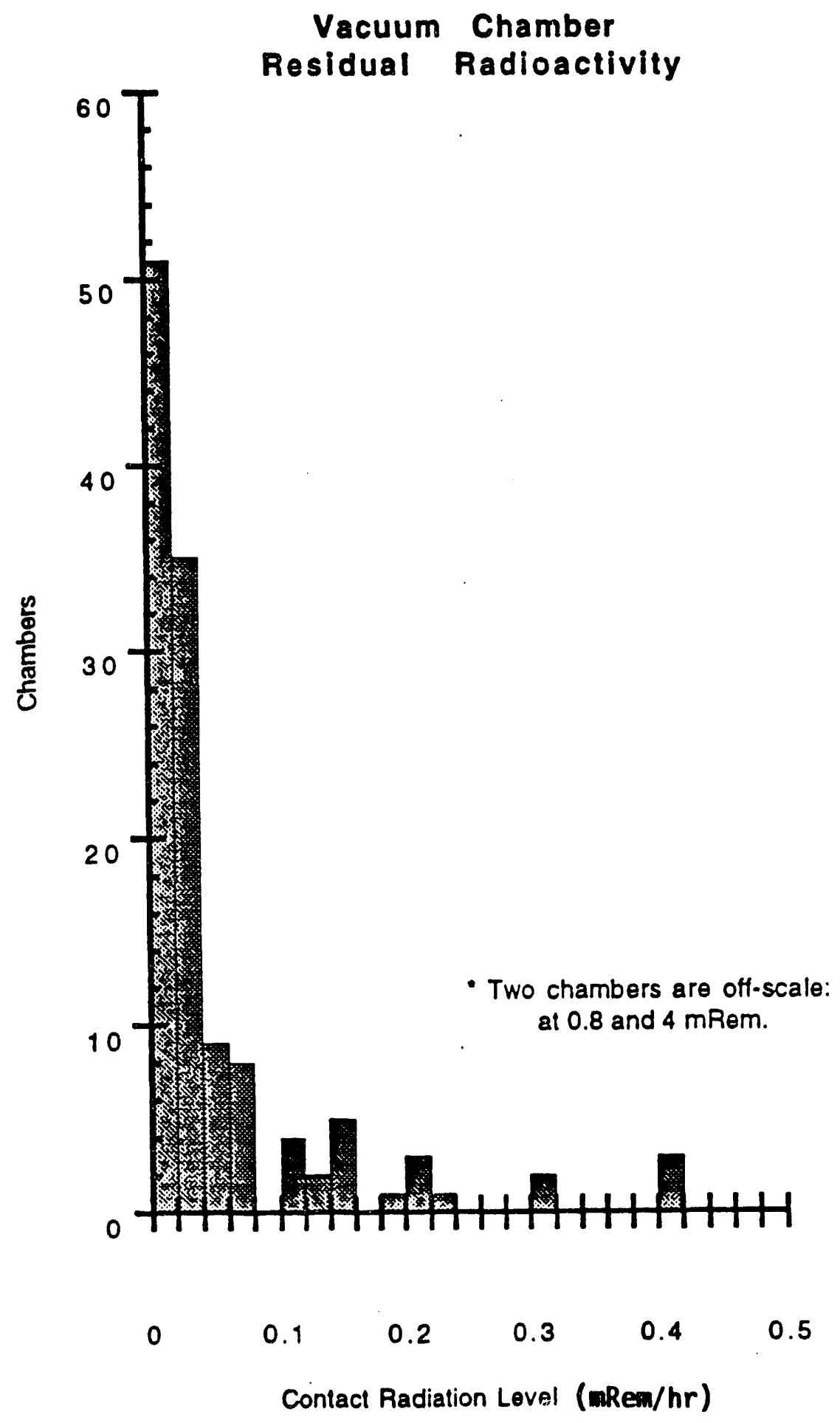

Figure 10. Vacuum Chamber Residual Radioactivity for CESR Waste Generation 
Procedures would be in place to test for activated materials and soil; proper disposal would take place as necessary using established methods.

\subsubsection{Effects From Normal Operations}

\section{Socioeconomic Impacts}

Operation of the proposed CESR-B would require the addition of approximately eleven permanent employees to the laboratory staff (nine technicians and two engineers). The increase in office space that is part of the proposed CESR-B would accommodate the expected increase in experimenters using the modified facility and participating in other high energy physics experiments at Wilson Lab. Currentiy, there are approximately 200 scientists who collaborate on research at the Lab. Of these, approximately 60 experimenters work at the $L a b$ at any one time. It is anticipated that the number of onsite scientists may increase to approximately 100, with the total number of experimenters increasing to 300 . A portion of that increase may involve scientists relocating to the Ithaca area.

This potential increase in employment (approximately 40 scientists) and the associated population change, in a county with a population of 94,000 , would have minor impacts on the local economy or community services.

Increases in solid or sanitary waste generation from operation of the CESR-B are expected to be minimal and within the capacity of the existing campus infrastructure. Wilson Lab is served by the Cornell owned sanitary sewer system that is tied into the Ithaca Area Wastewater Treatment Facility.

\section{Air Quality}

Operation of the CESR-B would not cause air emission of any substance regulated by the Federal Government or the State of New York. Approximately 500 liters liquid equivalent of helium gas per year are currently emitted during operation of the Wilson Lab. There will be no increase associated with the conversion to CESR-B because of improved recovery facilities. Helium emissions have no effect on human health or air quality.

Water vapor from the cooling tower on the east side of the laboratory may contain trace impurities from chemicals used to treat the water and water pipes. The heating load for the CESR-B would be about 4 times larger than the current heating load. Hence, the existing evaporative cooling tower would be expanded by adding additional cells. No environmental effects are expected from these trace releases from the cooling towers.

Operation of the CESR-B at Cornell University would have a negligible effect on air quality. 
Water Ouality, Supply and Use

Groundwater that seeps into the Wilson Lab tunnel, located 50 feet below ground, is discharged into the Cascadilla Creek. This groundwater is not contaminated and can be discharged without a New York State Department of Environmental Conservation permit. It is combined with stormwater during storm events. Annual average seepage into the tunnel is estimated to be 1-2 gallons per minute. This seepage is not expected to increase due to facility modifications for CESR-B.

Although not required by law, a Spill Prevention Control and Countermeasures (SPCC) Plan has been adopted by the Wilson Lab. This plan was last revised in July of 1990. The SPCC was prepared in accordance with Environmental Protection Agency guidelines on oil pollution prevention (40 CFR Part 112). Oil contained in the capacitors located in the accelerator tunnel is free of Polychlorinated Bi-Phenyl (PCB) contamination. In the event that water seeping into the tunnel does become contaminated, an alternate system is avallable to discharge seepage into the sanitary sewer system. Drains in the laboratory were last surveyed in 1990 and remedial construction performed to assure proper routing to either storm or sanitary sewers. Any discharges to the sanitary sewer would be made in accordance with pretreatment program requirements. Operation of the CESR-B would have a negligible effect on the water quality of surface and groundwater.

Chilled water demand would increase to serve the new space cooling requirements of the CESR-B. Approximately 300 to 400 tons additional cooling would be required. The campus chilled water system does not have any spare capacity, so that additional demands would require additional construction of central chillers. Additional chilled water capacity has been added in 1987 and again in 1992. Additional chillers, with a total of 4000 tons of capacity, are presently being planned to meet other new chilled water loads, and this would simply be an increment that is included in the future chilled water projects.

Process water cooling demands served by the cooling tower and heat exchanger on the east side of Wilson Lab are expected to increase from an existing load of 5 MWe to approximately 15 MWe of heating load (10 MWe increase), as a result of CESR-B. The increased demands would be met by expanding the existing evaporative cooling tower station by adding additional cooling tower cells when it is relocated. The upgraded cooling system would be relocated on site to accomnodate the building expansion. The heat exchanger plates and pumps would have $100 \%$ redundancy. The cooling tower cells would be divided into four separate cells to provide sufficient reliability without redundancy. The increase in cocling tower load would require an additional approximate 140,000 gallons per day of water. About 120,000 gallons per day would be evaporated, and the remainder, 20,000 gallons per day would be blowdown to the sanitary sewer. All cooling tower blowdown on campus is currently disposed of as blowdown to the sanitary sewer. The additional water will be supplied by the Cornell Water Filtration Plant and Cornell water transmission 1lines, both of which have adequate spare capacity. 
The existing steam generation at the CHP and distribution system have sufficient capacity to handle increased loads from the CESR-B. The campus peak electricity demand, presently 37 MVA, would increase about $40 \%$ to accommodate the proposed 15MVA load for the CESR-B. This can be provided from the existing University owned 110 MVA transmission substation. The preferred method of supply to Wilson $L a b$ is to run another pair of $350 \mathrm{~A}, 13.2 \mathrm{kV}$ underground feeders from one of the existing switching stations to the Lab. The combination of four circuits would maintain needed system redundancy while meeting the requirements of the existing plus the proposed Laboratory electric load. An alternate method, which would provide electric service directly from the $115 \mathrm{kV}$ substation, would include a new overhead circuit located in one of the existing overhead service corridors, which runs about 200 feet from the Lab. The conductors between the service corridor and the lab would consist of insulated cable in an underground duct bank. The existing underground service would be maintained for use as a backup system.

Noise

The cooling tower fans would be the only additional source of noise from operation. The cooling tower expansion would not noticeably increase the noise level at any public receptor.

\section{Transportation}

The availability of additional laboratory space at CESR-B would result in a need for additional parking (approximately 50 spaces). No additional parking construction is planned as part of this action. The University would accommodate the increase by accessing existing nearby parking, by decreasing the need by the efforts of an ongoing trip reduction program, and by accessing additional space that is already planned as part of other campus projects immediately north of Wilson Lab. The increase in traffic is not expected to place any burden on existing roads or intersections.

\section{Sensitive Environmental Resources}

Since there are no cultural, archaeological or historical resources; rare, threatened, or endangered species; or activities planned in floodplains or wetlands near the Wilson Laboratory, there would be no operational impacts or sensitive environmental resources.

Hazardous Materials

Hazardous materials used during operation of CESR-B would be the same as those currently used for operation of CESR: methanol, acetone, isopropanol, nitric acid, phosphoric acid, hydrofluoric acid, sulfuric acid, some oil. The current average use of 36 galions of acid per month and 56 gallons of solvent per month would not change. Average inventories of acids ( 80 gallons) and solvents (101 gallons) would also not change. Cornell's Environmental Health and Safety (EHS) 
comprehensive hazardous material management program is sufficient to handle hazardous waste generated by operation of CESR-B.

\section{Radiation}

The proposed CESR-B would involve an increase in accelerator bean currents by comparison with current CESR. This increase in beam stored energy will result in an increase in radiation produced by the beams. It should be noted that the accelerator enclosure and laboratory bullding were originally designed for a synchotron operating with external targets which generated much greater radiation levels than being considered here. The radiation generated as gammas, neutrons and lost electrons will increase in proportion to the stored energy in the beams. Table 4 below compares the CESR-B beam stored energies with current CESR.

\section{Table 4. CESR-B Comparison Mith CESR (Hilson Lab)}

CESR-B Rings

Energy (GeV)

Total Current (Amperes)

Number of e $\left(10^{13}\right)$

Stored Energy (Joules)

$(17660+17750) / 2820=$
Low Energy Ring 3.5

1.98

3.15

$\begin{array}{ccc}17660 & 17750 & 2820 \\ 12.5 & \text { Increase in stored energy vs. present day CESR. }\end{array}$
High Energy Ring
8.0
0.87
1.38

$\begin{array}{ccc}17660 & 17750 & 2820 \\ 12.5 & \text { Increase in stored energy vs. present day CESR. }\end{array}$

CESR
5.5
0.20
0.32
2820

Relatively low energy synchrotron $x$-rays generated by the beams will increase in number in proportion to the stored beam energy as well, a factor of 12.5 . However, the material of the vacuum chambers containing this synchrotron radiation will be changed to copper which has an absorption coefficient 28 times greater than aluminum in the energy range of interest, so that the number of synchrotron $x$-rays escaping the vacuum chamber wili be less than in current CESR. A significant fraction of the background radiation produced by CESR and CESR-B arises from losses during the injection process. The efficiency of injection into CESR-B will be higher than in CESR due to the fact that the beams will not be in collision during injection in contrast to current CESR. To be conservative, this fact is not taken into account in the following estimate of the CESR-B radiation exposure potential. This estimate is based on the measured exposures at CESR described above in 5.2.10. If the shielding were not improved over the current status, then the exposures to radiation workers, non-radiation workers and the general public would be that of current CESR multiplied by the ratio of stored beam energy, 12.5. The result would be that the dose to radiation workers would be less than 125 mrem/year, compared to an ALARA goal of less than 500 mrem/year and the regulatory limit of 5,000 mrem/year. The dose to non-radiation workers and the general public should be less than 13 mrem/year, compared to an ALARA goal of less than $100 \mathrm{mrem} /$ year and a regulatory limit of $500 \mathrm{mrem} / \mathrm{year}$. 
However, the shielding in the Laburatory area will be enhanced by thickening the walls surrounding the detector and collision area to obtain the same exposure levels present in CESR as described in 5.2.10. The number of experimenters and staff would increase as cited above to about 100 more radiation workers. This number includes non-resident experimenters with personal film badges. The cumulative worker exposure would be 400 persons at $10 \mathrm{mrem} /$ year for a 15 year project life or less than 60 person-rems. There would also be 20-50 more non-radiation workers. This would translate into less than 100 persons at $1 \mathrm{mrem} /$ year for 15 years or 1.5 person-rens. Table 3, Section 5.2.10, shows the potential exposures to neighbors to be iess than 0.1 person-rem. Based on an occupation risk factor of $4 \times 10^{-4}$ fatal cancers/person-rem the number of potential fatal cancers for radiation workers, non-radiation workers and the general public are, respectively, $0.024,0.0006$, and 0.00005 .

\subsubsection{Effects From Accidents}

Because of the similarity of the proposed CESR-B operation to the current CESR operation, the risk from accidents should be comparable. Analysis of accident reports during the past 8 years show a lost-time injury rate of 1.2 injuries per 200,000 work hours.

Two types of radiological accidents that might be expected would be accidental beam dumps due to component failures, and "bad" injection conditions due to equipment misadjustments. Because these incidents are actually encountered in practice, their impact can be assessed by analysis of the radiation records from current operations.

The analyses presented above in Sections 5.2.10 and 6.2 .2 are based on the past 3 years of operation at CESR. This record includes beam dumps from all kinds of component and sub-system fallures, periods of "bad" injection due to a wide variety of misadjustments and periods of "machine studies" where unusual beam tuning situations are set up and studied for purposes of analysis and improvement. To assure that any of the beam dump incidents would produce very small exposures compared to the cumulative doses measured, a special test was made in which the beam was caused to dump near the high energy physics detector area in the lab building. Inside the shielding wall of this area a set of 4 dosimeters recorded an average of $1.3 \mathrm{mrem}$. To predict the effects of a beam dump accident at CESR-B, these measurements were increased by the stored energy ratio to CESR-B conditions and reduced by 1 tenth-value for the current CESR shielding wall and another tenth-value for the planned shielding improvements, as well as the increased distance to the nearest accessible area outside the shielding wall. The anticipated dose to a radiation worker standing just outside the wall would be 0.4 mrem or 0.0000002 latent fatal cancers. Note also that exposures from "bad" injection conditions are limited in operation by the radiation monitor interlocks, provided for that purpose, to instantaneous dose rates of $2 \mathrm{mrem} / \mathrm{hour}$. Upper 1 imits for total exposure of $10 \mathrm{mrem} /$ year for radiation workers and 1 arem/year at the building boundary 
have been calculated based on experience and specific measurements. These include dose from beam dumps and bad injection conditions in addition to dose from normal operations.

Another possible accident to consider would be the spill of contaminated cooling water. During present operations, no tritium has been found in the cooling water of the positron target (this is the place most likely to activate water). In CESR-B operation with higher injection rates, concentrations would be monitored and appropriate procedural controls instituted for personnel protection. If needed, the Cornell Department of Environmental Health and Safety is trained to ciean up contamination accidents. A small volume system using a heat exchanger would al so be instituted to confine the water to a controlled area, provide quick detection, and limit the extent of a possible spill.

The superconducting RF cavities, cooled by liquid helium, would be located in the modified tunnel areas. A sudden, accidental release from the 100 liter cryostat could lead to an oxygen deficiency hazard. The modifications would include a higher celling (from 8 feet to 11 feet) and vents to maintain safe oxygen levels (above $20 \%$ ). The new ventilation system would have a space hyperventilation mode to provide additional ventilation during emergencies and would be connected to the emergency power generator. Oxygen level monitors, designed to activate an alarm whenever a $20 \%$ oxygen concentration is reached, would be installed in key tunnel areas. As an additional safety measure, oxygen masks would be available at various tunnel locations to ensure safe egress should all emergency systems fail. A 100 liter release of helium into the external environment would not have a negative impact.

The risks from accidents associated with fire are minimized by preventative actions and controls specified by Cornell's Fire Safety Section of the Department of Environmental Health and Safety. The use of flammable substances in the accelerator areas is strictly controlled. These practices would be continued for CESR-B operation. A new fire detection system is being designed, including a VESDA system for the CLEO detector. Options are also being investigated for detection of cable fires in the tunnel. A special orientation was conducted to familiarize the Ithaca Fire Department with the facility and would be repeated periodically during CESR-B operations.

The risk associated with accidents involving hazardous substances in the operation of CESR-B would be similar to present CESR operation. Most hazardous chemicals are used in the superconducting cavity research at Newman Laboratory. Acids and solvents are used in the chemical room. A potential spill could range from a few milliliters to 3 or 4 liters. It is important to note that because of accident prevention and waste minimization programs all containers of hazardous materials are limited to the smallest practical size.

It is expected that the rate of laboratory ventilation coupled with a fast response time for spill clean-up would result in personnel exposures which are 
well below OSHA requirements. Spill containment and clean up materials are kept on location. Spilled material is not expected to form explosive mixtures with air because of the ample lab air exchange rates. These materials are used in chemical fume hoods thus reducing personnel exposure and limiting other related hazards.

The following chart lists estimated airborne concentrations for solvent spills taking place outside of containment (e.g., dropping a bottle on the floor) in Newman Lab Chemical Room.

$\begin{array}{rrr}\begin{array}{r}\text { Anount } \\ \text { (nL) }\end{array} & \begin{array}{r}\text { Material } \\ \text { Expected } \\ \text { Concentration } \\ \text { in Lob (ppm) } \\ \text { (ventiletton off) }\end{array} \\ & & \\ 500 & \text { Nethanol } & 532 \\ 1000 & \text { Methanol } & 1064 \\ 3738 & \text { Methanol } & 3978 \\ 500 & \text { Acetone } & 290 \\ 1000 & \text { Acetone } & 580 \\ 3738 & \text { Acetone } & 2167 \\ 500 & \text { Propanol } & 280 \\ 1000 & \text { Propanol } & 2094 \\ 3738 & \text { Propanol } & \end{array}$

\begin{tabular}{|c|c|c|}
\hline $\begin{array}{r}\text { Expected } \\
\text { Concentration } \\
\text { in Boom (ppm) } \\
\text { (15 ain. ofter } \\
\text { eplli) } \\
\text { (ventilotion on) }\end{array}$ & STEL & TMA"* \\
\hline $\begin{array}{r}26 \\
53 \\
198 \\
15 \\
29 \\
107 \\
14 \\
28 \\
104\end{array}$ & $\begin{array}{r}250 \\
250 \\
250 \\
1000 \\
1000 \\
1000 \\
500 \\
500 \\
500\end{array}$ & $\begin{array}{l}200 \\
200 \\
200 \\
250 \\
250 \\
250 \\
400 \\
400 \\
400\end{array}$ \\
\hline
\end{tabular}

-STEL - short term exposure linit for a person for 15 ainutes

WTA - time weighted average for an 8 hour/day, 40 hour workweek

Volumes greater than 4 liters of nitric acid, phosphoric acid, and hydrofluoric acid are used exclusively in a specially designated acid room which has a high ventilation rate of approximately 2 air changes per minute. given the smali volume of this room $\left(800 \mathrm{ft}^{3}\right)$, any fumes from acid spilled in this room will be quickly exhausted. Chemical room workers wear personnel protection equipment during all acid operations. Laboratory personnel can safely handle any small spills. Large spills would be cleaned up by EHS's hazardous material emergency response team. Neutralizing and absorbing agents which lower volatilization on contact would be used. Exposure to laboratory personnel from acid spills is not expected to be a problem. The potential impact on the environment of spilled acid and/or exhausted acid vapor is considered inconsequential.

In the event of a hazardous materials accident, Environmental Health and Safety and Environmental Compliance staff would immediately respond. Cornell's Hazardous materials Response Unit is a team of certified professionals, fully equipped to handle spills and other emergencies involving hazardous materials. They also provide hazardous materials response services to the City of Ithaca, Tompkins and other surrounding counties. 


\subsubsection{Effects From Decontamination and Decommissioning}

Non-radiological impacts associated with Decontamination and Decomissioning (D\&D) of CESR-B would be similar to those involved in facility construction, such as noise, dust, and related aspects. Assoclated environmental impacts would be temporary and would have only minor short-term or long-term effects on the Wilson Lab or surrounding area. Hazardous liquid or solid waste generated by D\&D activities would be handled and disposed of in accordance with applicable laws and regulations. Non-hazardous materials and wastes would be stored on-site or shipped to an approved disposal facility, as appropriate.

Radiological impacts assoclated with D\&D at CESR-B would be minimal. Any items containing residual radioactivity would be stored on-site in a dedicated area or shipped to an approved radioactive waste disposal facility.

\subsection{Unavoidable Adverse Impacts}

There are no unavoidable adverse impacts for either PEP-II or CESR-B.

\subsection{Irreversible and Irretrievable Comftments of Resources}

Manufacturing of new B-factory components will consume various natural resources. However, all of the materials utilized in the manufacture of these components are considered common and none of them represents the depletion of a critical resource. Other resource commitments (e.g., water, electricity, chemicals, labor hours) are comparable to those incurred for PEP or CESR.

\subsection{Cumulative and Long-term Impacts}

\subsubsection{Cumulative and Long-Term Impacts for PEP-II}

No cumulative impacts are expected from the proposed action. Dose-equivalents outside the shielding and at the site boundary resulting from normal operations are far below the applicable standards, both for PEP-II and for SLAC as a whole.

No measurable long-term environmental impacts are expected from the proposed action. Some portion of the waste products generated by PEP-II construction, normal operations and routine maintenance, and D\&D activities would require disposal and so would add to waste accumulation and the environmental impacts associated with disposal facilities. However, their contribution would be negligible. PEP-II operations are not expected to cause soil or groundwater activation (See Section 5.1.2; the Natural Sources of Radiation and Background Levels discussion in Section 5.1.7; and the Water Quality and Hydrology discussion and Radiation discussion in Section 6.1.2) and would therefore not contribute to the cumulative impacts of SLAC operations on groundwater and soil. 
As described in the Contributions to Background Radiation Levels from SLAC Operations discussion in Section 5.1.7, the maximum dose equivalent above background for an off-site nearest receptor 24 hours per day is estimated to be less than 2 mrem in an entire year (SLAC, 1992a). The dose equivalent attributable to PEP.II operations would have only negligible contributions to the cumulative impact of SLAC operations. As stated in the SLAC Radiological Control Manual (SLAC 1993i), non-radiological workers of SLAC are limited to a radiation dose from all SLAC operations of $100 \mathrm{mrem} /$ year, whereas for radiological workers, SLAC has adopted an annual factlity Administrative Control Level to ilmit the radiation exposure from all operations to 1500 arem/year.

There are no nuclear facilities or similar emission sources located on the San Francisco peninsula. The medical treatment factlities and other research facilities at Stanford University, located approximataly two miles from SLAC, are not expected to have measurably increased cumulative impacts when considered with SLAC's impacts.

The minimal impacts associated with construction and operation of the B-Factory at SLAC are not expected to pose any substantial effects on local offsite construction projects. There are no current or reasonably foreseeable major construction projects in the immediate vicinity of SLAC.

\subsubsection{Cumulative and Long-Term Impacts for CESR-B}

Based on the analysis presented in Sections 6.2.2 and 6.2.3, workers involved with the CESR-B are not expected to incur any harmful health effects from radiation exposures they would receive during normal operations or potential accidents. Similarly, members of the general public are not expected to incur any harmful health effects from CESR-B operations. The only other source of radiation exposure on campus is the Ward research reactor. Workers are not shared by the facilities, so there would be no cumulative exposures to these workers. Members of the public are not expected to receive any cumulative exposures that could lead to any harmful health effects.

Similarly, other minor nonradiological impacts are not expected to be exacerbated by any nearby activities. Cooling water demand for CESR-B will exceed current campus capacity; however, cooling tower expansion is included in the proposed CESR-B to meet that need. Minor parking disruptions associated with construction activities would be mitigated by other campus efforts to reduce traffic and provide more parking space.

Reasonably foreseeable planned activities include the proposed future campus expansion to the southeast of the Wilson Lab. However, these activities are just now in the programatic planning stage (as docunented in the reference DGEIS) and there will be no overlap. with construction of the CESR-B. 


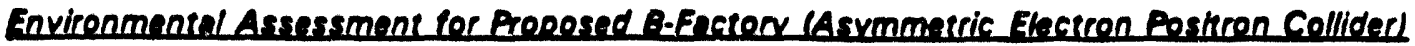

\subsection{PERSONS AND AGENCIES CONTACTED}

\section{For PEP-1I, the following agencies were contacted:}

- Bay Area Air Quality Management District, Milliam Taylor

- California Department of Fish and Game, Nancy Vierra, Information Services Coordinator for the Natural Diversity Database

- California State Office of Historic Preservation, Hans Kreisberg, Director

For CESR-B, no Federal or state agencies were contacted during the preparation of the environmental assessment of the alternative to construct and operate the CESR-B at Cornell University. However, appropriate agencies were contacted during preparation of the Draft Generic Environmental Impact Statement (DGEIS) for the proposed campus expansion. Documentation of those contacts are presented in the DGEIS.

Consultation with the State Historic Preservation Office to confirm the absence of archeological sites and with the U.S. Fish and Wildlife Service regarding compliance with the Endangered Species Act would be concluded and documented prior to any construction. Neither resources are expected to occur in the project area and no compliance difficulties are anticipated.

Consultation with local agencies will be required to obtain several local approvals from the Town of Ithaca to enable construction and operation of the CESR-B. These include:

- a Site Plan Approval from the Town Planning Board,

- a Building Permit from the Town Bullding Department, and

- a Special Approval from the Board of Zoning Appeals.

These approvals are regularly sought and obtained for projects in the Ithaca area; no obstacles to securing these permits for the CESR-B are anticipated.

There is no land-use conflict created with the construction of CESR-B. Institutions of higher learning are specifically listed as permitted uses at the CESR-B site, an ?-30 zone. Educational uses, like dozens of commonplace, non-residential uses in the zone which are also iisted as permitted, require a "special approval" of the Town's Board of Zoning Appeals.

Because there is no separate "educational" or "institutional" zone in the Town of Ithaca, most of the Cornell campus in the Town of Ithaca is in this residence district, $R-30$. In fact, most of the Town of Ithaca is zoned residential and special approvals are a standard procedure for virtually all non-residential uses. The Town's zoning regulations specifically allow for construction of bulldings for institutions of higher learning with a special approval (Article $V$ Section 18 subsection $3(b)$ of the Town of Ithaca zoning Ordinance, as of January 27, 1993). The numerous Cornell buildings in the 
Town of Ithaca R-30 district have successfully obtained the special approval required.

In an area near to Wilson Lab, special approval has been granted recently by the Town's Zoning Board of Appeals to the following Cornell bulldings: a Life Safety headquarters bullding; a Service and Maintenance garage for the campus vehicle fleet; and a Care of Grounds building. Most recently, in 1992, the Town of Ithaca gave special approval for the addition of modular offices to Wilison Lab. 


\section{B.0 gLOSSARY NMD ACROHYMS}

Accelerator - device which raises the energy of elementary particles to high energies to allow the exploration of the structure of matter at extremely. small distances. There are two main types of accelerators, those which use protons, such as the Superconducting Supercollider (SSC), and those which use electrons, such as the proposed SLAC B-Factory. Unilke reactors, accelerators consume energy rather than produce energy.

Antimatter - particles which are identical to their matter equivalents (antiprotons are the antiparticies of protons, positrons are the antiparticles of electrons), except that they possess certain properties which are opposite those of their partners. For example, electrons have one unit of negative electrical charge, while positrons have one unit of positive electrical charge. Antimatter is typically produced in high energy collision processes, or in radioactive decay. When particles and antiparticles of the same species are brought together, they annihilate each other, producing pure energy.

BAAQMD - Bay Area Air Quality Management District.

Background Radiation - All sources of radiation at a given point other than the scurce in question. Radiation received either naturally from the earth or cosmic rays from outer space, or received artificially as a result of weapons testing. This term also includes radiation from medical $x$-rays.

$B$ mesons - a species of hadron which contains a bottom quark and a lighter quark. The observation of $C P$ violation in the decays of $B$ mesons holds the promise of providing an explanation for the underlying cause of CP violation, as the predictions of the Standard Model are rather definite.

Beam Dump - An energy-absorption device for halting a particle beam.

Blowdown - Discharge of mineral-1aden cooling-tower water to reduce the concentration of total dissolved solids (TDS) in the cooling system. Cooling towers remove heat by evaporation, which increases the mineral content of the water remaining in the system. Removal of a portion of this water helps maintain system efficiency and reduce maintenance. Blowdown from SLAC's cooling tower system empties into the sanitary sewer.

BSY - Beam Switch-Yard. Like a railroad switching yard, the BSY permits the distribution of various types of beams from SLAC's inear accelerator to any of several experimental setups in the research yard.

CESR - ("Caesar") Cornell Electron Storage Ring, an accelerator located at Cornell University, New York, New York. 
CESR-B - ("Caesar B") Proposed Cornell Electron Storage Ring modification.

$C P$ - Charge Conjugation and Parity, in reference to matter/antimatter interactions. CP Symetry dictates that the collision of a particle with its antiparticle produces total annihilation of both. CP Violation is a slight distortion in this inherent symmetry, and is the reason why our universe is composed of matter and not antimatter or an equal mixture of matter and ant imatter.

Electron - The lightest subatomic particle with a non-zero rest mass occurring in nature. It has a negative electrical charge of 1 unit. More technically, the electron is a fermion which undergoes only weak, electromagnetic, and gravitational interactions.

Electron-Volt - The kinetic energy picked up by an electron while passing through a potential difference of one volt. Equal to $1.6 \times 10^{-12} \mathrm{erg}$.

FFS - Final Focus System, which is a component of the Stanford Linear Collider (SLC) at SLAC.

GeV - Giga-electron-volt; represents one billion electron volts.

HER - High-Energy Ring; the refurbished version of the existing ring in PEP.

Interaction Region (IR) - Any one of six symetrically located straight sections along the circumference of the PEP ring where beam collisions can occur and experimental data are collected.

Isotope - For a given element, two or more nuclides which have the same number of protons but different numbers of neutrons in their nuclei are called isotopes. Radioactive isotopes are now called radionuclides.

KEK - Koh Enerugit Kenkyusho, a high-energy physics research laboratory in Japan.

LBL - Lawrence Berkeley Laboratory (formerly known as Lawrence Radiation Laboratory); a part of the University of California at Berkeley, California.

LCH - Low-Conductivity Water, which is used for cooling accelerator and experimental apparati. LCW is domestic water which has been distilled to remove or reduce its mineral content in order to increase the water's resistance to the flow of electricity.

Lepton - Any of a group of subatomic particle having a spin equal to $1 / 2$ and a mass less than those of the mesons.

LER - Low-Energy Ring; the new, second ring to be constructed as part of PEP-II. 
Linac - Linear Accelerator.

LLNL - Lawrence Livermore National Laboratory, a DOE facility in Livermore, California.

Luminosity. The rate at which beam particles collide in a storage ring. PEP-II design calls for $10^{32}$ collisions per square centimeter per second.

Matter - the stuff of which we and our surroundings are composed. Physicists classify matter into two broad categories: hadronic matter or "hadrons", which is composed of quarks (examples are protons and neutrons) which interact via nuclear forces, and leptonic matter or "leptons" (examples are electrons and muons), which interact via electroweak forces.

Meson - A particle with mass greater than the electron mass and less than the mass of a nucleon (proton or neutron).

MeV - A unit of energy representing one million electron-volts.

mrem - millirem; equal to one-thousandth of a rem $\left(0.001\right.$ rem, or $10^{-3}$ rem). See rem.

NEPA - The National Environmental Policy Act, which requires that all environmental impacts and alternatives to a proposed action are considered before resources are committed for that action and before decisions are made.

Neutron - An electrically neutral particle with a mass equal to 1838 electron masses. Neutrons are stable when bound in nuclel, but a free neutron decays into a proton, an electron, and a neutrino having a half-life of twelve minutes.

NIT - North Injection Tunnel.

NPDES - National Pollutant Discharge Elimination System.

OSHA - Occupational Safety and Health Act. An act of Congress.

Quarks - the basic building blocks of hadronic matter. Quarks come in six varieties, grouped into three increasingly heavy families of two. These six varieties are called: (u (up), d (down)\}, (s (strange), c (charm)) and (b (bottom), $t$ (top)\}. All but the top quark have been definiluiy identified. Recent experiments strongly imply that there are no other families of quarks.

PEP - Positron-Electron Colliding-Beam Storage Ring Project.

PEP-1I - The proposed asymetric B-Factory at SLAC. 
Positron - The positively charged antiparticle of an electron.

Electron-positron pairs may be produced from gamma rays, and may subsequently combine to produce gamma rays by annihilation.

PS - Positron Source.

Proton - The nucleus of the lightest and most abundant hydrogen isotope. It is a positively charged stable particle having a mass of 1836 (1.e., it has 1836 times the mass of an electron).

Radioactive - Giving off radiant energy in the form of particles or rays produced by the disintegration of atomic nuclei. Radioactivity can be produced spontaneousiy in fissionable materials, or it can be induced in material that is not inherently radioactive, creating activation products. In sufficient doses, this radiant energy can be harmful to plant and animal iife.

Radionuclide - a radioactive isotope of a particular element.

rem - a special unit used for expressing an ionizing radiation dose that incorporates both physical and biological factors. This unit allows the direct comparison of biological dose from all forms of lonizing radiation such as $x$-rays, gamma rays, beta particles, protons, and neutrons. The natural background dose of ionizing radiation for individuals in the mid-Peninsula region is approximately one hundred millirem (100 mrem), or one-tenth of a rem $(0.1 \mathrm{rem})$.

RF - Radiofrequency, which describes the high-frequency microwave power used to impart energy to electrons in accelerators or storage rings. Low-frequency electric power from the local utility company at a steady flow is transformed into short, rapid bursts of extremely high power and high frequency.

RWQCB - Regional Water Quality Control Board.

SIT - South Injection Tunnel.

SLAC - Stanford Linear Accelerator Center. The center is dedicated to research in high-energy physics and in those fields that make use of its synchrotron radiation facilities. It is operated as a national facility for DOE by Stanford University. Primary facilities onsite include the two-mile linear accelerator, the PEP and SPEAR storage rings and the SLAC Linear Collider. SLAC is located approximately one mile west of the Stanford campus in the foothills on the San Francisco Peninsula in California.

SPEAR - Stanford Positron-Electron Asymmetric Ring, a small colliding-beam storage-ring facility at SLAC; a prototype for PEP. 
Standard Model - a theory which, in an economical way, organizes all known phenomena in the area of elementary particle physics. This theory describes in detail the manner in which the elementary constituents of matter, the quarks and the leptons, interact with each other through the carriers of the nuclear and electroweak forces. Tests of the predictions of the Standard Model are the main objective of much of high energy physics.

Storage ring - a type of accelerator in which large numbers of elementary particles are accelerated and stored in a beam and then brought into collision with a similar beam traveling in the opposite direction. Most modern accelerators are built as storage rings, as this configuration uses the energy of the beams most efficiently in probing short distances. The two beams can each be made of particles (matter), as in the SSC where each beam is composed of protons, or one beam can be composed of matter (e.g., electrons) and the other of antimatter (e.g., positrons), as in the proposed B-Factory. 
Environmentel Assessment for Proposed B-Fucten (Asymmetric Electron Posinron Collider)

\subsection{REFERENCES}

American Conference of Governmental Industrial Hygienists (ACGIH) (1990) Threshold Limit Values

Barry, S.J. (1976), Investigations on the Occurrence of the San Francisco Garter Snake at the Stanford Linear Accelerator Center. Pages 108-117 in: Draft Environmental Assessment, Stanford Linear Collider. 1982. Stanford, CA.

Cornell University (1993), CESR-B: Conceptual Design for B-Factory Based on CESR, June 1993.

Cornell University (1993), Oraft Generic Environmental Impact Statement Prepared for Development Program for Possible Future Expansion Southeast of Cornell University's Main Campus, January 1993, Ithaca, NY

Cornell University (1992), A Strategic Framework for Campus Precinct Development, 1993, Ithaca, NY

Department of Energy (DOE) (1988a), Environmental Assessment for the 1-2 GeV Synchrotron Radiation Source, Washington, DC.

Department of Energy (DOE) (1988b), DOE Order 5820.2A, Radioactive Waste Management, Washington DC., Sept. 26, 1988.

Department of Energy (DOE) (1990a), DOE Order 5400.5, Radiation Protection of the Public and the Environment, Washington, DC., Feb. 8, 1990.

Department of Energy (DOE) (1991), Occupational As Low As Reasonably Achievable (ALARA) Program, Draft Implementation Guide 5.XX, Washington, DC., $11 / 91$.

Department of Energy (DOE) (1992a), Policy on Waste Minimization and Pollution Prevention, August 20, 1992.

Department of Energy (DOE) (1992b), Radiological Control Manual, Washington, DC, DOE N5480.6

Department of Energy (DOE) (1992C), 1992 HEPAP Subpanel on the U.S. Program of High Energy Physics Research, April 1992, DOE/ER-0542P.

Department of Energy (DOE) (1993a), Occurrence Reporting and Processing of operations Information, Washington, DC, DOE Order 5000.3B.

Department of Health, Education, and Helfare (DHEW) (1970), Radiological Health Handbook, Pubiic Heaith Service, Food and Drug Administration, Bureau of Radiological Health, Rockville, Maryland, January 1970. 
Dubrow, M. (1992), SLAC Internal Record of Telephone Conversation with Lila Tang of the Regional Water Quality Control Board, September 22, 1992.

Dubrow, M. (1993), Memorandum to R. Jensen and 6. Harren dated January 12 , 1993. SLAC internal document, Stanford University, Stanford, CA.

Earth Sciences Associates (1993), Stanford Linear Accelerator Center: Identification and Summary of Potentially Contaminated Sites, May, 1993.

EG\&G Idaho, Inc. (1992), Oraft Safety Performance Profile: Stanford Linear Accelerator Center. Management Information Systems, Idaho National Engineering Laboratory, Idaho Falls, Idaho, EGG-SSDC-XXXXX.

U. S. Environmental Protection Agency (EPA) (1991), Proposed Revisions to the Federal Manual for Delineating Wetlands.

Federal Interagency Committee for Wetlands Delineation (1989), Federal Manual for Ident ifying and Delineating Jurisdictional Wetlands. U. S. Army Corps of Engineers, U. S. Environmental Protection Agency, U. S. Fish and Wild ife Service, and U. S. D. A. Soil Conservation Service. Cooperative technical publication.

International Commission on Radiological Protection (1974), Report of the Task Group on Reference Manuals. ICRP Publication 23, Pergamon Press, Elmsford, NY.

International Commission on Radiological Protection (1982), Cost-Benefit Analysis in the Optimization of Radiation Protection, ICRP Publication 37, Pergamon Press, Elmsford, NY.

International Commission on Radiological Protection (1989), Optimization and Decișion Making in Radiclogical Protection, ICRP Publication 55, Pergamon Press, Elmsford, NY.

International Commission on Radiological Protection (1991), 1990 Recommendations of the International Commission on Radiological Protection, ICRP Publication 60, Pergamon Press, Elmsford, NY.

Kase, K.R., Ipe, N., and Mao, S. (1993), Analysis of External Dose Rates During Operation of PEP-II, SLAC internal document, Stanford University, Stanford, CA, dated 12 January 1993.

King, M.J. (1989), Groundwater Supply Development Program, Stanford Linear Accelerator Center, Stanford, CA, Phase I: Resource Feasibility Analysis.

Jensen, R. (1993), Memorandum to M. Chang dated January 11, 1993. SLAC internal document, Stanford University, Stanford, CA. 
Lamarsh, J.R. (1983), Introduction to Nuclear Engineering, Second edition, Addison-Wesley Publishing Company, Reading, Massachusetts.

Lawrence Livermore National Laboratory (LLNL) (1990), Environmental Report for 1990, UCRL-50027-90.

National Council on Radiation Protection and Measurements (NCRPM) (1987a), Ionizing Radiation Exposure of the Population of the United States, Report No. 93. NCRP, Bethesda, MD.

National Council on Radiation Protection and Measurements (NCRPM) (1987b), Exposure of the Population in the United States and Canada from Natural Background Radiation, Report No. 94, NCRP, Bethesda, MD.

New York State (1984), Freshwater Metlands Map: Tompkins County, Map 9.

Science Applications International Corporation (SAIC) (1991a), Memorandum dated 8 August, 1991 from $K$. Toney to $M$. L. Brown regarding Sensitive Species in the SLAC area.

Science Applications International Corporation (SAIC) (1991b), Letter of 29 August, 1991 from P. Figura to M. L. Brown regarding Sensitive Species in the SLAC area.

Seib R.L. and Papenfuss, T.J. (1982), Survey of SLAC Lands for San Francisco Garter Snake. Appendix A of: Environmental Assessment, Stanford Linear Collider.

Stanford Linear Accelerator Center (1982), Environmental Assessment of the SLAC Linear Collider, DOE/EA-0154, September 1982.

Stanford Linear Accelerator Center (1991a), Conceptual Design Report for an Asymmetric B-Factory Based on PEP, February, 1991, SLAC-372.

Stanford Linear Accelerator Center (1991b), Emergency Preparedness Plan, SLAC-1-720-700000-105.

Stanford Linear Accelerator Center (1991c), Environment, Safety, and Health Manual, ESH-100, SLAC-1-720-70100-100.

Stanford Linear Accelerator Center (1992a), Annual Environmental Monitoring Report January-December 1991, SLAC-404.

Stanford Linear Accelerator Center (1992b), Waste Minimization Program Plan to Comply with California's Hazardous Waste Source Reduction and Management Review Act of 1989 for the Stanford Linear Accelerator Center. 
Stanford Linear Accelerator Center (1992c), Waste Minimization Program Plan to Comply with Department of Energy Order 5400.1 for the Stanford Linear Accelerator Center.

Stanford Linear Accelerator Center (1992d), Draft Radiological Sampling and Analysis of Soils and Sediments at and Around SLAC as Part of the Environmental Restoration Program, November 23, 1992.

Stanford Linear Accelerator Center (1992e), Hazardous Materials Management Handbook, SLAC-1-750-OAO6G-001.

Stanford Linear Accelerator Center (1992f), Radioactive Material Management Manual, SLAC-1-760-0A30Z-001.

Stanford Linear Accelerator Center (1992g), Guidelines for Operations, second edition.

Stanford Linear Accelerator Center (1992h), Lock and Tag Program for the Control of Hazardous Energy, SLAC-1-73-0A10Z-001.

Stanford Linear Accelerator Center (1992i), Radiological Control Manual, Environment, Safety, and Health Division, SLAC-1-720-0A052-001.

Stanford Linear Accelerator Center (1992j), FY 1992 Site Technical Information Document.

Taylor, W. (1992), Personal communication with P. Calderwood of SAIC.

Tran, H. (1993), Memorandum to R. Jensen dated January 25, 1993. SLAC internal document, Stanford University, Stanford, CA. 


\section{APPENDIX A}

\section{AGENCY CONSULTATION LETTERS}

A-1 


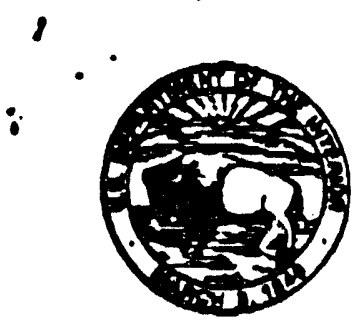

\title{
United States Department of the Interior
}

\author{
TISH AND WIDLITE SERVICE \\ Beologiead Dervloes \\ Bacranerto Plold olfles \\ 2800 cottage way, 2000 8-1303 \\ eceraneate, califoroia 95825-1046
}

Soptember 30, 1903

Mr. John S. Nuhlectedn

Department of Energy

Btanford Iinear Aeederator center

P.O. Dox 4349 - Mn11 stop on

Etenford, CA 94309

Bubject: Proposed asymmetsle riectron Postrzon cold1der

Dear Mr. WalkerI

We have received your september B, 1993 letter regarding construction and operation of the proposod Aeymmetrle ilectron positron colddder at stanford oniveraity. We have minimal commente to provide alnce the projeet will $11 \mathrm{kely}$ heve negligible impacte on $\mathrm{gloh}$ and wildilfe recource of epecial interent to the U.s. Fish and Wildilfe Bervice. Becaupe of parsonsel and elme conetralnte. we wild take no further action on the proposed projeet. Our decision does not lmply that there are no potential project impaets to fieh and widldfe resources. If you have not already done so, we recommand that you contact the californis Department of Fiah and Gane for further consultation.

rhank you for the opportundty to comment on this project. If you have eny questions, please contact ataff biologist peter lickwar at (916) $978-4613$.

\author{
sinceredy,<smiles>O=CC=CCc1ccccc1</smiles> \\ Dade plerce \\ Acting Fild supervieor
}

ce: ARD, ES, INS, Portlind, OR

DIr., CDEG, Saeramento, CA

Reg. Kgr.. CDFG, Ragion J, Younevldze, CA 
OFFICE OF hISTORIC PRESERVATION

DEPARTMENT OF PARKS AND RECPEATION

P.O. Dox

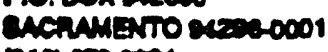

Pion $\cos$

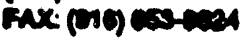

October 18, 1993

Mr. John 8. Wuhlesteln, Director

Reply To: DOE930908A

stanford site office

0.8. Department of Energy

P.O. BOX 4349 - BIN 8A

stanford CA 94309

Re: B-Factory Construction, Prospective PEP II Project, stanford IAC, stanford, santa clara county, CA

Dear Mr. Mublesteln:

Thank you for requesting my comments on the proposed undertaking clted above. Your request and accompanying documentation were submitted in order to satisfy DOE's responsibilities pursuant to section 106 of the National Historic Preservation Act and implementing regulations codifled at $36 \mathrm{CFR} 800$.

Based on staff review of the materials eurnished by DOE, I am herewith notifying you that I do not object to your determination that this undertaking will not affect historic properties. If DOE has otherwise complied with $36 \mathrm{CFR} 800.5$ (b), no further eteps in the Section 106 compliance process are necessary.

Please note, however, that DOE may have additional responsibilities undex $36 \mathrm{CFR} 800$ if any person requests the Advisory Council on Historic Preservation to review your findings; if this undertaking changes in ways that could affect historic properties; if previously undocumented properties are discovered during implementation of the undertaking or if a known historic property will be affected in an unanticipated manner; if a property that was to have been avoided has been inadvertently or otherwise affected; or if any condition of the undertaking such as a delay in implementation or implemnentation in phases over time may justify reconsideration of the no effect" determination.

Your cooperation in considering historic properties during the project planning process is appreciated. If you have any guestions, please contact the undersigned at your convenience.

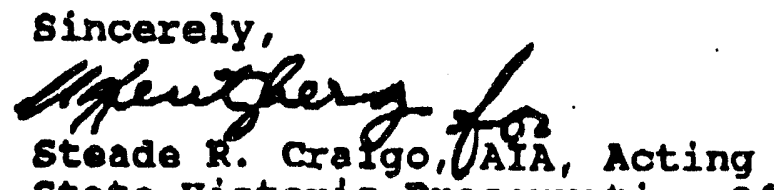

state Historic Preservation officer 


\section{Dor I}
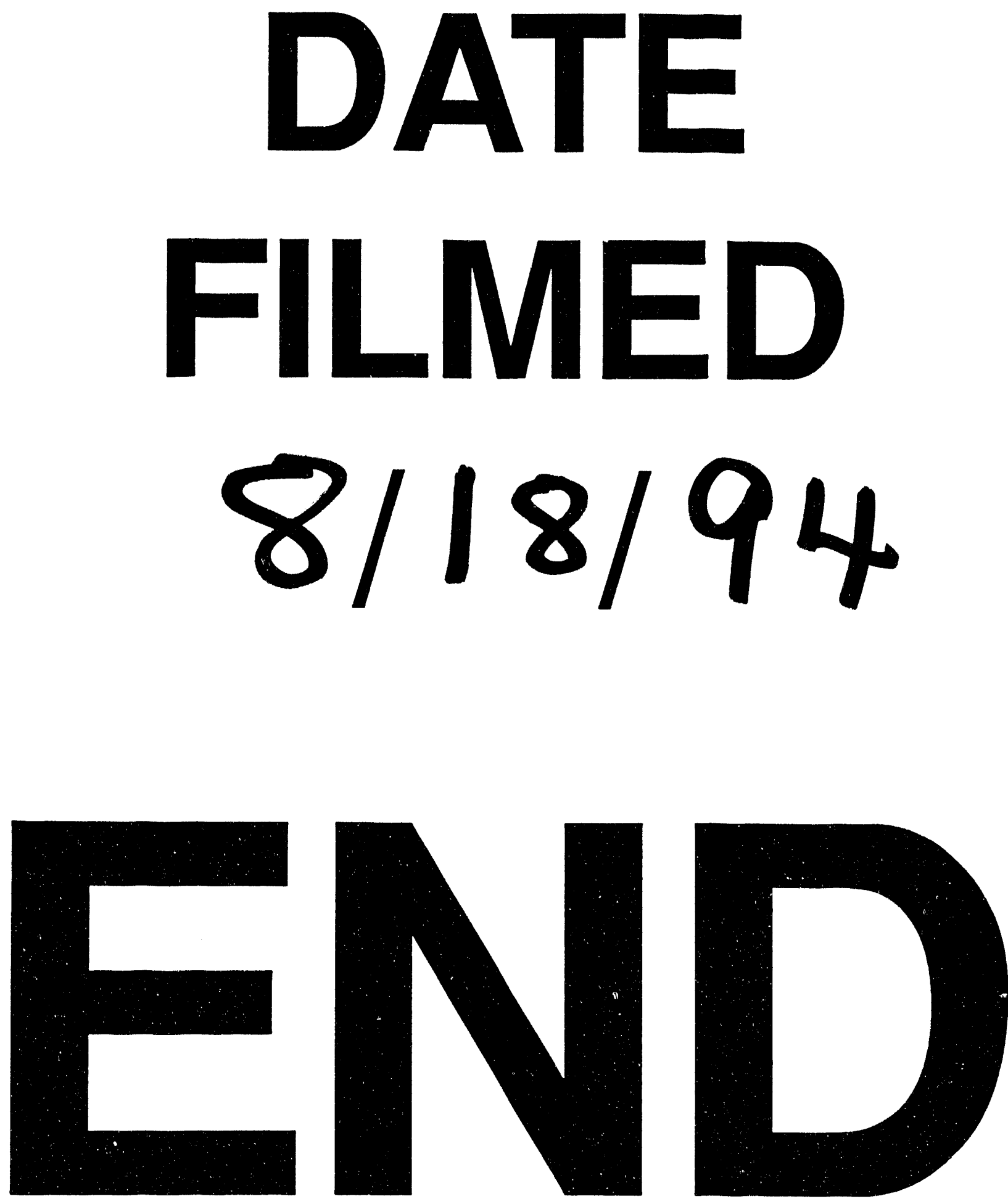
